\title{
IN SEARCH OF MEANING
}

LUDWIG WITTGENSTEIN ON ETHICS, MYSTICISM AND RELIGION

\author{
edited by \\ Ulrich Arnswald
}

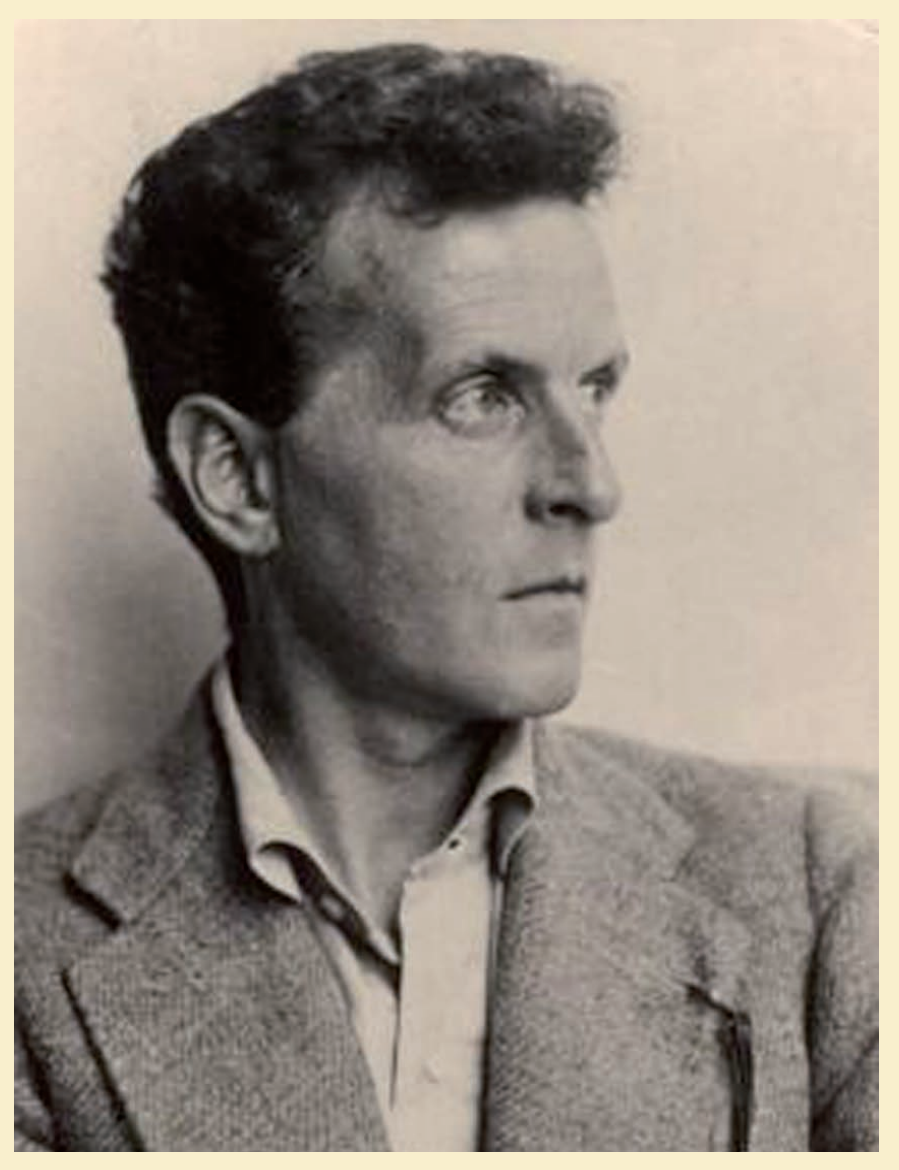



Ulrich Arnswald (ed.)

\section{In Search of Meaning}

Ludwig Wittgenstein on Ethics, Mysticism and Religion 


\section{EUKLID}

Europäische Kultur und Ideengeschichte

Studien. Band 1

Herausgeber: Bernd Thum, Hans-Peter Schütt, Institut für Philosophie, Universität Karlsruhe (TH) 


\section{In Search of Meaning}

Ludwig Wittgenstein on Ethics, Mysticism and Religion

edited by

Ulrich Arnswald

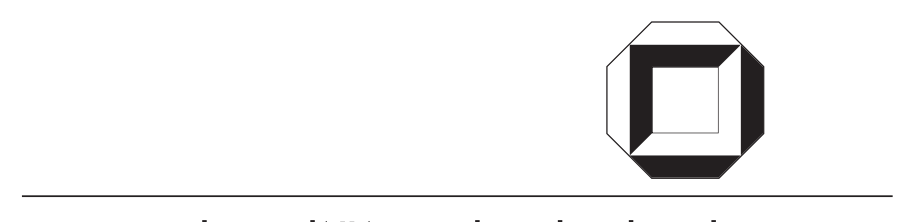




\section{Impressum}

Universitätsverlag Karlsruhe c/o Universitätsbibliothek

Straße am Forum 2

D-76131 Karlsruhe

www.uvka.de

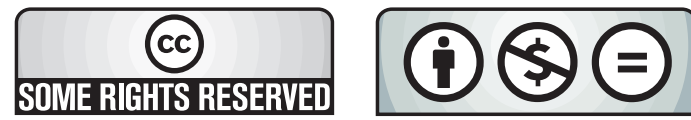

Dieses Werk ist unter folgender Creative Commons-Lizenz

lizenziert: http://creativecommons.org/licenses/by-nc-nd/3.0/de/

Universitätsverlag Karlsruhe 2009

Print on Demand

ISSN: $\quad 1867-5018$

ISBN: $978-3-86644-218-4$ 


\section{Contents}

Preface Ulrich ARnswald ............................................................ VII

List of Abbreviations of Frequently Cited References ..................... xI

I The Paradox of Ethics - 'It leaves everything as it is.'

ULRICH ARNSWALD .................................................................... I

2 'There are, indeed, things that cannot be put into words.' (TLP 6.522) Wittgenstein's Ethics of Showing Dieter Mersch 25

3 'If there is any value that does have value, it must lie outside the whole sphere of what happens and is the case.' (TLP 6.4 I) Liam Hughes SI

4 Philosophy and Life Anja Weiberg …….................................... 67

5 Sense of Ethics and Ethical Sense Jens Kertscher ................... 87

6 The Convergence of God, the Self, and the World in Wittgenstein's Tractatus JoHN CHURCHILL

7 'Objectively there is no truth' - Wittgenstein and Kierkegaard on Religious Belief Genia Schönbaumsfeld ............................ I I I

About the Contributors …............................................................ I $\quad$ 49

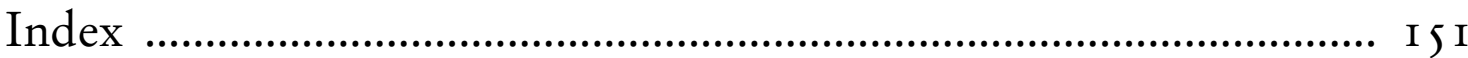





\section{Preface: The Most Important Aspects of Life - Ethics, Mysticism and Religion}

\section{Ulrich Arnswald}

The aspects of things that are most important for us are hidden because of their simplicity and familiarity. (One is unable to notice something because it is always before one's eyes.) The real foundations of his inquiry do not strike a person at all. - And this means: we fail to be struck by what, once seen, is most striking and most powerful.

Wittgenstein, PI \I 29

The essays collected in this volume explore some of the themes that have been at the centre of recent debates within Wittgensteinian scholarship. This book is an attempt to express the difficult nature of ethics, mysticism and religion, their problematic status in the modern world, and the possible justifications for ethical and religious commitment. Naturally, it also discusses some of the main ideas of Ludwig Wittgenstein. His very personal and often aphoristic way of writing cannot simply be restated or interpreted. However, his philosophy is in need of interpretation, and interpretations are-as we all know - often rather controversial.

The collected contributions aim, therefore, at bringing new insight into the essence of Wittgenstein's ethical and religious beliefs by understanding his concepts of thought and language in a more detailed way. In opposition to what we are tentatively inclined to think, the articles of this volume invite us to understand that our need to grasp the essence of ethical and religious thought and language will not be achieved by metaphysical theories expounded from such a point of view, but by focusing on our everyday forms of expression. The articles have in 
common an understanding of Wittgenstein as not proposing metaphysical theories, but rather showing us the way to work ourselves out of the confusions we become entangled in when philosophizing. Thus, the authors show from a Wittgensteinian perspective that the standard modern approaches to ethics cannot justify traditional moral beliefs.

The number of books and articles on Wittgenstein's philosophy is extraordinarily large, and due to this, in this volume no attempt has been made to record all debts and disagreements. This anthology is written with the conviction that the structure of Wittgenstein's ideas on ethics, mysticism and religion and the connections between them owe much to an imagination that is required for philosophy but can also very easily lead us nowhere.

On the basis of a Wittgensteinian approach the authors put forward an alternative account of ethics and religion that avoids this contradiction and recognises that the central issues in the ethical and religious fields cannot be resolved by conceptual analysis alone. By following this alternative account, we become aware of ethical theories and belief justifications that rest on overly simple accounts of the essence of human life.

The articles that have emerged are published in English for the first time and criticize more recent standard interpretations of Wittgenstein's work within the Anglo-Saxon academic community. This book is intended to be of interest both to those who are professional philosophers and those who are not. Works cited from Wittgenstein's writings are quoted in their published English abbreviations. At the beginning of the book a list of abbreviations of frequently cited references can be found.

This volume is a result of a project of the European Institute for International Affairs. The European Institute for International Affairs was founded as an independent, non-profit and non-partisan scholarly organisation whose main task includes encouraging the exchange of ideas and research in the domains of the social sciences and the humanities. This volume came together under the auspices of the University of Karlsrube and the European Institute for International Affairs, Heidelberg.

I am grateful to the EuKLID-series editors, Prof. Dr. Hans-Peter Schütt and Prof. Dr. Bernd Thum, both of the University of Karlsrube, who invited me to publish this book in their series. My gratitude also ex- 
tends, of course, to all the contributors to this volume for having accepted the invitation to think about Wittgenstein's ideas on ethics, religion, and mysticism. I am also indebted to Regine Tobias, Brigitte Maier and Sabine Mehl, at Universitätsverlag Karlsrube, as well as Prof. Lawrence K. Schmidt at Hendrix College, Arkansas, for their support and suggestions. Finally, I would like to express my special gratitude to Jutta Gemeinhardt who gave assistance during the preparation of this volume.

Heidelberg / Karlsruhe, July 2009 



\section{List of Abbreviations of Frequently Cited Reference}

AWL Wittgenstein, Ludwig: Wittgenstein's Lectures 1932-I935, from the Notes of Alice Ambrose and Margaret Macdonald, ed. by Alice Ambrose, Oxford: Basil Blackwell 1979.

$\mathrm{BB}-$ The Blue and Brown Books. Preliminary Studies for the "Philosophical Investigations", generally known as The Blue and Brown Books, Oxford: Basil Blackwell I958, ${ }^{2}$ I 964.

CV - Culture and Value, ed. by Georg Henrik von Wright in collaboration with Heikki Nyman, transl. by Peter Winch. Oxford: Basil Blackwell i980.

LC - Lectures and Conversations on Aesthetics, Psychology and Religious Belief, compiled from notes taken by Yorick Smythies, Rush Rhees and James Taylor, ed. by Cyril BarretT, Oxford: Basil Blackwell 1966.

LE - "Wittgenstein's Lecture on Ethics", in: The Philosophical Review, LXXIV, I965, 3-1 2.

LvF - Letters to Ludwig von Ficker, transl. by Allan Janik, in: Charles Grant Luckhardt (ed.), Wittgenstein. Sources and Perspectives, Ithaca, N.Y.: Cornell University Press 1979, 82-98.

LWL - Wittgenstein's Lectures I930-1932, from the notes of John King and Desmond Lee, ed. by Desmond LeE, Oxford I980: Basil Blackwell.

MT - Movements of Thought: Diaries 1930-1932, 1936-1937, in: Ludwig Wittgenstein. Public and Private Occasions, ed. by James C. Klagge and Alfred Nordmann, Lanham: Rowman \& Littlefield Publishers 2003, 3-255.

NB - Notebooks I9I4-I9I6, ed. by Gertrude Elizabeth M. AnsCOMBE and G.H. von Wright, transl. by Gertrude Elizabeth Margret Anscombe. Oxford r96r: Basil Blackwell.

OC - On Certainty, ed. by G. E. M. Anscombe and G.H. von Wright, transl. by Denis Paul and G.E.M. Anscombe. Oxford i969: Basil Blackwell. 
PG - Pbilosophical Grammar, ed. by Rush Rhees, transl. by Anthony Kenny, Oxford 1974: Basil Blackwell.

PI - Philosophical Investigations, ed. by G.E.M. Anscombe and G.H. von Wright, transl. by G.E.M. Anscombe, Oxford 1953: Basil Blackwell.

TLP - Tractatus logico-philosophicus, transl. by David F. Pears and Brian McGuinness, introd. by Bertrand Russell, London: Routledge \& Kegan Paul I96 I, rev. ed. 1963.

WVC - Wittgenstein and the Vienna Circle, conversations recorded by Friedrich Waismann, ed. by B. McGuinness, transl. by Joachim Schulte and B. McGuinness, Oxford 1979: Basil Blackwell.

Z - Zettel, ed. by G.E.M. Anscombe and G.H. von Wright, transl. by G.E.M. Anscombe, Oxford 1967: Basil Blackwell. 


\section{The Paradox of Ethics - 'It leaves everything as it is.'}

\section{Ulrich Arnswald}

[...] if a man could write a book on Ethics which really was a book on Ethics, this book would, with an explosion, destroy all the other books in the world.

Ludwig Wittgenstein, LE

This essay attempts to approach Wittgenstein's ethics with reference to its different facets. Perhaps, it is better to say with Wittgenstein that "[t]he same or almost the same points were always being approached afresh from different directions, and new sketches made.” (PI Preface). The aim is not only to trace Wittgenstein's footsteps by walking through the "landscape of ethics", but at least, too, to sketch out the radical nature of Wittgenstein's ethics. In the first part of the enquiry, the focus is on the question of the ultimate justification for ethical theories and their epistemological truth; and, by contrast, in the second part, emphasis shifts to the question of the connection of ethics and mystics. Part three explores whether Wittgenstein's ethics is metaphysics. In the fourth and final part, the relationship of ethics and religion is traced, to conclude with an outline summary of those special qualities, as observed in Wittgenstein's ethics.

\section{Against Universal Ethics}

"What is good is also divine. Queer as it sounds, that sums up my ethics. Only something supernatural can express the Supernatural", Wittgenstein wrote in Culture and Value (CV I929, 3). In this instance, ethics is almost placed on a religious plane, a fact that already emerges from 
Wittgenstein's reflections in the Tractatus Logico-Philosophicus, namely, that on the basis of the limit of language, it makes no sense to refer actions to ethical dimensions.

This project already assumes a specific understanding of ethics, based as it is, neither on an academic conception of individual moral directives for action, nor on a theoretically devised scheme, but on an ethical impulse. That impulse is dismissed by ethics as a normative theory or doctrine that, nonetheless, "by clarifying the status of ethical propositions, expresses the view that human action is not to be philosophically justified [...], or qualified, but rather to be taken as given" (Kroß I993, I 28). In Wittgenstein's late philosophy, this supposed paradox dissolves into a myriad of possible ways of acting, into the plurality and the unforeseen nature of human speech acts, that is, into the multiplicity of the grammar in its expressions of "good" and "evil".

The rejection of ethics as a formative doctrine or theory means that the ethical dimension is treated as transcendental, as it were, neither in need of an ultimate justification, nor with the capacity to make such a thing possible. For Wittgenstein, an ethical theory or doctrine can only be nonsensical. In the Tractatus, he justifies that view philosophically in the elucidations for the proposition 6.4 "All propositions are of equal value", by stating:

So it is impossible for there to be propositions of ethics. Propositions can express nothing that is higher. It is clear that ethics cannot be put into words. Ethics is transcendental. (Ethics and aesthetics are one and the same). (TLP 6.42, 6.42 I)

Moreover, the ethical dimension is extracted from the field of facets that are described in words. That leads to the paradox that acting in the world cannot contain any statements on the ethical quality of action, although the ethical dimension is meant to be linked to the sense of action and the actor's status. This aspect can be explained by the fact that the same action can be performed by any number of different "selves", that is to say, the same action can be described at one time as "evil" and at another as "good".

The significance of the "self" for ethics is particularly clear in Wittgenstein's Lecture on Ethics. Wittgenstein emphasizes to Friedrich Wais- 
mann that "[a]t the end of my lecture on ethics, I spoke in the first person". This is "quite essential", since "I can only appear as a person speaking for myself." (LE, I6)

In his lecture, Wittgenstein uses the term ethics in a sense that, on his conviction, also incorporates the greater part of aesthetics. As already noted in the Tractatus, he repeats the expression that " $[\mathrm{t}]$ here are no propositions which, in any absolute sense, are sublime, important, or trivial" (LE, 6), but adds by way of illustration that he meant "that a state of mind, so far as we mean by that a fact which we can describe, is in no ethical sense good or bad." (LE, 6) Here, the aforementioned plurality of "selves" is explicitly reflected in the possibility to describe the same ways of acting as "evil" and "good".

Wittgenstein's Lecture on Ethics is further founded on the consideration that the ability to define ethical propositions requires a theory of ethics. Yet this would only be possible, if there were a criterion or measure to prove the propositions as either suitable or unsuitable, as possible or impossible. To evaluate such propositions, they would have to be part of a system of self-referential statements, for only that kind of system can demonstrate a criterion with a logically justifiable basis. Hence, propositions only make sense, if they make statements about facts in the world. As in the natural sciences, a theory would have to describe these facts in propositions that are systematically ordered (Kroß I993, I 38). From this departure, Wittgenstein forces the destruction of the philosophical idea of a book of the universe, an idea that leads in his late philosophy to the recognition of a multiplicity of behavioural patterns, the plurality and heterogeneity of life forms. The lecture illustrates this as follows:

And now I must say that if I contemplate what Ethics really would have to be if there were such a science, this result seems to me quite obvious. It seems to me obvious that nothing we could ever think or say should be the thing. That we cannot write a scientific book, the subject matter of which could be intrinsically sublime and above all other subject matters. I can only describe my feeling by the metaphor, that, if a man could write a book on Ethics which really was a book on Ethics, this book would, with an explosion, destroy all the other books in the world. Our words used as we use them in science, are 
vessels capable only of containing and conveying meaning and sense, natural meaning and sense. Ethics, if it is anything, is supernatural and our words will only express facts [...]. I said that so far as facts and propositions are concerned there is only relative value and relative good, right, etc. (LE, 7)

Wittgenstein confirms by that flow of thoughts what he already called the transcendental nature of the ethical in his Tractatus: namely, that the ethical dimension is only revealed by its exclusion from articulate expression, that is, the absence of a state of affairs that can be described. For him, in our world of facts and states of affairs, no "absolutely right road" can be recognized with the coercive power of a judge, as it were, an absolute ethical power of creating acts and evaluating actions. He writes:

Now let us see what we could possibly mean by the expression, "the absolutely right road." I think it would be the road which everybody on seeing it would, with logical necessity, have to go, or be ashamed for not going. And similarly the absolute good, if it is a describable state of affairs, would be one which everybody, independent of his tastes and inclinations, would necessarily bring about or feel guilty for not bringing about. And I want to say that such a state of affairs is a chimera. No state of affairs has, in itself, what I would like to call the coercive power of an absolute judge. (LE, 7)

Even if it were possible to imagine an absolute and normative ethics as given, it could not possess the coercion of an absolute judge, for that power would still remain an indescribable state of affairs. A consensus in the definitions would obtain, yet it does not follow that this consensus would extend to the judgements. By rejecting the "the coercive power of an absolute judge" Wittgenstein destructs the universality claim of ethics, by conceding that the decision whether the demand to take "the absolutely right road" or the de facto remark "This is the absolute good!", accepted by individuals, exclusively depends on an individual's practical approach. Since every demand to adopt a certain way of seeing things always implicitly presupposes that there is another possibility, every idea of an absolute is a delusion.

Despite this sobering analysis, Wittgenstein recognizes a "drive" that is manifested in man's continued attempt to create ethical theories. These ethical theories are interpretations of human actions. That the number of such theories seems infinite is to be explained by humanity's wish to 
undertake such interpretations. In his early works, particularly the Tractatus, Wittgenstein attempted to research this wish by devising an objective philosophy. He confines his belonging to this life form, by writing:

I see now that these nonsensical expressions were not nonsensical because I had not yet found the correct expressions, but that their nonsensicality was their very essence. For all I wanted to do with them was just to go beyond the world and that is to say beyond significant language. My whole tendency and I believe the tendency of all men who ever tried to write or talk Ethics or Religion was to run against the boundaries of language. This running against the walls of our cage is perfectly, absolutely hopeless. Ethics so far as it springs from the desire to say something about the ultimate meaning of life, the absolute good, the absolute valuable, can be no science. What it says does not add to our knowledge in any sense. But it is a document of a tendency in the human mind which I personally cannot help respecting deeply and I would not for my life ridicule it. (LE, I If.)

Whilst Wittgenstein's late philosophy, on the one hand, destructs the idea of a higher or "absolute judge" and justifies the inaccessibility of theories in ethics, his reflections permit, on the other hand, the definition of "self" as hanging ethics on the peg of "subject/self" and not linking that connection to the prevailing state of affairs in the world. By using the phraseology "saying I" in his Lecture on Ethics, Wittgenstein makes it a fait accompli that demonstrates certainty; and, in that sense, the point is reached where ethics and religion unavoidably collide and, for the "Isaying" Wittgenstein, become one. In terms of ethics, the "self" obtains a special significance.

In that way, the quest for an ultimate reason, as well as the definition of the highest aims in human life make no sense in Wittgenstein's context of an ethical theory. His philosophical investigations remain devoid of ethical determinants for human action and without a final justification, since instead of a unified, ultimate truth, what emerges is a plurality and heterogeneity of life forms and a respective variety of behaviours that could contain a multiplicity of truths. In this regard, Wittgenstein's late philosophy could also be described as "linguistic relativism" (cf. Machan I98 I, 359), in which case, however: 
[...] Wittgenstein's relativism, used as an instrument of critical objection to the metaphysical content of epistemology, is itself not motivated by epistemological factors; its basis is precisely not a sceptical dismissal of the possibility of statements claiming truth, but rather the rejection of that truth claim, as it could be guaranteed with the assistance of the theory of knowledge (Kroß I993, I45).

Ethics can neither be an ultimate source of reason, nor a guarantee for epistemological truth. As a matter of course, ethical determinants for human actions remain without a conclusive justification.

Now the question arises as to what motivates an individual to take ethical action, in view of the lack of conclusive justification, or guaranteed truth for the correct way of acting. In the following section, attention is focused on whether the mystical dimension substitutes for Wittgenstein the epistemological motivation for ethical action.

\section{The Mystical Dimension of Ethics}

At the end of I9I9, Wittgenstein wrote to Ludwig von Ficker, the editor of the periodical Der Brenner (“The Torch”) about the Tractatus:

You see, I am quite sure that you won't get all that much out of reading it. Because you won't understand it; its subject-matter will seem quite alien to you. But it isn't really alien to you, because the book's point is an ethical one. I once meant to include in the preface a sentence which is not in fact there now but which I will write out for you here, because it will perhaps be a key to the work for you. What I meant to write, then, was this: My work consists of two parts: the one presented here plus all I have not written. And it is precisely this second part that is the important one. My book draws limits to the sphere of the ethical from the inside as it were, and I am convinced that this is the ONLY rigorous way of drawing those limits. In short, I believe that where many others today are just gassing, I have managed in my book to put everything firmly into place by being silent about it (von Wright I982, 83).

The tension at the core of the book manifests itself in the concept of "showing" that Wittgenstein uses to expose the illusion of an intrinsic link between the ethical obiter dicta and the coherent logical and empirical philosophy of language that forms the overwhelming part of the book 
(cf. Edwards 1982, 19). Wittgenstein therefore distinguishes between showing in the sense of representational language and showing, to "climb up the ladder" to a right view of the world. The former can be shown with a symbolic system, whilst the latter cannot be shown, but must reveal itself. Wittgenstein identifies this with the mystical: "There are, indeed, things that cannot be put into words. They make themselves manifest. They are what is mystical.” (TLP 6.522)

The content of the treatise reveals itself to the reader, therefore, not only by its explicit meaning, but also by what is not said. What is essential here, that is, ethics, only commences beyond the limits of language, namely, at the point where silence begins. The limits of language are drawn within language. All other aspects (such as ethics, aesthetics, religion) do not belong to the sphere of articulate sense. These things remain inarticulate and can only be shown by the mystical realm.

The difference between "showing" and "showing itself" corresponds to the distinction between the representational language of theoretical philosophy and the practical drive, to discover an essential way of thinking and means of confronting the deepest human concerns of life. These aspects, in turn, do not concern representable and contingent facts, but necessities of human life, such as the question of eternity, of "good" and "evil", of the will that changes the world etc. A key aspect of the Tractatus is the ethical deed, even though this viewpoint is worked out in a theoretical work that rather contradicts these formal reflections (cf. Edwards I 982, 27). The medium is contrary to these thoughts, as it cannot be assumed that the underlying insights into the nature of subjectivity, of ethics, and religion could be articulated by logical analysis. Rather, these aspects show themselves in the form of a philosophy that runs against the limits of language and so endeavours to say what cannot be said. For that reason, it is extremely difficult to identify the link of logic and ontology in the treatise and the transcendental insights that Wittgenstein viewed as the real content of the book (cf. Stern I995, 70-72). Hence, Wittgenstein also promises encouragingly that those who are inclined to understand him are to be richly rewarded by "seeing the world aright": 
My propositions serve as elucidations in the following way: anyone who understands me eventually recognizes them as nonsensical, when he has used them - as steps - to climb up beyond them. (He must, so to speak, throw away the ladder after he has climbed up it.)

He must transcend these propositions, and then he will see the world aright. (TLP 6.54)

Naturally, this recognition cannot be verified, since it lies beyond what is the knowable. A person, having surmounted the propositions of the Tractatus and having "seen the world rightly" will no longer try to express their recognition, knowing, as he does, that it cannot be expressed (cf. Anscombe 197 I, I7 I). All questions of human life and ethical values are thereby effectively seperated from the sphere of scientific research. Hence, it can be argued, that everything that is a matter of human concern - whether ethics, aesthetics, religion or even philosophy itself fall into the category of the mystical for Wittgenstein. Nevertheless, at the very least, a general knowledge can be derived from the Tractatus, namely, that whatever can be known does not exhaust reality, that there are things in life that cannot be discussed (cf. Maslow I96 I, I62).

In a strict sense of experience, one cannot communicate exactly what one experiences. This is not to say that Wittgenstein rules out communal feelings, or communication of impressions. We can exchange impressions and values, we can even partake of the same moral values, we can follow the intuitions of other people - yet, all this, only to a certain degree, given that we cannot experience exactly the same sense data and content.

The meaning of life cannot exist within the boundaries of the world, but rather: "The sense of the world must lie outside the world. In the world everything is as it is, and everything happens as it does happen: in it no value exists - and if it did exist, it would have no value. [...]" (TLP 6.4I) However, Wittgenstein advocates the thesis that we can have intuitions whose transcendental character cannot be put into words and is based on mystical feelings, whose reality is recognized, as it were, beyond space and time. This supra-natural element is for Wittgenstein " $[\mathrm{t}]$ he solution of the riddle in space and time that lies outside space and time." (TLP 6.43 I 2) And further: 
The solution of the problem of life is seen in the vanishing of the problem. (Is not the reason why those who have found after a long period of doubt that the sense of life became clear to them have then been unable to say what constituted that sense?) (TLP 6.52I)

By reaching such knowledge of the problem of life that drives us to "climb up the ladder", then the problem as such disappears. It fades, since it must fade, since the solution to the problem of life lies precisely in its disappearance. It is questionable, whether the disappearance is the reason why the solution cannot be spoken, or whether the solution, the "climbing of the ladder", or the disappearance, from the outset, represent, an expressible experience. Even Wittgenstein cannot give an answer to the question, although he concludes that precisely this incommunicable dimension must amount to what we call mystical and that in this respect what cannot be put into words is shown.

For Wittgenstein, the answer to the question of the meaning of life resides in oneself. Attention has to be directed to oneself since the power to change the world only lies in the power to change one's own attitude toward the world. This power is a mystical force and, as such, mystic becomes the last bastion of things in life that mean the most to us: namely, all ethical conceptions, all things that we cannot express and that are nonetheless of fundamental significance for us (cf. Maslow i96 I, I60). Hence, the ethical intent of the Tractatus does not appear as an arbitrary by-product of Wittgenstein's philosophy of language and thought. Since "[1] ogic is not a body of doctrine, but a mirror-image of the world" (TLP 6.I3), the treatise's logic and the language philosophy only proves the philosophical incompetence of atomistic, logical-empirical philosophy of language. Because of this, it shows that silence can be the only medium for the revelation of the mystical force. Silence is the outcome of recognition for those who "throw away the ladder after [they have] climbed up it."

As a consequence, the subject matter of ethics, for Wittgenstein, significantly differs from what most people think ethics is about. Neither theorizing about certain behaviour patterns, nor researching the problems of behaviour amongst others can be at the heart of ethical enquiries. Rather, the fundamental question in ethics must be a preoccu- 
pation with being-in-the-world and the meaning of life. Individuals can only know how to live in this world by understanding the meaning of being-in-the-world and life itself. It is crucial to distinguish these widely diverging conceptions of ethics. To Wittgenstein, ethics has no special task in discourse amongst different people, whilst we treat ethics as a whole as a field of inter-subjective discourse (cf. Diamond I99 I, 9).

Wittgenstein's conception of ethics is scarcely to be distinguished from a religion, as each discipline is concerned with the meaning of the world and life. That Wittgenstein says nothing about how to live one's life, is justified by his theory that " $[\mathrm{t}]$ he world is independent of my will” (TLP 6.373). This rules out being judged for doing something deliberately, and as a consequence our usual understanding of the ethical cannot any longer be applied. According to TLP 6.423, "[i]t is impossible to speak about the will [...] as [...] the subject of ethical attributes", and "the good or the bad exercise of the will [...] can alter only the limits of the world, not the facts [...]" (TLP 6.43). Ethical significance can only be traced back to the ethical will, not to the world at large. The ethical will alters the limits of the world by changing the attitude one takes toward the world. In that way, the ethical will also changes the perception of how one sees the world. Only oneself can change the limits of one's world by directing one's attention to the ethical will, without which it is impossible to allow the development of good will. This attention can only be experienced in the mystical, where the meaning of life can be shown. The significance of ethics, which cannot be put into words, can only lie in a praxeological context, that is to say, in the way in which the individual's attitude to the world is to be changed and not his basic conviction, in order to learn how to lead one's life and give it meaning (cf. Edwards I982, chapt. 2).

The ladder that we are meant to climb up and then throw away in the Tractatus helps us to achieve a view of the world sub specie aeternitatis. At this point, the mystical is shown. The meaning of life is to be revealed in the mystical realm that is devoid of space and time. In the timelessness of the experience of an event, timelessness means the same as eternity. In this sense, a view of the world and of the individual life can be obtained sub specie aeternitatis. This holds true "if we take eternity to mean not 
infinite temporal duration but timelessness, then eternal life belongs to those who live in the present." (TLP 6.43 I I)

For Wittgenstein, ethics is an instrument for giving meaning to one's own being-in-the-world. Since this meaning can only be achieved through one's own ethical will, every kind of ethical impulse is based on a mystical experience, or on an experience of showing. To assess the importance of the mystical dimension for Wittgenstein's ethics, it is necessary to elaborate the extent to which the mystical corresponds to the metaphysical dimension, or whether, using mysticism as a prop, Wittgenstein merely wants to convey a metaphysical theory of meaning that lies outside of our experience.

\section{Ethical Mysticism without Metaphysics}

For Wittgenstein, there is a human "drive", to devise a "picture of the world" that gives life meaning and helps to explain the world. That is, so to speak, to provide a kind of certainty on the basic questions of our existence. This "drive" in human beings corresponds to a "metaphysical need", a striving for ultimate truths and securities.

That anything exists at all, this fact carries the great fascination that preoccupies Wittgenstein. The sudden meaningfulness of this fact is a known experience in the sphere of mystics and it again occurs as such in Wittgenstein's work. Already in the Tractatus logico-philosophicus, this "basic question of metaphysics", that is, why anything exists at all, is described as mystical: "It is not bow things are in the world that is mystical, but that it exists." (TLP 6.44)

However, although Wittgenstein pursues the question of existence for his entire life, he never touches the secret nature of "the basic question of metaphysics." He does not even try to clarify this question. Already in proposition 6.5 of the Tractatus, Wittgenstein explains why he will never confront this "basic question", even if the underlying experience, namely the sense of wonder about existence, is extremely significant:

When the answer cannot be put into words, neither can the question be put into words. 
The riddle does not exist.

If a question can be framed at all, it is also possible to answer it. (TLP 6.5)

Wittgenstein's mysticism is not metaphysical, since it is not about a theory of the "meaning of the world" outside of our experiences. For him, the ethical questions of philosophy as doctrine belong to metaphysics, his own project of ethics as activity, or the quest for the ethical life is, however, post-metaphysical, so to speak, not related to the experience of mystical knowledge and not appealing to metaphysics to assist with his answers. Mystics can neither be expressed in statements, nor can it name any sort of truth. "True" or "false" are not relevant categories to mystics. The fact that he tolerates the clarification of the "question of the meaning of being", the sense of wonder about existence, does not stop him from producing a critique of metaphysical questions and answers.

Wittgenstein exposed the fact, in a paradoxical way and by negation, that every natural language is underpinned by its own ontology. Every "natural" or not "formalized" language must possess a particular metaphysics that is identical with its "meta-language". For Wittgenstein, philosophical propositions are not within the limits of language, defined again by its inner structure. Rather, philosophical propositions, that is, propositions of metaphysics, are inevitably and incurably speculative, since they transcend the limits of language and also the limits of the world, because: "The limits of my language mean the limits of my world.” (TLP 5.6)

Since, however, according to TLP 5.6 I "logic pervades the world" and "the limits of the world are also its limits", there can be no legitimate metaphysics, since there is, next to the sphere of substantive empirical propositions and that of "nonsensical" propositions of logic, no further legitimate sphere. As in TLP 4.022, a proposition shows "how things stand if it is true. And it says that they do so stand." For that reason, a proposition in which a state of affairs is expressed, not only contains "the truth-possibilities of a proposition" (TLP 4.43I), but at the same time, it is "the expression of its truth conditions" (TLP 4.43 I). That is to say that the proposition is an expression for the fact that whoever expresses it holds the view that his truth conditions are 
fulfilled. In any case, "no proposition can make a statement about itself, because a propositional sign cannot be contained in itself $[. .$.$] ”$ (TLP 3.332). Thus, it is virtually inherent to the essence of metaphysics that "the distinction between the factual and conceptual investigations" is blurred and at the same time it is the task of "philosophical investigations" to make this explicit. In Zettel, it is stated: "Philosophical investigations: conceptual investigations. The essential thing about metaphysics: it obliterates the distinction between factual and conceptual investigations." $\left(\mathrm{Z}_{45} 8\right)$

Nevertheless, in the Tractatus, Wittgenstein almost commits the same mistake of intending to state something metaphysical, that is, to mean to say something that cannot be said in words. As Wittgenstein's philosophy of language endeavours to say things that cannot be put into words in an empirical way, he finally has to end the project of explaining the world - yet not without satisfying his own "longing for the transcendent" (CV I93 I, I 5), by his "propositions - as steps - to climb up beyond them" (TLP 6.54). Only by "throwing away the ladder" does Wittgenstein succeed in not sliding into the metaphysical realm. The turnabout at the last minute leaves the "transcendent", that is to say, the view of the world sub specie aeternitatis, in the sense of proposition 6.522 of the Tractatus, as "things that cannot be put into words" and therefore as "mystical".

Wittgenstein's thought is a constant reversal at the limits of traditional philosophy:

Wittgenstein attempts to bring a philosophy to an end, namely, philosophy as doctrine, of which it is often said that it is 'the' philosophy. His thought makes it possible to observe the history of this philosophy from the periphery, as the history of wonder about the existence of the world and of the need to gain clarity about this astonishing world and the role of human beings within it. (Kroß I993, I8 I)

His work stands for a philosophical description, instead of attempts at metaphysical elucidation. His philosophy consists of a variety of philosophical perspectives and standpoints. It wards off metaphysics that presents itself as being rational. Wittgenstein's critique of metaphysics also showed two points at the same time: 
Firstly, as theoretical options, scepticism and relativism are still based on false, quasi-metaphysical ideas of what we can actually know. Secondly, metaphysical pictures already place a burden on many of our everyday notions, even leading astray in "small" cognitive situations. We can become objectivizing metaphysicians everywhere, even against our will, when understanding any sensible action. (Rentsch I999, I44)

The question of "being itself" and the end of "metaphysics" are one and the same. "The mystical" that Wittgenstein speaks of is not a way of being, but rather a situatively chosen life form. The "mystical" is therefore not a "metaphysical zero point". From this point, a new attack against metaphysics as striving for the "meaning of being" cannot commence Sisyphus-like. Rather, it is an enduring end to philosopby as doctrine and a beginning of a philosophy as activity. Human language practice is ahead of every philosophy as doctrine, so that it cannot be overtaken. Hence, 'the' philosophy recedes behind life. What emerges instead of systematic observation is "differential observation of human life and practice.” (Kroß I 993,65).

In the Tractatus, "sense" is used as a terminus technicus. To say that a statement makes "sense" is the same as the observation that the statement relates to objects in the world and that it is contingent. By the same token, to say that a statement is nonsense is only to state that it is not about such a statement. The category "nonsense" largely serves in the Tractatus to differentiate and is not a tool of critique. Wittgenstein's concept of "nonsense" bears no relation whatsoever to the everyday use of the term. In this regard, it follows that the view of philosophical statements as nonsense is not synonymous with their absurdity or nonsensical character. Because it is impossible to make sense about what ultimately is to be "reasoned", it can only be shown. Since

[...] the "riddle of existence" (is) [...] no riddle like any other that might be dissolved into some other methods still available today. Rather, it is a riddle that is essentially without resolution. If it belongs to the conditions of suitability for a question that the possibility of an answer cannot be excluded on principle, then "the basic question" is, in this sense, at least "nonsensical". (Birnbacher 1992, 135) 
Metaphysical projects, for Wittgenstein, are "nonsense", since they lead beyond the sphere of "meaningful statement". However, this nonsense is, for many people, a highly meaningful nonsense that is to be respectted; and, hence, metaphysics is not primarily a "nonsensical" chaos, but rather an attempt to domesticate that entity. Wittgenstein undertakes an enduring destruction of metaphysics, since after its fall, that is, the release from a "generality that is already to be assumed", there is no longer any danger of falling back into it, given that the destruction of the dogma of generality "creates a situation of openness and also contributes to a tentative new order.” (Kroß I999, I 86).

The question of sense is a basic characteristic of ethical questioning and also forms the basis of the desire for metaphysics. Wittgenstein shows, however, that ethics must not also be understood metaphysically. The "mystical" that Wittgenstein proposes as the ethics of the individual is not a way of being but a life form. In that sense, it is false to claim, as some do, that Wittgenstein even intensifies the metaphysical interpretation of ethics, by associating ethics with mystical and religious experiences. Neither mystics nor religion are based on a "generality that is already existing", a viewpoint that is rather a criterion of metaphysics.

In the following section, emphasis is on the link of religious and ethical language in Wittgenstein's view.

\section{Ethical Feeling and Religion}

Wittgenstein's ethics is rooted in "wonder about existence", in the fascination "that something exists at all." An ethical feeling results out of the wonder of being-in-the-world that is equally the basis of religion and aesthetics that also emerge from the mystical that manifests itself in a world-view sub specie aeternitatis. In the diaries, the following entry occurs: "The work of art is the object seen sub specie aeternitatis; and the good life is the world seen sub specie aeternitatis. This is the connexion between art and ethics." (NB, 7.IO.I6) The connection of ethics, religion and aesthetics is especially striking in Wittgenstein's work. Each element is based on the experience of an event that cannot be articulated in the form of logical-empirical propositions. Rather, it is an 
event of mystical character, in the sense of an observation of the world following from outside and, as a result, leading to a change of perspective on the world.

Ethics and religion are attempts to draw a sense out of life and they are nothing other than answers to the "astonishment about the existence of the world". In this context, it is understandable that individuals lend meaning to their being in the world, by claiming to know their action as ethically considered and often being able to understand their existence as part of a religious whole. For Wittgenstein, this is nothing more than "significant" nonsense, even if it is to be respected. Neither ethics nor religion requires language for belief, since neither can be rejected as "true" or "false". They are expressions of a striving for meaning, a hope for the experience of an event that shows itself-in-the-world in the form of mystical knowledge. The knowledge lies, namely, in the event that can exclusively be perceived as an unspeakable power of the mystical. It could also be said with Wittgenstein that we can name this "[...] meaning of life, that is, the meaning of the world [...] God." (NB, I I.6.16) Such mystical experiences must necessarily be experienced by the self, for "propositions about God, good and evil, the meaning of life etc. are false propositions and these themes therefore point to the sphere that cannot be put into words, just like all propositions that show no facts." (Weiberg 1998, 45) Statements about God and religion therefore lose every meaning that they cannot convey in words. The meaning of belief is not discredited in that way, for "How things are in the world is a matter of complete indifference for what is higher. God does not reveal himself in the world." (TLP 6.432)

The rule of silence also holds true for ethics (as well as aesthetics), namely, the assertion of inexpressibility "in the limits of language that are the limits of our world". Here, the religious aspect of ethics comes to light, for the definition of what we call God is one and the same as striving for an ethical life, for a meaning in life and in the world that manifests nothing other than a life in the sense of God.

Yet how does an individual arrive at faith? Wittgenstein can imagine a number of possibilities: faith can be accepted through education. In this case, faith is only a part of what a child learns to believe, since "the 
child learns to believe a host of things. I.e. it learns to act according to these beliefs." (OC, I44) It is also plausible that individuals are convinced of the correctness of an intuition by simplicity or symmetry (cf. OC, 92). Furthermore, there is the conscious possibility of deciding for a particular system:

It strikes me that a religious belief could only be something like a passionate commitment to a system of reference. Hence, although it's belief, it's really a way of living, or a way of assessing life. (CV i 947, 64)

This turn towards religion can be seen as synonymous with the turn to a world-view or a particular world image, since whatever is perceived as truth, after the decision, is independent of the system of values that one decides to support. For that reason, in any system of values, it is possible to see those respective foundations of the house on which one builds one's convictions: "I have arrived at the rock bottom of my convictions. And one might almost say that these foundation-walls are carried by the whole house." (OC, 248)

Wittgenstein is not critical of faith, but rather of the attempt to justify faith scientifically. It should not be judged, whether someone believes in religious pictures and symbols or not, but an attempt to prove the existence of God by the means of reason appears dishonest. Shortly before his death, Wittgenstein writes:

A proof of God's existence ought really to be something by means of which one could convince oneself that God exists. But I think that what believers who have furnished such proof wanted to do is give their 'belief' an intellectual analysis and foundation, although they themselves would never have come to believe as a result of such proofs. (CV I950, 85)

To persuade others of the existence of God with proofs, as supplied by the Church and believers, is an attempt doomed to failure. In Wittgenstein's view, this matter is known to Christianity, since it is based on "historical narratives":

Christianity is not based on a historical truth; rather, it offers us a (historical) narrative and says: now believe! But not, believe this narrative with the belief appropriate to a historical narrative, rather: believe, through thick and thin, which you can do only as the result of a life. Here you bave a narrative, 
don't take the same attitude to it as you take to other historical narratives! Make a quite different place in your life for it.-There is nothing paradoxical about that! (CV I937, 32)

Wittgenstein's thought on religion and ethics are in stark contrast to the world-view of science. They have quite different modes of thought, whose foundations are neither to be justified nor reasoned. Whoever develops an ethical feeling or accepts a faith no longer needs an answer for this, since he has already reached the foundation of his faith. The foundation of faith or ethics is a system of values that cannot be questioned, since they are either recognized as "true" or not. Wittgenstein writes: "At the foundation of well-founded belief lies belief that is not founded." (OC, 253)

For Wittgenstein, truth is not the primary aspect, but rather "truthfulness" - truthfulness in the attempt to give meaning to individual life. Above all, that is a question of personal style, because ethics can be judged as little as truthfulness, although it remains the basis of the meaning that an individual desires in life. Here, Wittgenstein also sees a consensus of ethical striving with the Christian religion: "I believe that one of the things Christianity says is that sound doctrines are all useless. That you have to change your life. (Or the direction of your life.)” (CV 1946, 53)

The language itself suggests that the validity of ethics and religion is worthy of generalization, yet that also obscures the fact that it cannot be found in propositional statements. By contrast, it is worth remembering:

[...] that there is not a religious language-game shaping the entire discourse of a religious individual, but a religious world-view that forms the basis of his thought and action in a way that cannot be questioned. The differences between religious and non-religious individuals manifest themselves primarily not in language, but in an individual life. (Weiberg I998, I4I)

In the broadest sense, neither ethics nor religion can be distinguished, since both disciplines exclusively fall within the realm of human action. However, Wittgenstein differentiates between both these forms of faith, by lending different weight to each. Religious faith represents a 
higher level of belief, whilst ethical faith can be described as on a lower level. The difference that Wittgenstein means to summarize is:

$[\ldots]$ that in the first case, the individual feels ill and in the second case merely imperfect. In each case, quite different attitudes to life are outlined, as far as dealing with problems are concerned and with the independent initiatives of individuals. Whoever feels imperfect regards himself as guilty of this state, he fights with his own self, with his own character (like Wittgenstein), whereas a religious believer, who feels ill, is not conscious of any guilt. He puts his fate in good faith into the hands of his doctor - that is, God - and hopes for recovery (from outside)-and in that way he behaves more passively. (Weiberg I998, I63f.)

Whoever takes Wittgenstein seriously, is hardly likely to be engaged in theology or the philosophy of religion, but either to limit his research to the description of a religious language-game, or "only" to believe. The search for truth in the sense of an academic discipline is, after its destruction, nonsensical. Such a quest cannot resolve the problems. Only religion as activity can help individuals in the search for the meaning of life. Religion, like philosophy, cannot be treated as a doctrine, since it is a practice, whose significance can only be shown, by acting accordingly. By contrast to ethics, in its constant relation to the quest for the meaning of life, the religious believer achieves certainty for himself, since " $[\mathrm{t}]$ o believe in a God means to understand the question about the meaning of life. [...] To believe in God means to see that life has a meaning." (NB, 8.7.16) All doubts on the problem of life are ruled out for the believer and faith is so strong that he no longer tries to question or prove his faith with the aid of reason. In this case, what holds true of the deeply devout believer is that "[r]eligion is, as it were, the calm bottom of the sea at its deepest point, which remains calm however high the waves on the surface may be.” (CV I 946, 53)

\section{At the End of Ethics - A New Beginning}

The idea of ethics is related, in philosophy, to the attempt to establish a canon of norms and methods to vouchsafe the universality of ethical concepts and rules for action. These norms and methods are directed at 
ethical questions, conflicts and problems of inter-subjective behaviour that are to be resolved by ethics, by developing these issues into a normative science of generally legitimate propositions. This theory of ethics can be seen as a science of the justification of ethical decisions, so to speak, a theory that is identical to the teleology of academic ethics that often makes Being, in a circular way, out of the principle of duty and, ultimately, derives again that principle from an artificially constructed Being. Universalist ethics is, for that reason, largely characterized by the disappearance of the distinction between Being and a sense of moral obligation.

Briefly to recapitulate the central results of "these hikes through Wittgenstein's ethics": For Wittgenstein, it makes sense neither to search for an ultimate legitimacy to ethics, nor to seek guarantees for truth as a theory of knowledge. Ethical theories for human actions must remain, for him, without a final justification. In place of an ultimate truth, Wittgenstein posits, as a philosopher of pluralism, a multiplicity of life forms and ways of behaviour that each contains their respective truth. Ethical knowledge can only be achieved in the mystical sense. According to Wittgenstein, philosophical ethics cannot promote the meaning of life, but only working on one's individual self, that is to say, the quest for an ethical sense is an instrument of the individual's being-inthe-world and the desire to find meaning in life. As this meaning can only be found through one's own ethical will and, in turn, its expression lies in the experience of the perception of the mystical, every kind of ethical belief rests on a mystical experience of showing. This question of meaning is not only a basic feature of ethical, but also metaphysical enquiry. Yet Wittgenstein supplies examples to demonstrate that the ethical impulse cannot nearly be considered as metaphysical, since "the mystical" element that is proposed as the ethics of the individual is not a way of being, but a life form. It is a praxeological concept, whose goal is to understand philosopby as action. Furthermore, Wittgenstein shows that ethics and religion can only occur through the sphere of action and the doctrine of faith is to be rejected just as a philosophical doctrine of ethics, for neither can solve problems. Religion as activity may help individuals in their quest to find a purpose in life. By contrast to the ethical 
explorer, who is constantly searching for the meaning of life, the religious believer has already achieved certainty in relation to the meaning of life.

What is the outcome for the traditional conception of ethics as an academic tradition? Wittgenstein adopts quite a different idea than philosophers of what ethics can and should achieve. He intended not to solve the problems of philosophy, but those of his own existence. Hence, he lays no claim to ethics in the sense of a scientific theory. As a philosophical discipline, ethics can achieve nothing, since every attempt to create an objective and absolute claim is bound to fail for problems that cannot be summarized in a general theory. As a result, Wittgenstein strove, by his praxeological individual ethics, for a complete destruction of scientific ethics: "I think it is definitely important to put an end to all the claptrap about ethics - whether intuitive knowledge exists, whether values exist, whether the good is definable." (WVC, 68f.) Yet his goal was not to forbid such statements, but to expose their "valuelessness" and to achieve a paradigmatic change in the picture of ethics.

The meaning of ethics for human life cannot be derived from any scientific basis. It cannot be treated as a research field that can be mastered by scientific methods. Ethics cannot be reduced to a system of propositions that establish a code for the phenomena of our world in analogy to scientific theories. Ethics is essentially bound to the "subject/self”. An external, "higher being”, or an "absolute judge” does not exist in Wittgenstein's view. Any experience of value is always the experience of the individual subject.

The question of ethics is always a subjective one about the right way of living. That can only be determined by each individual on his own account and, for that reason, ethics cannot be stated in universally valid terms. The discipline can neither be a science, nor act as a doctrine of the right way of living, since it is more or less beyond the bounds of theory, not within the range of generally valid maxims or moral appeals. Wittgenstein therefore avoids formulating a binding doctrine of virtue and duty, as well as falling foul to an ethical relativism, by developing an alternative philosophy as activity, as it were, the praxeological concept of an individual "clarification" of life conduct. Hence, the ethical 
will directing ethical conduct as a practice in relation to the questionable nature of life is turned into the decisive factor of a successful life.

The individual world-view determines ethics and every individual must answer the question of the right conduct, without concrete reference to philosophical theories, in accordance with his own life situation; and that questioning is not an exception, but rather the continual activity that endures throughout his lifetime. Ethics can therefore be seen as working through things for the individual self. At the close of the Tractatus, this view is stated more explicitly:

We feel that even when all possible scientific questions have been answered, the problems of life remain completely untouched. Of course there are then no questions left, and this itself is the answer. (TLP 6.52)

In the belief that he had solved the scientific problem of ethics, Wittgenstein also recognized that little is achieved by solving that philosophical problem. The actual ethical matter, the meaning of one's own existence, is to be confronted anew, as though it were a perpetuum mobile, time and again. In the preface to the Tractatus, Wittgenstein already noted: "And if I am not mistaken in this belief, then the second thing in which the value of this work consists is that it shows how little is achieved when these problems are solved." The problem of life remains the individual's permanent search for ethical sense.

The question of sense in life can never be answered. In a way, life is the quest for an ethical meaning and life is in toto also the answer. Ethics is a doing, the achievement of individual principles and the constant reflection of the self-consciousness of "subject/self" and the individual view of the world. How we live shows who we are. The practice of searching for a meaning of life is ethical action in itself. In the diaries this thought is described as: "The will is an attitude of the subject to the world. [...] The act of the will is not the cause of the action but is the action itself." (NB, 4.I I.I6) Action cannot be ethically judged, since it presents the self-elected life form of a person that cannot require justification. The fact that others' actions may not be judged ethically by Wittgenstein's viewpoints may be unsatisfactory. Yet academic philosophy cannot offer more, since as Wittgenstein aptly commented: 
Philosophy may in no way interfere with the actual use of language; it can in the end only describe it.

For it cannot give it any foundation either.

It leaves everything as it is. (PI $\$ 124)$.

Translated by Suzanne Kirkbright

Bibliography

Anscombe, Gertrude Elizabeth M. (1971): An Introduction to Wittgenstein's Tractatus, Philadelphia I97I.

Birnbacher, Dieter (1992): Wittgenstein und die „Grundfrage der Metaphysik“, in: Wilhelm Vossenkuhl (ed.), Von Wittgenstein lernen, Berlin 1992, I 2 I- I 36.

Diamond, Cora (199i): The Realistic Spirit: Wittgenstein, Philosophy, and the Mind. Cambridge, MA r99i.

Edwards, James C. (1982): Ethics without Philosophy: Wittgenstein and the Moral Life, Tampa 1982.

Kross, Matthias (1993): Klarheit als Selbstzweck: Wittgenstein über Philosophie, Religion, Ethik und Gewissheit, Berlin 1993.

- (1 999): Philosophieren in Beispielen. Wittgensteins Umdenken des Allgemeinen, in: Hans Julius SchneIder / Matthias Kross (eds.), Mit Sprache spielen, Berlin I999, I69-I87.

Machan, Tibor R. (I98I): „Ein besserer und gescheiterer Mensch“: Eine Wittgensteinsche Idee menschlicher Vortrefflichkeit?, in: Edgar Morscher / Rudolf Stranzinger (eds.), Ethik: Grundlagen, Probleme und Anwendungen, Wien i98 I, 359-364.

Maslow, Alexander (196r): A Study in Wittgenstein's Tractatus, Los Angeles I96r.

Rentsch, Thomas (1999): Praktische Gewissheit - Jenseits von Dogmatismus und Relativismus, in: Hans Julius SchneIder / Matthias Kross (eds.), Mit Sprache spielen, Berlin I 999, I 37-I 47.

Stern, David G. (i995): Wittgenstein on Mind and Language, New York I995. 
Weiberg, Anja (1998): „Und die Begründung hat ein Ende“: Die Bedeutung von Religion und Ethik für den Philosophen Ludwig Wittgenstein und das Verständnis seiner Werke, Wien 1998. WRIGHT, Georg Henrik von (I982): Wittgenstein, Oxford 1982. 


\section{"There are, indeed, things \\ that cannot be put into words." (TLP 6.522) \\ Wittgenstein's Ethics of Showing \\ Dieter Mersch}

Es gibt nichts Gutes, außer man tut es.

Erich Kästner

I.

Bertrand Russell is attributed with an anecdote that originates from the time, before World War One, of his friendship with Wittgenstein. In a state of extreme agitation, Wittgenstein was said to have come to Russell one night and paced up and down the room in silence. Russell asked him: "Wittgenstein, do you think about logic, or about your sins?" "About both!” was his reply (cf. McGuinness I989a, 48). Evidently, the problems of logic and ethics meant the same to him. As with two sides of the same coin, when every attempt to influence one side also brings about a change of the other, Wittgenstein promised himself just as much an answer from the solution of logical questions as ethical ones. ${ }^{1}$ Two puzzling remarks from the Tractatus make the connection clear: "Logic is transcendental." (TLP 6.13) And: "Ethics is transcendental." (TLP 6.42 I) The first remark is preceded by: "Logic is not a body of doctrine, but a mirror-image of the world." (TLP 6.I3); the second by: "The sense of the world must lie outside the world. In the world everything is as it is, and everything happens as it does happen: in it no value exists - and if it did exist, it would have no value." (TLP 6.4I) The latter remark, in turn, implies the conclusion: "So too it is impossible

1 Cf. McGuinness's answers in Mersch 1991, 85 f. 
for there to be propositions of ethics. Propositions can express nothing that is higher." (TLP 6.42) Furthermore, a no less erratic diary entry from the time of the production of the Tractatus records: "Ethics does not treat of the world. Ethics must be a condition of the world, like logic." (NB, 24.7.16) And one week later, like an exclamation follows: "But this is really in some sense deeply mysterious!” (NB, 30.7.16)

\section{II.}

Wittgenstein's early work, the Tractatus Logico-Philosophicus, and the quintessence of the puzzle is mainly a book about logic, about the relationship of sentence, thought and fact, as well as about basic propositions and the isomorphology of language and world. Nevertheless, the slim volume of discontinuous propositions is challenging; and Wittgenstein claimed that the truth of these propositions was "unassailable and definitive" and "to have found, on all essential points, the final solution of the problems" - though admittedly adding: "And if I am not mistaken in this belief, then the second thing in which the value of this work consists is that it shows how little is achieved when these problems are solved." (TLP Preface) Even if insights into ethics only emerge sporadically and in a few dark passages at the end, the Tractatus is indeed a perfect mirror of both sides of the coin. In a letter to friend and publisher Ludwig von Ficker, Wittgenstein had written that the meaning of his book was actually an ethical one:

I once wanted to give a few words in the foreword which now actually are not in it, which, however, I'll write to you now because they might be a key for you: I wanted to write that my work consists of two parts: of the one which is here, and of everything which I have not written. And precisely this second part is the important one. For the Ethical is delimited from within, as it were, by my book; and I'm convinced that, strictly speaking, it can ONLY be delimited in this way. (LvF, 94-95)

That means: the work cannot be interpreted by its explicit content. In proportion as it contains what can be said by logical analysis, it also implies the inexpressible. It refers it to the place of a silence. It already belongs as a gesture to what it remains silent about: on silence, its basis, 
only silence remains. For that reason, the second part does not contain an unwritten "secret doctrine"; rather, it is simultaneously evident in what is written: it marks what, according to the final sentence, "we cannot speak about" (TLP 7), that is, it compels an ascetic of speech. Wittgenstein calls it "the mystical" (TLP 6.522). The ethical belongs to it.

The thought is as striking as it is strange: the essential factor withdraws itself; the ethical begins at the point where language falls silent. The restriction of speech by logical analysis of language encloses what cannot be said like an inner space, lending it its shape; everything else, like ethics, but also metaphysics and aesthetics, is excluded, not submitting to the structure of science. They are not discursive, not propositional, therefore, they also contain no knowledge, no statements, no definitions to be decided upon. In this sense, it is claimed that the Tractatus sets a limit of thought, or rather: a limit of the linguistic "expression of thoughts". The limit is drawn inside language, as a boundary for whatever makes sense by the predicative proposition, whilst everything else belongs to the field of nonsense (TLP 4.I I 3, 4.I I6, 5.6I). And Wittgenstein says about the predicative proposition, which he understands as an image, as an injective function (TLP 3.3 I 8) that he has the facts as argument that, in turn, can be judged by yes-no-standpoints: "A proposition is a picture of reality." (TLP $4.0 \mathrm{I}$ ) "A proposition must restrict reality to two alternatives: yes or no." (TLP 4.023) “To understand a proposition means to know what is the case if it is true." (TLP 4.024) Thus, what can be sensibly expressed coincides with whatever can be expressed in true and false propositions: "The general form of a proposition is: This is how things stand." (TLP 4.5) Accordingly, Wittgenstein only allows scientific speech to be valid (cf. TLP 6.53). It is isomorphic to the possible world order. Therefore, language is encircled by what is logical as the possible, just as the world is encircled by the logical: "Logic pervades the world: the limits of the world are also its limits." (TLP 5.6I)

By contrast, the nonsensical refers to whatever cannot exist in truefalse disjunctions, whatever does not attribute meaning to the signs within a proposition, whatever consequently has no object that it refers to. If the meaning of two propositions lies in its "agreement and dis- 
agreement with possibilities of existence and non-existence of states of affairs" (TLP 4.2), then the nonsensical or aporetic speech does not permit such a decision; it stays in the realm of the systematically undecidable. It is not a question of forbidding such talk, but certainly of identifying its undecidability and hence its "valuelessness". Not only metaphysical statements fall into that category, insofar as they do not refer to states of affairs, but also all totalizing discourses, like speaking about logic, about language - or the propositions of the Tractatus itself. Hence, it is also stated: "Logic is transcendental" (TLP 6.I3) as equally "Ethics is transcendental" (TLP 6.42I), or "My propositions serve as elucidations in the following way: anyone who understands me eventually recognizes them as nonsensical [...]" (TLP 6.54). For the transcendental nature of logic lies in the fact that it is "prior to every experience - that something is so" (TLP 5.552), as with the transcendental nature of ethics that the significance of anything existing at all must lie beyond the world. Logic must assume existence as a precondition that admittedly withdraws from experience; ethics must assume the sense of existence that, in turn, cannot be expressed: "It is clear that ethics cannot be put into words." (TLP 6.42 I) Ultimately, the nonsensical nature of such statements is described as a vehicle, in order that "when he has used them - as steps" it is possible to climb beyond them. The individual "must transcend these propositions, and then he will see the world aright.” (TLP 6.54)

Nevertheless, as the "Logico-Philosophical Treatise" itself hardly leads in this way ad absurdum, the nonsensical per se proves equally less excluded. Rather, it fulfils its function in showing. That does not mean that the nonsensical shows itself in every case: there are infringements of syntax or semantics that have no reference or indicative character whatsoever; and yet, there is something that can be expressed as equally as shown (cf. Mersch 1999). It might be said that the region of the nonsensical - not of the senselessness that is exclusively reserved for logical syntax, tautology and contradiction ${ }^{2}-$ is further to be subdivided into areas of the merely confused and: of outlawing whatever is

2 Cf. TLP $3.33,4.03$ I 2, 4.46 I-4.462, 6.I, 6.I I , 6.2. 
shown. The latter refers to the "whole" of logic, language and world. These aspects - such as language and world - cannot be spoken about in meaningful propositions, at best, by way of them, by betraying something that remains removed from their propositional content:

Propositions can represent the whole of reality, but they cannot represent what they must have in common with reality in order to be able to represent it - logical form.

In order to be able to represent logical form, we should have to be able to station ourselves with propositions somewhere outside logic, that is to say outside the world. [...] What expresses itself in language, we cannot express by means of language. Propositions show the logical form of reality. They display it. (TLP 4.I 2f.)

In other words, language exposes its structure, as equally as its reaction to the world in speaking and every attempt to say this as well inevitably becomes entangled in a paradox. Hence, "what can be shown, cannot be said." (TLP 4.I 21 2)

At the same time, there is a characteristic difference between the showing of language through speech and the showing of the world in it. By virtue of speaking, language reveals bow it is: it reveals as a practice its form; whilst from the fact of the world in which language is spoken about, it emerges that language is: it discloses its existence. Hence, it is said of logic that it "is prior to the question 'How?', not prior to the question 'What?"' (TLP 5.552), whilst the existence of the world precedes its question "what": "It is not bow things are in the world that is mystical, but that it exists." (TLP 6.44) Since language only deals with the states of affairs in the world in true-false oppositions, a statement about its existence would not be a sensible proposition; it would refuse the expressible, insofar as the question "that" names no possible fact: "Does it make sense to ask what there must be in order that something can be the case?" (TLP 5.5542). Instead, the facticity of "that" signifies the inexpressible: it shows itself at the point where language does not reach: it lights up in silence as happening (Ereignis). For that reason, Wittgenstein also speaks of "wonder": the expression is also in the 1914I9I6 diaries, as later in the Lecture on Etbics that was held between 
1929 and I930 (NB, 20.10.I6; LE, 8). In the Tractatus, it is connected as such with the mystical (cf. TLP 6.44, 6.522). What is not meant is: the inexpressible exists as a transcendent or inexplicable entity beyond language; rather, it happens first and foremost from the opposition between what can be said and shown. The mystical represents the place where every definition of the question of "what" or "how" ceases and only the pure presence in relation to absence manifests itself. That means: the world, as the self-revealing entity, "is" only in the event. ${ }^{3}$

Nevertheless, in view of the showing of language and world, it is still necessary to distinguish between positive and negative mystics. The former refers to the indefinite nature of logical form, the latter to the mystery of existence. Positive mysticism includes the Tractatus in terms of content and its impossible undertaking to speak about something on which silence is the only possibility. In every sense, the perspective of the expressible is, in that case, a prior condition. That is determined by the postulate of the isomorphology of thought, speech and world that, in turn, gives preference to an ontology of logic, in order, ultimately, to progress to the inexpressibility of its structure. Accordingly, at the close of the Tractatus, Wittgenstein again returns, in mirror-like fashion, to the beginning: since the proposition "shows how things stand if it is true", but it "says that they do so stand"; whereas in the proposition that the world is, by the act of speaking about it, it is shown bow it is (cf. TLP 4.022, 6.44). The proposition therefore speaks about something, yet not "about its own speaking”. A later insight corresponds to that proposition, insofar as language blocks its reflection as much as its totalizing. "What is spoken can only be explained in language, and so in this sense language itself cannot be explained." That is the gist of an

3 The expression "event" or "happening" (Ereignis) implies that the distinction between what can be said and not said is not accessible: it is not a constructive effect of a discourse: it happens. It is therefore also not, as Derrida and J. Butler meanwhile seem to infer, marked arbitrarily and, by that, not transferable.

4 In his I975 dialogue with a Japanese, Heidegger calls, with good reason, his dialogue "Aus einem Gespräch von der Sprache" - a conversation of (von), not “about” (über) language. 
analogous remark from Philosophical Grammar that anticipates Wittgenstein's late philosophy: "Language must speak for itself." According to that idea, there is no exhaustible philosophy of language that might not essentially reduce it - a consequence that Wittgenstein ultimately drew in his merely "exemplary" proceedings of the Philosophical Investigations by the fact that he no longer speculated "about" the question of the "what" and the "that" of language and nor "about" the difference of saying and showing. Rather, he allowed these aspects to flow into the method of description itself, by only demonstrating partial languagegames as "critical models of comparison" that explain themselves by example (PI $\rrbracket_{23} ;$ PG , 6I-63.) It can therefore be said: the Investigations no longer proceed logically, but in an explanatory fashion; language, or to be more exact: a plurality of language-games shows itself by its use; it fulfils itself in the act of performance. By contrast, the "that" of reality can only appear where language falls silent: "I am only describing language, not explaining anything." (PG, 66)

On the other hand, negative mystics already reaches into that sphere of the inexpressible that for Wittgenstein coincides in the same measure with the exclusion of metaphysics, as with the ethical and the aesthetic dimension. In the Tractatus, no corresponding mention is made of them anywhere, not even in the form of speech, of the absence of speech. However, their essential indifference is not only a symptom of their inexpressibility, but above all, of that sound, with which they themselves touch the secret of existence. Admittedly, only a vague "feeling" announces that "experience par excellence" (cf. TLP 6.45; LE, 8). It is shielded from silence like a taboo: "God does not reveal himself in the world." (TLP 6.432)

5 PG, 40. That the difference between saying and showing is a sign of the continuity of the early and late philosophy, so that it is plausible to take this sign as pointing to the unity of Wittgenstein's philosophy is also studied by Watzka 2000, $23 \mathrm{f}$.

6 "How things are in the world is God", is the context of an unnumbered remark form the time of writing the Tractatus; [cf. TLP Critical Edition, 255]. In this respect, an affinity is also shown with Schelling's idea of God. 
III.

Meanwhile, the I9I4-1916 diaries as well as the 1932-37 Lecture on Ethics and parallel notes from 1929-30 by Waismann of the Vienna Circle contain a series of references that give a deeper insight into what is meant. ${ }^{7}$ The reflections contain a loose collection of thoughts on the will, death, as well as the "meaning of life" and "the whole of the world" that extend beyond the cryptic propositions in the Tractatus and allow them to be deciphered. The consistent link of ethics, aesthetics and religion is especially noteworthy. The Tractatus already postulates their connection with the brief remark: "It is clear that ethics cannot be put into words. [...] (Ethics and aesthetics are one and the same.)” (TLP 6.42 I) The suggested connection endures at least until the I930s and probably forms one of the basic positions of Wittgenstein's philosophy. Thus, almost fifteen years later, it is stated in the Lecture on Ethics: "Now I am going to use the term Ethics in a slightly wider sense, in a sense in fact which includes what I believe to be the most essential part of what is generally called Aesthetics." (LE, 4) Moreover, the following entry is noted in the diaries: "The work of art is the object seen sub specie aeternitatis; and the good life is the world seen sub specie aeternitatis. This is the connexion between art and ethics." (NB, 7.10.16)

Spinoza's doctrine echoes in the formulation. The view sub specie aeternis is a step out of reality; the viewpoint of eternity warns of departure from the world. ${ }^{8}$ That also means: the ethical as well as aesthetics do not refer to the existence or non-existence of facts, that is, to objects of science. Therefore, they are also not capable of being articulated in

7 Cf. NB; LE; WVC; MT. In the war years, above all, the confrontation with death is decisive, just as the diary entries end with the definitive view that suicide is the original $\sin$ (NB, IO.I.I7). See especially McGuinness I988, 33 Iff., 349ff., who cites above all Tolstoy's The Gospel in Brief, but also Lichtenberg and Schopenhauer, as references for Wittgenstein's ethics.

8 Spinoza I996, (Ethics, V/P29 \& $\mathrm{P}_{30}$ ) particularly highlights that to observe things according to the species of eternity means to see them, insofar as the Being of God incorporates their existence. 
sentence form; ${ }^{9}$ moreover, it is neither a case of establishing "laws" nor of justifying criteria or norms. Rather, the ethical and aesthetic dimensions require a change of attitude. Time and again, Wittgenstein outlines the point that there is no transition from the logic of language to ethics or aesthetics, because they owe their existence to the break with discourse. They literally occupy the place - like religion ${ }^{10}$ - of the Other of the discourse. Hence, it is disputed in the Lecture on Ethics whether a factual statement can "ever be, or imply, a judgement of absolute value": even a book including all possible descriptions would still contain "nothing that we would call an ethical judgement or anything that would logically imply such a judgment." (LE, 6) That also means: there can be no scientific ethics: "Ethics, if it is anything, is supernatural [...]". (LE, 7) In this way, Wittgenstein not only says that the ethical falls out of the domain of the factual, hence leaving no conclusion from being to duty, but he refers the ethical principally into another context. In other words, there is no "translation" between the expressible and the inexpressible of the ethical or aesthetics, but only a "leap" - just as Heidegger said in Identity and Difference that the sentence makes a "sentence" in the sense of a "leap". ${ }^{11}$ However, we only leap in an abyss, as is further stated, as long as the logos, that is, the predicative speech and therefore the perspective of the world are posited in the absolute sense, yet not, where "we leap and release ourselves" (Heidegger 1978, 20).

One way of such a release, for Wittgenstein, lies in the proposition " $[t]$ o view the world sub specie aeterni $[\ldots]$ as a whole - a limited whole." (TLP 6.45) To keep something as "whole" demands an outside view, as especially characteristic for aesthetic experience. This is impossible as

9 "Aboutness" in this sense is not a definition of art, as Arthur Danto states in The Transfiguration of the Commonplace.

${ }^{10}$ In the $1930-32$ and $1936-37$ diaries, it is stated in this sense: "Believing begins with belief. One must begin with belief; from words no belief follows." (MT 27.I.37)

11 Note: Heidegger's usage rests on a word play on the ambiguity of the German "Satz" and 'Sprung" that can mean 'sentence' or the initiation of a 'leap' or 'jump'. This word play is difficult to render in English. 
view, because it would presume taking the "whole" into view from a position that is already vacated, that is, remaining beyond the limit first conditioning its possibility. However, it is decisive that such a guarantee transforms the view, ${ }^{12}$ pointing to whatever presently conceals itself within the whole: the uniqueness of its existence. The following remark was entered in the diary under the date, I I June i9i6:

I know that this world exists.

That I am placed in it like my eye in its visual field.

That something about it is problematic, which we call its meaning.

That this meaning does not lie in it but outside it.

That life is the world. (NB, i r.6.16)

In that entry, the connection between ethics and aesthetics is also expressed: the view sub specie aeternis draws attention to the sudden nature of the "that". It is the experience of the moment (Augen-blick). The perspective of eternity and timelessness of the moment mean the same thing:

If we take eternity to mean not infinite temporal duration but timelessness, then eternal life belongs to those who live in the present. (TLP 6.43 I I $)^{13}$

The distinction of the moment is, then, not a typical characteristic for mysticism; ${ }^{14}$ rather, conversely, it springs forth from the moment of the "turn", which secures the existence of the world as ekstasis, as presence. That is to say it coincides with the experience of the ekstatic present itself, the moment that "leaps forward" that again does not describe a point in time, but out of time. Its experience implies abstaining from the world - and therefore from the whole. The unity of aesthetics with the ethical emerges from the interconnection of contemplation and

12 The diary contains the following remark about this: "The usual way of looking at things sees objects as it were from the midst of them, the view sub specie aeternitatis from outside. In such a way that they have the whole world as background." (NB, 7.10.16)

13 Similar remarks are also in NB, 8.7.I 6 and MT i 5.2.[37].

14 McGuinness suggests as one feature of mystics the turn to the moment, cf. i $989 \mathrm{~b}, \mathrm{i} 67, \mathrm{i} 80 \mathrm{f}$. 
abstinence. The mystical forms its bridge: "Feeling the world as a limited whole - it is this that is mystical." (TLP 6.45)

The thought is Schopenhauerian in kind, ${ }^{15}$ since after all, Schopenhauer's philosophy left manifold traces in the diaries. At the same time, Wittgenstein gives it a different emphasis. The Otherness of the discourse, the dimension of inexpressibility that is adopted in the ethical is founded in the extraordinary experience of existence as presence: Wittgenstein introduces in his Lecture on Ethics the fact "that [...] I wonder at the existence of the world" alongside feelings of being "absolutely safe" and "guilt" as "the first and foremost example" for what he understands by "absolute value" (LE, 8). "That" something "is" this "only frightful" in Heidegger's words (Heidegger 1984, 2) forms, in this sense, the basis of ethical feeling. It classically coincides with the beginning of meta-physics itself. That something is and not nothing - therein lies proof, for Leibniz, of that original trouble that Schopenhauer also described as the "balance wheel" and as "the watch of metaphysics that never runs down". (Schopenhauer, II, I7I). Together with the PlatonicAristotelian "wonder" (thaumazein) that forms the "basic attitude" (Heidegger) of thinking as such. ${ }^{16}$ For Schelling, that attitude stands at the beginning of all philosophy: appearance of that transcendence that points to the "unpremeditated" and "the inexpressible" that, as in Wittgenstein's work, is similarly claimed only to "show" itself. ${ }^{17}$

Aesthetically, the experiences of aura and the sublime correspond to that attitude. Both are related. Whilst the world is guaranteed in its entirety, the view also emerges as more alien. Becoming estranged by destroying every measure in intuition is, for Kant, one feature of the sublime that also confronts the present with the aspect of presence itself. ${ }^{18}$ In precisely this way, Benjamin exemplified the phenomenon of aura in the paradigm of the answering look: "deriving the concept of aura as a projection of a social experience amongst humans in nature: the

\footnotetext{
15 Schopenhauer I, I78ff. (\$34). Similar ideas are in Kierkegaard (1952, 49).

16 Heidegger speaks especially of a fundamental question of metaphysics, cf. I $965,42$.

17 Schelling 1977, I67; TLP 6.522.

18 Cf. Kant i957, $328 \mathrm{ff}$. (A $73 \mathrm{ff}$. .).
} 
look is requited." (Benjamin 1974a, 670). The passage illuminates the non-intentional character of the aura-like entity; what plays a role is not the seeing that sees something, but the reciprocal experience of a "look" as "moment" (Augen-blick). ${ }^{19}$ That something looks back emphasizes its ulterior nature and therefore opens the play of near and far that, for Benjamin, belongs to the constituent features of the concept of aura:

The trace is the appearance of nearness, as far away as might be what is left behind. The aura is the appearance of a distance, as near as might be what it calls to mind. We grasp the matter in the trace; in the aura it overcomes us. ${ }^{20}$

In that sense, the implication is the inaccessibility of existence as the uniqueness of a presence, which affords distance, as blindingly and selfeffacingly in proportion as it captivates the look. It enables us, too, to draw nearer to the "face" of reality, its irreducible otherness that first and foremost lies in the fact that it "is". Wittgenstein means nothing else when he speaks of a view sub specie aeternis: "Aesthetically, the miracle is that the world exists. That what exists does exist." (NB, 20.10.16)

When Wittgenstein therefore speaks of ethics, he rises to something that moves him, aura-like, as the "wonder of existence." The function of aesthetics in that process is as a point of entry and metaphor, just as the religious dimension increasingly functions later. ${ }^{21}$

19 The word "look" includes the reciprocal effect of looking and being looked upon. Benjamin refers in this context to Paul Valéry: "The things which I see also see me just as I see them." Cf. Benjamin, "Analecta”, I93, I94, quoted after Benjamin I974a, 647. A note from the context of the Lebre vom Äbnlichen also underlines: "Are there earthly beings as well as things looking down from the stars? Are they actually first beginning to look from the sky above? Are the celestial bodies with their faraway look the primeval phenomenon of aura?" (Benjamin, 1977, 958)

20 Benjamin, I982, 560 . In a letter to Adorno of 9.1 2.38, the opposition of trace and aura is expressly developed as the key to comprehending the concept of aura. Cf. Benjamin 1974b, I I02.

${ }^{21}$ Religious uncertainties almost exclusively dominate in the 1930-32 and 1936-37 diaries. Cf. also Watzka 2000, 82ff. However, from the start, the reflections on the Tractatus accompany religious - and not just aesthetic - metaphors. More- 
Both correspond to each other, describing related experiences. They find their most intense roots in the uncanny nature of the "that". Brecht already objected to Benjamin that a mystical aspect is implied in accordance with the aura (cf. Brecht I974, I4). The theological element is certainly the most consistent motif in Benjamin's thought, as a fragment of the Passagenwerk underlines: "My thought relates to theology as blotting paper to ink. It is completely absorbed by it." 22 However, Wittgenstein, who felt himself moved by a similar sentiment, tries not to articulate it in the first place: existence itself, as well as the "whole", cannot be put into words. At best, what can be shown is the "that" and, specifically, in the form of an indirect indication, as a reference to the riddle. To put it into a word anyway, to express it, as stated in the Lecture on Ethics, is to approach "misusing language". $(\mathrm{LE}, 8)$ Wittgenstein repeatedly emphasizes that religion, as previously ethics and aesthetics, reaches a "quite different level" that can neither be affirmed nor negated; rather, it proves to be "significant nonsense", that ultimately requires no words. ${ }^{23}$ The expression "significant nonsense" evokes, by its paradoxically unfathomable nature, the whole ambiguity between impossible speech and necessary transgression. What counts is not to reject it per se, but certainly to support it with asceticism. Wherever it still speaks, its function lies in the allusion.

Nevertheless, Wittgenstein rejects its status as a simile, as similes would still stand "for something", they would project a picture in place of the missing concept and, in that way, they would emphasize its omission: "And yet I am reluctant to use these images \& expressions. Above all these are not similes, of course. For what can be said by way of a

over, the reconstruction of the aesthetic from the dimension of aura already reveals its genuinely religious meaning.

22 Benjamin I982, 588; Mosès 1994, 92, also emphasizes that the mystical or theological motif is the "most constant" in Benjamin's work.

${ }^{23}$ In the Lectures and Conversations on Aesthetics, Psychology and Religious Belief, Wittgenstein also professes on religious faith: "I can't say. I can't contradict that person." (LC, 55) That statement is no evidence of his own faith, even if its depth and intensity is reliably documented in the diaries. Rather, it shows its indecision. 
simile, that can also be said without a simile." 24 It is therefore not a question of rhyming or poetry; and yet, this qualification does not automatically exclude any metaphorical meaning. Rather, the word "misuse" refers to a "catechrestic process". Mystical speech is always accomplished in catachreses; its function lies in the expression of otherness. By causing a break in language, or by opening a gap, they turn around at the limit of what can be put into words and in this way they open themselves to the inexpressible. In the list of rhetorical tropes, it is a case of figures of "deconstruction": they find their fulfilment in breaking the discourse. That explains their incomprehensibility, absurdity, or systematically nonsensical character. In one of Wittgenstein's lectures on religion from around 1938, it is noted: "Anyone who reads the Epistles will find it said: not only that it is not reasonable, but that it is folly. Not only is it not reasonable, but it doesn't pretend to be." 25 The religious catachresis crosses the zone of "falling silent", yet in such a way that what is actually said no longer matters. Rather, something has to occur at its limits, which is no longer saying, but which allows experience to bappen. ${ }^{26}$

In this respect, on several occasions, Wittgenstein returns in the Conversations with the Vienna Circle to the Kierkegaardian motif of a futile "running against the paradox" (cf. Kierkegaard 1952, 42f.):

${ }^{24}$ MT i 5.2.[37]; cf. also LE, 9.

25 LC, 58; likewise, it is stated in the Conversations with the Vienna Circle: "Is talking essential to religion? I can well imagine a religion in which there are no doctrinal propositions, in which there is no talking. Obviously the essence of religion cannot have anything to do with the fact that there is talking. [...] Thus it also does not matter at all if the words used are true or false or nonsense." (WVC, I I 7) The triplet of true, false or nonsensical even emerges from a logic of triple value, the failure to acknowledge the tertium non datur.

26 The 1930-32 and 1936-37 diaries contain the following reference: "A sentence can appear absurd \& the absurdity at its surface be engulfed by the depth which as it were lies behind it. This can be applied to the thought concerning the resurrection of the dead \& to other thoughts linked to it." (MT I.I 2.[36]) 
Astonishment about the fact of the world. Every attempt at expression leads to nonsense. Man has the tendency to thrust against the limits of language. This thrust points to ethics (cf. WVC, $68^{27}$ ). ${ }^{28}$

Nevertheless, this failure does not seal their inferiority, but on the contrary, the Lecture on Ethics concludes with a special tribute:

I see now that these nonsensical expressions were not nonsensical because I had not yet found the correct expressions, but that their nonsensicality was their very essence. For all I wanted to do with them was just to go beyond the world and that is to say beyond significant language. My whole tendency and I believe the tendency of all men who ever tried to write or talk Ethics or Religion was to run against the boundaries of language. This running against the walls of our cage is perfectly, absolutely hopeless. Ethics so far as it springs from the desire to say something about the ultimate meaning of life, the absolute good, the absolute valuable, can be no science. What it says does not add to our knowledge in any sense. But it is a document of a tendency in the human mind which I personally cannot help respecting deeply and I would not for my life ridicule it. (LE, I 2)

IV.

Wittgenstein's ethics is rooted in the experience of the "that" of existence as existence. It includes the emptiest thing qua language because no proposition leads to it and no proposition results from it; and yet, it contains qua experience the utmost sense of being shattered, the confrontation with the ultimate riddle. The discord is revealing: the ethical feeling emerges from this sense of being shattered; it means being moved by the puzzling nature of the "that", yet without saying anything sensible about it and that also means without the ability to instruct. For that reason, for Wittgenstein, ethics emerges from a turn to the mystery

27 Note: suggested translation.

${ }^{28}$ Cf. further WVC, 69: "In ethics, we are always making the attempt to say something that cannot be said, something that does not never will touch the essence of the matter. [...] But the inclination, the running up against something, indicates something." 
that is to be achieved in each individual case. That seems little, if anything at all. The conclusion of the Tractatus seems to imply a similar message:

We feel that even when all possible scientific questions have been answered, the problems of life remain completely untouched. Of course, there are no questions left, and this itself is the answer. (TLP 6.52)

And he adds:

(Is not this the reason why those who have found after a long period of doubt that the sense of life became clear to them have then been unable to say what constituted that sense?) (TLP 6.52 I)

In a curious way, nonetheless, the fragmentary remarks coincide in the concepts of the "mystical", the "world as a whole", as well as "life", "sense" and "will". Their relation that is yet to be deciphered relates to the ethical. Direct, ethical doctrines are to be distinguished from that dimension, or normative morals with their registers of directives for action, maxims and rules, or what Hegel called 'ethical life'. Rather, Wittgenstein's primary concern is the search for the basis and foundations of another form of reference. It is to be described by the unity of mystics, wholeness of the world and sense of life. Again, the way that their connection is created and takes effect as a unified link confirms their specific "relation" - their religio. It might be said: Wittgenstein's ethics is mystical, his mystics an ethical one.

(i) Wholeness of the world: once again, the starting and key point is represented by reference to the elementary experience of "that", through which the world as a whole is placed in question. The whole identifies no order, no structure of things; rather, it permits the questionable nature of existence to emerge. Hence, what appears relevant for the ethical is not the whole "as" a whole entity, as a kind of "care" about the world, not even what it "is" or "might be", neither its poverty nor vulnerability, as conversely, its hopes, a utopian perspective, but merely the fact "that" there is a world and that in it, as stated in the Tractatus, "everything is as it is, and everything happens as it does happen" (TLP 6.4 I). In this respect, the puzzle of its existence does not pose a question that could be answered with a proposition, a plan or a task, but 
rather it touches the "intangible" itself. By exposing the uncanny aspect of the "that", Wittgenstein thinks from intangibility. In particular, he explains its ethical significance by the example of Christianity. In the Conversations with the Vienna Circle, he answers Waismann's question whether the being of the world is connected with the ethical:

Men have felt a connection here and have expressed it in this way: God the Father created the world, while God the Son [...] is the ethical. That men have first divided the Godhead and then united it, points to there being a connection here. (WVC, i 8 )

The passage explains the connection in religious metaphors. The intangibility of existence is associated with the name of "God", where the metaphor "God the Father" stands for the creation itself, ${ }^{29}$ the "Son" for humility in view of the contingence of what cannot be done - the simple fact that it is not within man's powers to determine the "that" in the sense of being (ex-sistere). It names what is given in the sense of absolute gift. ${ }^{30}$ Wittgenstein dresses it up with a theological meaning; yet this meaning contains an ethical dimension, because the etbical first emerges from the relationship in the sense of a relation to the gift.

(ii) Sense of life: the meaning of "sense" is also elucidated from this standpoint. The expression that seems to include a totality raises the suspicion of an objectification. However, the guarantee of intangibility implies looking back to the individual life. Wherever the "that" is placed in question, the issue of "sense" also arises - not as an issue of expression or interpretation, but as the puzzle-like figure of that experience of contingency from which the groundlessness and instability of the whole becomes evident. To put the matter differently: it is

29 In this sense, a diary entry of I 5.3 .37 reads: "But formerly you saw God perhaps in the creation, that is, in the world." (MT I 5.3.[37]).

30 Here, "gift" is not to be understood as though "something" would be that would "give" it - that would be theology. In this regard, it is illuminating that, from the outset, Heidegger connected the "ontological difference" between Being and being (Seiendes) to the difference between "It is [...]" and "There is [...]", where "There is Being" and "There is being" (Seiendes) are used with a different meaning; cf. Heidegger I962, 2 I 2, 2 I 4, 226ff., 230, 3 I 6. 
the abyss of reality that again succeeds in opening a perspective on the sense of life as an "absolute value". For that reason, in the early diaries, "world" and "life" are identified with one another in the first place: "The meaning of life, i.e. the meaning of the world, we can call God." (NB, Ir.6.I6) Whilst the connection appears implausible, in so far as the guarantee of groundlessness of "that" should also evoke a parallel experience of "absolute value", thus, implying the "most nihilistic" as the "highest"; and nonetheless, the implication warns of the insight that we hold in our hand the "world as a whole" as little as we ourselves. Rather, together with the world, we are given up to the realm of intangibility. From that position alone is life to succeed in winning sensitivity for the "sense".

As a result, what "sense" means is shown by the turn to the intangible realm: "To believe in a God means to understand the question about the meaning of life. To believe in a God means to see that the facts of the world are not the end of the matter." (NB, 8.7.r6) In that case, "sense" would be a category that can be interpreted first and foremost from the perspective of the puzzle of the whole. That is to say it refuses an intentional construction. Sense is neither produced as discourse, nor guaranteed by acts of symbolizing or understanding; rather, we must commit ourselves in each case with our entire life. You could say: the intangibility of the "that" denotes that outrage that we can neither overcome nor answer, because we always answered it with our life. Life is finite from the location of its mystery: it draws its special value, its meaning from that location. In that case, sense would be an event that is awakened by the puzzle of "that" and passes through it, responding to it. Then ethics refers to the way of responsiveness as the form of a practice. It is rooted in the absolute difference that conditions the unavoidable character of answering. The sense of the ethical emerges from this unavoidability. To think and act from the intangible, that is, from that location that we cannot reach, from what we cannot even name or distinguish - ultimately that represents Wittgenstein's self-imposed burden, which he was never to overcome in a lifetime.

In this way, the connection of logic and ethics, as noted in the introduction, can be more deeply appreciated. All thought emerges as 
ethical, and wherever that is not so, there would be no thought worthy of respect. For that reason, philosophy means for Wittgenstein a selfimposed restriction. To him, it meant to work at himself. That holds true both for the initial silence accompanying the discontinuity of the Tractatus, $^{31}$ as well as for the later quietist phase, the feeling of the inviolability, the singularity of phenomena, whose inexpressible dignity could only be "felt". These elements embody a respect towards the world and towards being that resembles the attitude of "serenity": "[Philosophy] leaves everything as it is." (PI \I 24)

(iii) Life as will: to give life a sense means, as follows, to connect it with the experience of the intangible, or it means to answer a basic feeling of "powerlessness". The intangible is confronted with what is not made, what cannot be made; correspondingly, an entry in the diaries reads as follows: "I cannot bend the happenings of the world to my will: I am completely powerless." (NB, I I.6.16) And further: "The world is given me, i.e. my will enters into the world completely from outside as into something that is already there. [...] That is why we have the feeling of being dependent on an alien will." (NB, 8.7.16). That is matched by the proposition from the Tractatus: "The world is independent of my will.” (TLP 6.373) However, precisely in this idea lies an original responsibility (Ver-Antwortung). This does not refer to whatever can be taken on board in each case; it does not mean accepting the consequences of a particular action, rather the actual sense of responsibility lies in the necessity of the responsiveness. I cannot avoid answering the state (Ge-Gebenheit) of the whole; rather, with the "gift" of being a sphere of human power is appealed to that is absolutely withdrawn.

31 We approach a point that ought to be more closely investigated. The propositions of the Tractatus stand monolithically next to one another, like additions that are placed; they reject both a discursive structure as well as a nexus of causality. That means that the textual ordering of the Tractatus consists of discontinuous sections; it operates itself according to the difference of saying and showing: amongst them is a gaping silence that the conclusion expressly commands. 
Wittgenstein also describes this as "the higher" ${ }^{32}$ Ethics finds its relation from this behaviour to the withdrawal. It means the way of being as a whole and of behaving towards the whole. It therefore does not tolerate any instruction; it reaches fulfilment in doing. It is a practice: it shows itself.

On that basis, the ethical has its function in the performative. Here, performance means fulfilment in life. During the phase of the Tractatus, Wittgenstein characterizes this under the direct influence of Schopenhauer as "will". The Schopenhauerian will is, however, not subjectively weighted; it refers to the act as such, beyond all categories of the subject. It corresponds in that sense to the ekstasis of the "that" (quod) in Schelling's work, which is one reason why Schopenhauerand later also Nietzsche - interprets will in an ekstatic sense. He discovers it as an absolute entity that posits a hypothetical principle beyond the sphere of mere subjectivity that is also effective in nature: as "blind, irresistible urge" or "blind impulse, an obscure, dull urge, remote from all direct knowableness". ${ }^{33}$ By that token, it is a striving that wants nothing other than its own life. It is the "will to life" that wills nothing other than to will, that is, "will to will". Hence, it also does not know what it wants, but still only wills itself and by willing also brings forth itself. "The will alone is; it is the thing-in-itself, the source of all those phenomena. Its self-knowledge and its affirmation or denial that is then decided on, is the only event in-itself." (Schopenhauer I, I84). Every special expression of the will of the subject finds its relation from that context: as "law" of a groundless, aimless and senseless desire that permeates all being.

Wittgenstein adopts this conception, yet in such a way as "will" names the whole of the act of completion. He no longer characterizes a metaphysical principle, but the "attitude of the subject to the world." (NB, 4.II.I6) Will thus becomes a position that first brings life qua practice into relation with the questionable nature of being. In this

\footnotetext{
${ }^{32}$ Here lies the meaning of such cryptic references as: "Propositions can express nothing that is higher." (TLP 6.42)

${ }^{33}$ Schopenhauer, I, 275 (\$54) and I, I49 (\$27).
} 
respect, the ethical can neither be represented nor confirmed by a theory nor by thinking; it is solely in acting. ${ }^{34}$ For that reason, it is stated in the preface to the Tractatus, as previously mentioned, that this shows how "little is achieved when these problems are solved": the emphasis of the formulation lies, in this instance, not on an intended response to philosophical questions, but in doing as the other, unspoken side of the treatise. The practice that is thus in parenthesis is not absorbed in the sum of single references; they are not determined by the individual actions of a subject, but they emerge from the "whole of life" as an indefinite entity. ${ }^{35}$ In other words, it is constituted in relation to the intangible, to the absolute "gift" and to the location that this assumes in the individual's action (and thought). This gift can never be excluded, because even the act of non-relating would be a form of relationship. Hence, it is also stated: "Things acquire 'significance' only through their relation to my will.” (NB, I 5.I0.16). Only by that means do the world and things achieve "sense". That means: the manner in which the puzzle of existence appears or conceals itself, how it is accepted or rejected, worshipped or rejected, enjoyed or annihilated, is first and foremost an anchor for what is called the ethical. It is also influenced by the way in which the secret appears in our life and finds a place. Everything depends on how the intangible affects us, how we

34 The connection is an immediate one in the diaries: "The act of will is not the cause of the action but is the action itself. One cannot will without acting. [...] willing is acting." (NB, 4.I I.I6); and likewise further, MT 6.5.[3 I]: "But an ethical proposition is a personal act. Not a statement of fact."

${ }^{35}$ Here, he borrows a similar figure that was also leading for Heidegger: the whole of life emerges in this case from the 'anticipation of death' (Vorlauf zum Tod), cf. Heidegger 1962, $255 \mathrm{ff}$. ( $(\mathbb{S} 52,53)$. What is meant is no fatalistic turn towards death, but rather the opposite, thinking from the "approach" of the future of death as an intangible entity, which only life and its understanding refers to its necessary "finitude". That death is the future of every "mortal" implies that its undeniable approach originally provokes a standpoint on morality and therefore on the whole of life. The relation between "striving for the absolute" and departing "to battle through life toward death" is also to be found in Wittgenstein's later diaries, MT 20.2.[37]. 
invite it into our doing, whether we try to give it dignity, or to refuse it to ourselves. In this sense, the modesty, reserve or unwillingness, which Wittgenstein prefers from the beginning, can also be viewed as a gesture of answering.

Now it is also clear why Wittgenstein, as already suggested at the outset, calls the ethical as well as the logical "transcendental", that is, a "condition of the world" (NB, 24.7.16) The structure of facts, the grammar of language and the form of answering, as well as acting, correspond to each other. That is the essential insight of his late philosophy: as we see the world, so too, we live, we view things and speak of them:

I mean: mustn't it then have implications for your life, commit you to something? [...] After all, another life shifts completely different images into the foreground, necessitates completely different images. [...] That does not mean that through the other life one will necessarily change one's opinions. But if one lives differently, one speaks differently. With a new life, one learns new language games. (MT i 5.3.[37], 4.2.[37])

Thus, a correspondence of language, life and being is professed. The ethical contains nothing else: the practice of answering the withdrawal of the world is reflected in the "interweaving" of life forms with language-games and produces that unified "band" (religio) that, in a real sense, amounts to its religious nature and ethics of silence. This continues until the late philosophy and is a further proof of the continuity of Wittgenstein's style of thinking.

V.

Wittgenstein's notes on ethics are of a very personal and private nature. They carefully avoid every hint of preaching or pathos. It is notable that no general value judgment is made anywhere, no instruction emerges, not even any general recommendations are expressed. At the most, subjective standpoints are defended, partly construed in secret code or supported by reprimands and the rigour of self-imposed accusations in the style of a confession. Wittgenstein possesses no 
ethics in an actual sense, no practical philosophy, no moral message. He neither formulates obligations nor does he assert duties, virtues or universal commands. Also, Wittgenstein does not demand anything of others, yet he demands all the more of himself. In that respect, his rhapsodic reflections develop their relevance only in self-reference to his own life. With respect to his Lecture on Ethics held at the same time, he expressly notes in the Conversations with the Vienna Circle:

At the end of my lecture on ethics I spoke in the first person: I think that this is something very essential. Here there is nothing to be stated any more; all I can do is to step forth as an individual and speak in the first person. $(\text { WVC, I I } 7)^{36}$

To what extent is that so? In the first instance it is the case because the ethical in Wittgenstein's work has nothing to do with general concepts or justifications, but solely with subjective life forms; and further, because these aspects derive from how, in each case, they unmistakably relate to the puzzle of existence, to the experience of the "that". The restriction to the first person perspective therefore indicates that we are alone with our answer in the ethical sphere - and that this answer must always turn out to be different, unique.

That does not mean: the structure of answering is a matter of individual choice. If Wittgenstein occasionally allows himself an inspiration from Schopenhauer or Kierkegaard, it is neither a philosophy of life nor existentialism. Rather, the special tone of his writing is an indication of the concrete, historical crisis, the historical collapse and the dissolution of traditional ethics as well as traditional value systems in the inter-war period. Neither Christian faith nor the rational ethics of responsibility from the Enlightenment hold true-Wittgenstein is also at point zero of the ethical. In the groundlessness of devalued time, he strives to win back a root, a new sense of stability. He does this with his own radical approach. At the same time, he feels intensively the

${ }^{36}$ It is further stated: "[...] And here it is essential [...] that I am speaking for myself." (WVC, I I 8 ) 
"ash of culture" ${ }^{37}$, the decline of the epoch and the loss of selfanchorage like a rod through the centre of his personality. He suffers that process as an inner torment of the soul and a torturous feeling of guilt. At times, they carry the indelible face of despair: "Our age is really an age of the transvaluation of all values. (The procession of humankind turns a corner \& what used to be the way up is now the way down etc.)", he noted in October 1930 in his diary (MT 22.[10.30]). And in 1945, shortly before the end of the war, he spoke of a new "darkness" (PI Preface): a catastrophe without healing.

The only thing that then remains is to throw the weight of the individual person in the balance of time, to withstand its lack of healing power. In that case, Wittgenstein found solace during the 1914-1916 war years, above all, in works of Tolstoy and Dostoyevsky, but also in Augustine and mystics like Angelus Silesius and Ralph Waldo Emerson. They ultimately helped him to what he felt was his own, very personal answer to the riddle of life, which he in no way intended to recommend as exemplary: the attempt to bring himself and his own life "into the clear", that is, into an equilibrium. For that reason, it could be said that Wittgenstein's own project lies in the persistent striving for an identity as equilibrium. In the diaries, however, this balance is described as an agreement with aspects that suggest a conception of the whole (NB, 8.7.16). Such agreement appreciates the "dependence"; it avoids intervention, it lets "be". The ethical position that Wittgenstein therefore achieved for himself then consisted of an attitude of balancing, of measure. However, just as there is lastly no criterion for the right balance, which is rather consistently under threat of falling to one side or the other, there is also no measure for the measure: this is shown.

At the same time, a new paradox emerges in that respect, which Wittgenstein again preferred not to see in his entire approach and tendency: it excludes reading into his ethics more than merely a very private striving for integrity. Turning away from the world, refusal,

${ }^{37}$ MT 8.I0.[30]. On the context of the history of ideas cf. also Janik and Toulmin 1987; as well as my introduction, Mersch I991, 24ff. 
which first permits the attitude of non-intervention, is lastly rooted in the negation of the other. Therefore, in his solution lies a reversal and betrayal of what is precisely a constituent part of the ethical problem. Ethics beyond the question of alteriority remains blind; it forfeits, to think radically, its status as ethics. Ultimately, Wittgenstein was in default of an answer to this problem: his ethics of showing was solely restricted to the individual; it resigned to personal deed; for that reason, an answer to the individual "puzzles of life" also conditioned not answering the puzzle of others.

Translated by Suzanne Kirkbright

Bibliography

Benjamin, Walter (1974a): Charles Baudelaire. Ein Lyriker im Zeitalter des Hochkapitalismus, in: Gesammelte Schriften, Vol. I.2, Frankfurt/Main I 974, 509-690.

- (1974b): Briefwechsel mit Adorno, in: Gesammelte Schriften, Vol. I.3, Frankfurt/Main I 974 .

- (1977): Anmerkungen, in: Gesammelte Schriften, Vol. II.3, Frankfurt/Main 1977.

- (I982): Das Passagenwerk, in: Gesammelte Schriften, Vol. I, Frankfurt/Main 1982.

BRECHT, Bertolt (1974): Arbeitsjournal, Erster Band 1938-42, Frankfurt/Main I974.

Heidegger, Martin (1969): Was ist Metaphysik, Frankfurt/Main I 969 (9th edition).

- (1962): Being and Time, translated by John Macquarrie and Edward Robinson, New York 1962.

- (1975): Unterwegs zur Sprache, Pfullingen 1975 ( 5 th edition).

- (1978): Identität und Differenz, Pfullingen 1978 (6th edition).

- (1984): Grundfragen der Philosophie, in: Gesamtausgabe, Bd. 45, Frankfurt/Main I984. 
JANiK, Allan / Toulmin, Stephen (1987): Wittgensteins Wien, München I 987 .

KANT, Immanuel (1957): Kritik der Urteilskraft, in: Werke in I 2 Bd., Wiesbaden 1957 .

Kierkegaard, Søren (1952): Philosophische Brocken, Düsseldorf I952.

McGuinness, Brian (1988): Wittgensteins frühe Jahre, Frankfurt/Main I 988.

- (1989a): “Der Grundgedanke des Tractatus”, in: Joachim Schulte (ed.): Texte zum Tractatus, Frankfurt/Main I989, 32-48.

- (I989b): “Die Mystik des Tractatus”, in: Joachim Schulte (ed.): Texte zum Tractatus, Frankfurt/Main 1989, I65-191.

Mersch, Dieter (ed.) (I99I): Gespräche über Wittgenstein, Wien r 99I.

- (ed.) (1999): "Das Sagbare und das Zeigbare. Wittgensteins frühe Theorie einer Duplizität im Symbolischen”, in: Prima Philosophia, Bd. I 2, Heft 4, 8 5-94.

MosÈs, Stéphane (1994): Der Engel der Geschichte, Frankfurt/Main I994.

Schelling, Friedrich W.J. (i 977): Philosophie der Offenbarung, Frankfurt/Main 1977.

Schopenhauer, Arthur (1969): The World as Will and Representation, 2 Volumes, translated by E.F.J. Payne, New York I969.

SPINOZA, Baruch (1996): Ethics, edited and translated by Edwin Curley, London 1996.

WatzKa, Heinrich (2000): Sagen und Zeigen, Stuttgart 2000. 


\section{'If there is any value that does have value, it must lie outside the whole sphere of what happens and is the case.' (Tractatus 6.4 I) \\ Liam Hughes}

The above quotation is part of section 6.4I of Wittgenstein's Tractatus, which marks the beginning of a discussion of ethics and the mystical. In what follows, I shall try to understand and assess the idea that all that is of value lies outside the world, in terms of the Tractarian philosophy. I shall also use the Notebooks 1914-1916, where many of the key points are to be found in a more extended form. Given that the remarks on ethics in the Tractatus are of a piece with the rest of the philosophy expressed there, it is interesting to speculate on how much of it would be abandoned in the light of his later changed views on the nature of language. I devote the concluding paragraphs to such speculation.

Wittgenstein's ethical ideas are difficult to articulate for several reasons; they are difficult in their own right and the gnomic character of the expression adopted in the Tractatus does not help one. They are unlike what typically passes for discussion in ethics, and finally, not least, because Wittgenstein himself says they are inexpressible. Certainly, Wittgenstein never held a moral theory - indeed his efforts in this area were designed to put a stop to such theorising. When discussing Schlick's book on ethics Fragen der Ethik Wittgenstein asks:

Is value a particular state of mind? Or a form attaching to some data or other of consciousness? I would reply that whatever I was told I would reject and that not because the explanation was false but because it was an explanation.

If I were told anything was a theory, I would say, No, no! That does not interest me. Even if this theory were true, it would not interest me-it would not be the exact thing I was looking for. (WVC, I I6) 
The view expressed here is like a leitmotiv for Wittgenstein's early views of ethics. Although the Tractatus is essentially concerned with the ethical, a point Wittgenstein insists on in the Preface of the bookthe sense of "the ethical" here is not straightforward. In a book on ethics one might expect to find discussion of how one should live one's life (albeit couched in abstract terms), the goal of existence; what counts as valuable; how one can justify one course of behaviour over another; whether moral principles are generalisable and so on. Moreover, at a certain point the ethical views propounded will have to take account of the wider society and their impact on social and political arrangements. One finds little of this in the Tractatus (Griffiths 1976, 97). Wittgenstein's concern there was quite different. He wanted to make clear the boundaries of what could intelligibly be said. To this end, approximately five-sixths of the book deals with questions of logic - how language relates to the world, how it is possible to say anything at all. It turns out that all that concerns value falls outside what can be said. However, there is an indication that though what is of value cannot be expressed, it is shown by for instance, the manner in which one lives one's life - one's attitude to suffering, adversity and especially one's death. Value can also be revealed through the Artsmusic, drama and literature.

\section{I.}

What sense can we make of the claim that value lies outside the world? To understand this we need to grasp Wittgenstein's rather special use of the word "world". The Tractatus opens with:

The world is all that is the case.

The world is the totality of facts, not things. (TLP I, I.I)

A proposition depicts a fact; it is a picture or model of reality. If we understand it we know that such and such is the case, if it is true - and not the case, if it is false. Just as notes on the stave of a musical score show how the piece of music is to be played - is a representation of the 
music; similarly, the proposition shows its sense. If one can read music, theoretically, one can play an entirely new piece - it is a matter of understanding a system of musical notation. Likewise, if one understands a language, one can comprehend an entirely new proposition.

A proposition shows its sense.

A proposition shows how things stand if it is true. And says that they do so stand. (TLP 4.022)

Now, if we consider some moral injunction such as, "You should consider the feelings of others" or a more generalised statement like "Infidelity is wrong" we can see that these do not describe any state of affairs. They do not picture any fact and in short say nothing about the world. The same applies to judgements of aesthetic value - if we say, "This symphony is greater than that one" we may be able to support what we say by reference to form or structure; however, we will not be able to say in what the value of the music consists. Wittgenstein asks:

What is valuable in a Beethoven sonata? The sequence of notes? No, it is only one sequence among many, after all. (WVC, i i6).

Indeed as with ethics Wittgenstein will countenance no explanation of the value of a piece of music - it does not reside in the composition or the circumstances surrounding its creation - the thoughts, feeling and emotions of the composer. One can follow Wittgenstein's reasoning here, once one accepts his terms. The judgements above do not say anything about the world - they do not say how things are. They in fact introduce another level - a notion of comparison and difference, grading and appraisal - an idea of hierarchy. But "All propositions are of equal value." (TLP 6.4) and later on "Propositions can express nothing that is higher" (TLP 6.42). "It is clear that ethics cannot be put into words. Ethics is transcendental. (Ethics and aesthetics are one and the same)" (TLP 6.42 I).

What status therefore do these ethical and aesthetic judgements have? On Wittgenstein's account we are, strictly speaking saying nothing when we say such things. They are nonsensical. They attempt to say what can only be shown. It is important to understand that these statements are not nonsensical in the sense of being gibberish - like ill- 
formed sentences or nonsense verse. The fact that they are nonsensical does not mean that they do not have a point. If we consider the propositions of logic, which are really tautologies and therefore have no content they say nothing but none the less, show something about the world. They represent the scaffolding of the world. It is important to bear this in mind, lest we conclude that all that is important can be spoken about and thus ethics, religion, metaphysics and whatever else that cannot be caught within the scientific net may be consigned to the philosophical scrap-heap. Paul Engelmann remarks:

Positivism holds - and this is its essence - that what we can speak about is all that matters in life. Whereas Wittgenstein passionately believes that all that really matters in human life is precisely what, in his view we must be silent about. (Engelmann 1967, 97)

This is clearly a cautionary reminder of the extent to which Wittgenstein's work was misunderstood by his contemporaries. For instance, those who used the Tractatus to attack metaphysics, but in so doing entirely missed the ethical point of the book (cf. Janik and Toulmin 1973, I69). It is essential that one treats the Tractatus as a complete philosophy which deals with logic; revealing its character and drawing a boundary around what can be said, thus making manifest the ethical which must remain unsaid. The hope is that if one thinks through this, one is able to view the world aright and hence the ethical function of the book will be achieved.

"Logic is transcendental" (TLP 6.I3). It is important to bear in mind that logic is not part of the world. It is rather, a transcendental requirement of our being able to speak about it. To bring out part of this point consider the examples: "This rose is red" and "Venus is the morning star" the logic of the word "is", is different in each case - that of "predication" and "identity", respectively (cf. Mounce, 198 I, 28). One can know this only from knowing what it makes sense to say and this is determined by the logic of the language. Logic determines all possibilities but for this reason says nothing about the world. It shows itself as a kind of scaffolding necessary for the projection of meaning. 
The method of projection is not expressed in what is said, but without it nothing could be said. So far we have noted the delimiting function of logic - it prescribes the sayable. Thus it is not part of the world. The ethical too stands outside the world, which consists of facts. So like logic, ethics is transcendental. Given that we can make sense of the role of logic - to what extent can we elucidate the ethical? It is a characterisation of the ethical to say that what is of value is inexpressible, though a minimal one. Fortunately, Wittgenstein does provide further comment in scattered remarks, which elaborates on that skeletal account.

\section{II.}

One of the consequences of all propositions being equal (being on the same level) is that agency as we ordinarily understand it disappears. The human being becomes simply part of the phenomena of the world. Qua phenomena, human occurrences are of no more significance than anything else that happens in this world; than the lives of beasts and insects, the falling of the leaves. Wittgenstein writes somewhat startlingly:

There is no such thing as the subject that thinks or entertains ideas. (TLP $5.63 \mathrm{I})$

If I wrote a book called The World as I found it, I should have to include a report on my body and should have to say which parts were subordinate to my will, and which were not etc., this being a method of isolating the subject, or rather showing that in an important sense there is no subject; for it alone could not be mentioned in that book.

Peter Winch in his essay on "Wittgenstein's Treatment of the Will" (1972, II2) quite rightly notes tensions and inconsistencies in the passage above. If I distinguish those occurrences which are under the control of my will from those which are not, in order to isolate the subject (i.e. the distinction between being able to walk at will, and for instance, perspiring, which is not under our control), then it seems odd to say that this shows that in an important sense there is no subject. If 
one accepts that there is no subject then one seems forced to draw the conclusion that the distinction in the first place was bogus and those things I do, and what happens to me, are on the same level. Perhaps, Wittgenstein is struck by the fact that there is a similarity between what we do and what merely happens to us. It might be said that our capacities are just natural historical facts about us, about which we have neither choice nor control. In any case, it is not the thinking "I" or the "I" of psychology that is the subject of ethical attributes but the metaphysical "I". This raises the question what the metaphysical "I" is, which I hope will emerge as we develop Wittgenstein's account. The metaphysical "I" is synonymous with some notion (as yet unclear) of the will. Thus, Wittgenstein writes: "[I know] [...] that my will penetrates the world. That my will is good or evil.” (NB, I r.6.16) For Wittgenstein, "There are two godheads: the world and my independent I" (NB, 8.7.16). The task of life is bringing these two into harmony; but how is this to be done? One can find something of an existential slant in Wittgenstein's way of thinking about the problem. We are thrown into the world $-\mathrm{a}$ world that exists before our coming, a world which is alien and in which we are powerless. "That is why we have the feeling of being dependent on an alien will." (NB, 8.7.16). At this point in his reflections Wittgenstein seems to equate the world with God or at least the sense of the world. "How things stand, is God. God is how things stand." "What we are dependent on we call God." (NB, I.8.r6) Later he makes the point explicitly: "In this sense God would simply be fate, or what is the same thing; The world which is independent of our will." (NB, 8.7.I6). This equation between God and the world helps make some of Wittgenstein's remarks clearer (cf. Zemach, I966). The good life is quite simply the happy life. Being happy or unhappy depends on my attitude to the world. The world itself is neither good nor evil - such valuations arise with the entry into the world of the metaphysical "I". I must therefore simply accept everything that happens in the world - including the misery of the world because I cannot change it. The good will then is related to acceptance. Our freedom exists in recognising and embracing necessity. We can however make ourselves independent of fate. In a revealing sentence, Wittgen- 
stein writes: "I can only make myself independent of the world - and so in a sense master it - by renouncing any influence on happenings." (NB, i r.6.16)

One could see such renunciation as submitting to the will of God. In practical terms, having a good will is not a simple matter. We must live a life of knowledge, which is the only bulwark against the misery of the world. We need to be indifferent to "the amenities of the world" and if we are blessed by having them, we should treat them as "so many graces of fate" (NB, I 3.8.16). We become involved in unhappiness once we wish things were otherwise. This arises when one thinks one can alter or affect the world - that one's desires or wishes are somehow privileged. Anything that we do, including what we think, is just part of the world and happens not as a result of our will but according to the laws of nature. Given that the only necessity is logical necessity and there is no logical necessity between will and world there can be no guarantee that what we will is successful. Even "the supposed physical connection" (which Wittgenstein regards as a fiction) is not something in our power to will (cf. NB, 5.7.16).

To understand our position in the world we must view it sub specie aeternitatis - as a limited whole. That is to say, no part of the world is privileged or preferred to another. No state of affairs is more desirable than another. It is not the way the world is that is important but that it is. When one views the world in this way, no longer in the midst of things; the psychological agent becomes no more important than any other part of the world. One's life is seen as if from beyond. Looking at the world in this way changes nothing in the world - it does not alter the facts. However, in another sense, one's whole world changes - it is the sense of the world that changes: "The world of the happy man is different from that of the unhappy man." (TLP 6.43)

Wherein does the difference lie? It cannot be just in respect of their happiness or unhappiness. Neither can it reside in the fact that one has a happy optimistic disposition while the other tends to have a depressive one. These would be merely features of the world with which we must come to terms. Rather, their lives are different in that the happy person is in agreement with the world. This means being free from fear 
and hope - the two great enemies of happiness. Both of these propel the subject into the future with all its uncertainties. Thus by being afraid of what will or may happen at some future date, we destroy our present happiness through anxiety; while hoping for something in particular to happen may wreak havoc on our equilibrium if the hope is unfulfilled. "To be happy one must live in the present. For life in the present there is no death" (NB, 8.7.I6). Under such circumstances one is "in agreement with that alien will, on which I am dependent. That is to say I am doing the will of God" (NB, 8.7.I6). Thus, "[f]ear in the face of death is the best sign of a false i.e. a bad life" (NB, 8.7.I6). On this view, being happy - though it certainly seems to involve contentment - is also to do with understanding life and having a certain view of our position in the world.

Here clearly it is the metaphysical "I" which looks at the world in this way, since the "I" of psychology is itself just part of the world. The metaphysical "I" is not part of the world or in the world, but a boundary of it (NB, 2.8.I6). This "I" is transcendental, it is not an object. "I objectively confront every object. But not the I." And later on in the same entry: "The I makes its appearance in philosophy through the world's being my world." (NB, I 2.8.I6). It is my world in that for there to be a world there must be consciousness. It is to this centre of consciousness, which we call the "I" that the world is given. Hence, it is $m y$ world.

One of several difficult points in understanding Wittgenstein's ethics - is how something outside the world can be the subject of ethical attributes and related to this how in the absence of agency the issue of ethical attributes can arise at all. One might say that if one does not act, a fortiori, one does not act well or badly. Moreover, we judge people by what they do and not merely by their attitude to life, though what they do will obviously be informed by it. I do not think that Wittgenstein can answer this difficulty within the framework of his Tractarian philosophy. I shall however, explore one line of explanation, which ultimately fails though I hope in an instructive manner.

One needs to distinguish the person or subject qua phenomenon in the world, the subject of psychology and the metaphysical subject. The 
former disappears like the Humean self becoming, not as in Hume's work, impressions, but part of the world of facts. However, the subject is not captured exhaustively in descriptions of its factual nature. The spiritual or metaphysical part lies in the life of knowledge, reflection and judgement. One has the feeling that Wittgenstein separates the factual nature of actions from their meaning or significance. Or perhaps, we can say that actions under a merely factual description have no significance. Objectively speaking they have no meaning.

Accordingly, in his Lecture on Ethics written some years after the Tractatus but still very much in its spirit, he argues that any judgement of value that can be re-described in terms of factual propositions, is merely a relative judgement and belongs to the world. While those that could not be so described were true ethical propositions and expressed absolute value. Wittgenstein makes the point firstly, that the word "good" can be used in a relative and an absolute sense. If we say, "this is a good knife" we are saying that it serves its purpose well. Similarly, if we say, "X is a good runner" we can explain the sense of "good" by the use of other terms, such as " $\mathrm{X}$ can run a mile in such and such a time" (cf. LE, 6).

So to come to Wittgenstein's own example, he imagines someone saying of an other that he does not play tennis well, to which the other replies that he does not want to play any better. This would be the end of the matter and the critic might say; "Well, that's all right then." This judgement depends on what the individual wants. Consider the example where someone has told a preposterous lie and the critic says: "You're behaving like a beast" and he says "I know but I don't want to behave any better", could he then say "Ah, then that's all right."? Certainly not; he would say "Well, you ought to want to behave better" (LE, 5). When we speak of what the critic "could" say here, we are drawing attention to a grammatical feature of such judgements - that is to say, we are drawing attention to what it makes sense to say in such cases (cf. Rhees 1970, 97). This is an absolute judgement and it cannot be couched in other terms. It is not relative to the individual's wants. The grammar of the absolute or ethical judgements makes it impossible for them to be re-phrased in factual terms or explained in such terms. 
Given, that ethical judgements are judgements of absolute value for Wittgenstein, one may ask; to whom or what are they attributable? The short answer is the metaphysical subject, but this requires explanation.

Just as there two senses of subject-the psychological and the metaphysical, so there are two corresponding senses of "will" - though Wittgenstein is rather unclear about this. The 'will' which, belongs to the world, is presumably the will that we share with animals and the rest of nature. Part of the phenomenal world à la Schopenhauer. It encompasses all our psychological strivings, appetites, desires and actions considered as phenomenal events. Then, there is the ethical will, which seems to relate to the ordinary will in a similar way as the metaphysical subject relates to the psychological. Put simply, these pairs of distinctions are just different characterisations of the same thing. The metaphysical will or subject is that which endows meaning to actions and the world.

Wittgenstein makes an important distinction between "wishing" and "willing”. Unlike "wishing" which may precede or accompany an action, "willing" is the action itself. He reaches this break-through (which pre-figures his discussion of the will in the Philosophical Investigations) towards the final entries in the Notebooks. But an action takes place in the world, so how does the ethical enter? Perhaps we can say that an action qua event in the world has no ethical character; however, the sense of the action namely, what it is I intend to do, does. Let us consider the example of cutting someone's leg off - if the intention in this case is to save the person's life, the moral character of the action will be different than if done from other motives, i.e. malice. Whichever motive or intention the agent has will not alter the "factuality" of what takes place. Thus the ethical will is the character of the action given by the intention of the agent.

However, when we analyse such examples we realise that they will not do the job we require of them. What I want, or intend just collapses into the ordinary psychological notion of the will. Whenever one tries to draw the distinction, one ends up, either falling back into the ordinary and rejected notion of the will or evacuating the concepttion of the metaphysical will of sense. 
In the Notebooks, we see Wittgenstein struggling with these difficulties regarding just what role he can assign to the will. He is drawn to the idea that the phenomenal will - the will as commonly understood has some foothold on the world and has some connection with ethics. In the Tractatus, he presents a more clear-cut and decisive view. The notion of ethics there, is more or less forced on him by his concept of the will and world being radically divided - the former located outside the world and therefore can do no real work and the latter, which consists entirely of "facts". The Lecture on Ethics shows an interesting departure from the austere pronouncements of the Tractatus and importantly, the beginning of the use of examples. These examples though not all serving the same function, throw light on the problems we have been examining.

Like in the Tractatus, Wittgenstein wants to show that what is most important in life - that which is of value - cannot be expressed. One example he uses of absolute value is the concept of "feeling absolutely safe". But as he himself points out, one can only be safe from this or that under such and such circumstances. The idea of absolute safety no matter what happens, is not an intelligible one - so far as our language allows. There is a tendency in our nature to say such things, which Wittgenstein recognises and regards as worthy of respect. This tendency can be described as pushing against the boundaries of language. Analogies could be drawn with Socrates when he says " $[. .$.$] no evil can$ happen to a good man either living or dead [...]" (Plato I970, 5I6). That a good man cannot be harmed uses a notion of "harm" that is not any ordinary one. Nothing that we normally regard as harm touches him. It expresses a particular attitude to adversity such that whatever happens his integrity will not be destroyed. Or again, the biblical reminder; "What does it profit a man to gain the whole world and lose his soul?" These remarks all point to an ethic that is not of this world (cf. Winch, 1972).

When Wittgenstein speaks of wondering at the existence of the world he makes explicit a paradox with which we have been struggling. He asks how it is possible that something that is dateable, an experience, could have absolute value. In one way, he is tempted to reject 
the idea as pure nonsense. However, he knows that he has had such experiences and that they are entirely real. He even tries to address the paradox by suggesting that another way of expressing his feeling is seeing the world as a miracle. This point is elaborated by his observing that if what we call a miracle were to occur, namely, something that has never been encountered before (a person spontaneously growing the head of a lion); once we began to reduce it to various facts and regarded it scientifically, then the miracle would vanish. Basically, he wants to emphasise that the world of ethics is incompatible with the world of facts and the scientific viewpoint. The idea that the ethical is not borne by the psychological subject is reiterated in a spirit reminiscent of an example that we have already discussed, when he remarks:

If for instance in our world-book we read the description of a murder with all its details physical and psychological the mere description of these facts will contain nothing which we could call an ethical proposition. The murder will be on exactly the same level as any other event, for instance the falling of a stone. (LE, 6)

This seems quite a difficult position to sustain. For one thing, describing the act as murder introduces an ethical dimension. It points to an unlawful killing, which is not ethically neutral. Secondly, since it includes psychological detail e.g. about intention and motivation we are in a position to assess guilt to some extent. We know that some behaviour is under our control while other is not. Thus murdering someone is not at all, on the same level as the falling of a stone. If a murderer were to use such an analogy as his defence in court, he would be laughed to scorn. What exactly is Wittgenstein saying here? He is saying that there can be no ethical propositions, simpliciter. What people do from the point of view of their physical and psychological states is on precisely the same footing as, a stone falling, a change in the weather, fruit ripening or whatever. To examine the first point, let us agree with Wittgenstein that there will be no ethical propositions in such a description, still nothing precludes the appearance of recognisably ethical thought and reflection in such a book. The murderer's motivation may be revealed to us - he decides to commit murder to avenge a perceived wrong done to his family. He may see the killing as 
an unpleasant duty he is called upon to perform. However, after the deed he sees things very differently and suffers intense remorse. He comes to realise that he should never have done such a thing and seeks punishment for his crime. (It should be noted that each of the italicised words involves ethical notions) Clearly, one does not have to look far to find books, which raise and treat such ethical issues, such as Shakespeare's Hamlet or Dostoyevsky's Crime and Punishment. (Wittgenstein's book "The World as I found it" is something quite different). Whether or not one can find examples of ethical propositions in these works is beside the point, though I believe one can. The point is that if people did not live lives in which ethical matters were fundamental such books would not be the great works they are. And unless people lived such lives the concerns expressed there would be unintelligible.

The second point is related to the above discussion and can be disposed of quickly. The idea that in this book (Wittgenstein's) descriptions of psychological and physical states, which include human actions such as murder, could be on the same level as natural events is untenable. If someone were to write such a book as a kind of modernist experiment it would be unlike any book ever written. To put the point more strongly it would be scarcely intelligible because it would not describe anything that was recognisably human. Wittgenstein is committed to the view that the book in question could contain feelings of pain and rage. However, if these higher-order concepts are used as opposed to, for instance, purely scientific descriptions in physical or neurophysiological terms - these then bring with them a range of human reactions. For instance, reactions to the pain of the victim; questions about the appropriateness of the rage and to whom the rage was directed and so on. In other words, we are dealing with quite a different set of considerations from those, which would arise in connection with a natural occurrence. As noted above considering the actions of others as natural events is something that we cannot do, apart from in the most exceptional circumstances (cf. Strawson, 1974).

Leaving these difficulties aside it is nonetheless true that the Lecture on Ethics shows important developments from the period of the 
Notebooks and the Tractatus. There is the use of examples, which was to become an essential feature of his later works. We see Wittgenstein attempting to give expression to his ethical and religious experiences whereas to do so during the Tractatus period would have been seen as a kind of profanation of what we must pass over in silence (cf. Nieli, 1987). As in the Tractatus he is looking for some essential feature, a commonality in these experiences which links them together. Two of his examples, namely, "the feeling of absolute safety" and "wondering at the existence of the world" he shows to be nonsense when analysed in terms of our normal concepts. They seem to function like similes, which however cannot be rephrased in literal terms. One of the examples, as we have seen, brings out a quite legitimate logical or grammatical difference between judgements of relative and absolute value.

III.

One feels the ethics of the Tractatus is the result of profound inner questing - an ethic of one individual trying to come to terms with the misery of life. It is an essentially inward-looking ethics, emanating as it does from an austere and rigorous view of language, with the world being the realm of facts. Given the further fact of the agent not being part of the world, it follows that ethical value can have no place there.

If Wittgenstein were to write on ethics in the spirit of the Philosophical Investigations, one would expect quite a different picture. The conception of the will and thus agency is different. A person knows what he intends to do without recourse to any evidence. I can tell someone that I am going to raise my arm in one minute and do it. Others know about my behaviour inductively. This has important implications for agency and responsibility. In the Tractatus there was only a problematic connection between what you wanted or willed and what happened. Given that there was no logical connection it seemed that the only connection there could be, was an inductive one. This meant that the resulting action was entirely contingent and one was, so to speak, at the mercy of fate. But the relation between "willing" and 
"doing" is an internal one. The world is not independent of my will. I act in and on the world. What I do and fail to do makes a difference and it is not merely the attitude, which I have to it that matters.

Just as the later Wittgenstein brought out how language was an essentially social phenomenon and not the property of any individual; so too ethical concern can only arise because of the existence of others. Language games emerge and develop with the social practices people engage in. In order to understand the various language games, including talk of right and wrong, we must understand the practices and forms of life in which these are embedded. Ethical and aesthetic judgements take place in particular historical circumstances. What may be a moral issue in one society may not be one in another. Or what may be a moral dilemma for one individual in a given society may not arise for someone else of the same society. To understand these ethical issues or in some cases to even understand them as ethical issues may require considerable background and filling out of the context. For these and other reasons, Wittgenstein would insist on the use of examples to elucidate such problems.

However he would not have changed his view on the radical distinction between "fact" and "value" and that one could not derive an ethical conclusion from any factual argument. Again, on his view, the idea that a system of ethics, for instance, the Christian one, could be right or wrong, does not make sense, unless it means simply that one agrees with it or accepts it (cf. Rhees I970, IOI). Consequently, there could not be a science of ethics. Wittgenstein rejects what goes with this, the generalisability of ethical judgements, and when he spoke about ethics, he spoke in the first person and he considered this to be essential (cf. WVC, i 17 ).

Finally, placing value outside the world or "passing over it in silence" are not options that are available to us. It is only because people think and talk about ethical matters - make judgements regarding the rightness or otherwise of actions, that we have any conception of excellence and perfection. If morality did not affect our daily lives, have an impact on our world; it could not be an issue in some later life or other realm. Wittgenstein's later writings help us see that if there is any value that 
does have value it must lie within what happens and the judgements we make on these.

\section{Bibliography}

Engelmann, Paul (1967): Letters from Ludwig Wittgenstein with a Memoir, Oxford 1967.

Griffiths, A. Phillips (I974): Wittgenstein, Schopenhauer and Ethics, in: A. Phillips Griffiths (ed.), Understanding Wittgenstein, Royal Institute of Philosophy Lectures, Vol. 7, I972/73, London I974, 96I 6 .

Janik, Allen / Toulmin, Stephen (1973): Wittgenstein's Vienna, London 1973.

Mounce, H. O. (1981): Wittgenstein's Tractatus. An Introduction, Oxford I98I.

Nieli, Russell (1987): Wittgenstein from Mysticism to Ordinary Language, Albany, NY i 987.

Plato (1970): Great Dialogues of Plato, translated by W.H.D. Rouse, ed. by Eric H. Warmington and Philip G. Rouse, New York i 970.

Rhees, Rush (1970): Some Developements in Wittgenstein's View of Ethics, in: Rush RheEs (ed.), Discussions of Wittgenstein, London I 970, 94-I03.

STRAwSON, Peter F. (1974): Freedom and Resentment, London I 974.

Winch, Peter (1972a): Wittgenstein's Treatment of the Will, in: Peter Winch, Ethics in Action, Oxford I 972, I IO-I 29.

- (I972b): Can a Good Man be Harmed, in: Peter WINCH, Ethics in Action, Oxford 1972, 193-209.

Zemach, Eddy M. (1966): Wittgenstein's Philosophy of the Mystical, in: Irving M. CopI / Robert W. BEARD (eds.), Essays on Wittgenstein's Tractatus, London 1966. 


\section{Philosophy and Life}

\section{Anja Weiberg}

To Ludwig Wittgenstein philosophy and life are inextricably linked, and ethical demands are made on both: the requirement for truthfulness in thought and action alike. According to Wittgenstein, truthfulness is the only means to prevent thought and life from becoming merely some artful trick, a Kunststück. To get an idea of Wittgenstein's understanding of truthfulness, one first needs to go into various aspects of his later philosophy. Therefore, in the first part of this paper I will examine Wittgenstein's understanding of terms such as world-picture, language, knowledge, reality, and truth. In the second part I intend to explain the importance of the concept of style, which in my opinion is central to Wittgenstein's work, and will subsequently show how style provides the opportunity to avoid a relativistic position. Finally, in the third part I would like to outline possible requirements which may be expected of a philosophy after, and, in accordance with Wittgenstein.

\section{I.}

It was primarily in On Certainty that Ludwig Wittgenstein described terms like knowledge, reality, and truth to be dependent on a worldpicture, thus making them lose much of their claim to absolute right and turning them into relative terms embedded in cultural and social circumstances. It is the mark of a world-picture that it ultimately rests on the acceptance of certain unexamined propositions; propositions which become fixed in our thinking as early as the stage of primary language acquisition:

The child learns to believe a host of things. I.e. it learns to act according to these beliefs. Bit by bit there forms a system of what is believed, and in that system some things stand unshakeably fast and some are more or less liable 
to shift. What stands fast does so, not because it is intrinsically obvious or convincing; it is rather held by what lies around it. (OC, I44)

Certain propositions - those who constitute the foundations of our world-picture - are, as a rule, not called into question and are (precisely because they have not been acquired explicitly as something which cannot be questioned) difficult to doubt, if one can doubt them at all: "That is to say, the questions that we raise and our doubts depend on the fact that some propositions are exempt from doubt, are as it were like hinges on which those turn." (OC, 34I)

From this follows with regard to our knowledge that it cannot be objectified beyond our world-picture. Rather, certainty is the basis of our knowledge, since the foundations for this knowledge rest on the social acknowledgement of specific unexamined propositions: "We are quite sure of it' does not mean just that every single person is certain of it, but that we belong to a community which is bound together by science and education." (OC, 298) The foundations of my worldpicture are too self-evident to be voiced or even questioned, which does not prove their rightness, however, because "[a]t the foundation of well-founded belief lies belief that is not founded" (OC, 253). Our certainty regarding various things results not least from our answer to the question, whether doubt is a feasible option, and which consequences would follow our doubt: "From its seeming to me - or to everyone to be so, it doesn't follow that it is so. What we can ask is whether it can make sense to doubt it." (OC, 2) Once we start to doubt the foundations of our world-picture we are in danger of becoming unable to act. If I lost certainty in my being human, in the fact that there is my hand, that the world exists, etc., I would hardly be able to act at all.

Wittgenstein connects those statements on the foundations of a world-picture time and again with the grammar of our language. In his Philosophical Investigations he elucidates the function of grammar in the following manner: "Grammar does not tell us how language must be constructed in order to fulfil its purpose, in order to have such-andsuch an effect on human beings. It only describes and in no way explains the use of signs.” (PI \$496) Wittgenstein calls propositions, which deal with the foundations of our world-picture, grammatical 
sentences or logical sentences (in order to describe a language-game) (cf. OC, 51, 56, 319). In contrast to empirical sentences, which we can test ${ }^{1}$ and which are actually tested quite often, grammatical sentences are those "which have a peculiar logical role in the system of our empirical propositions", for we affirm them "without any special testing” (OC, I36; cf. OC, 88). Clearly it makes an enormous difference whether the articulated statement may be proven and argued about, or whether the proposition in question contains certainties which are never questioned, may not even reasonably be called into question, or, certainties which, once we doubt them, take us to the very limits of our ability to act.

Propositions reach the status of a grammatical sentence simply by their being used in such a way within the frame of a world-picture and its connected language games. Whether a sentence takes on the role of an empirical sentence or a grammatical sentence cannot be verified by looking at it, but is dependent on the context of the respective language game. Not a specific characteristic of the sentence as such, but the question of its usage within a community and within a language-game is of relevance for its status. One of the examples Wittgenstein gives in this context is the statement "I know that I have two hands." It is not common usage to verify the existence of one's hands (it's something one usually doesn't even think about) - one takes them for granted. If, however, one stops being certain of their existence (i.e. because one doesn't see them) one would at the same time abandon trust in the method of verification (i.e. looking at them). If, for example, I were to wake up tomorrow morning and, for reasons unknown, fail to see my hands, I would not doubt their existence but my eyesight. On the other hand, there are situations in which the sentence "I know that I have two hands." makes perfect sense and can be used like an easily verifiable empirical sentence. Thus, for example, if someone has been operated on, and one is in doubt whether the operation involved an

1 "Can" is used here in the sense that a grammatical sentence would lose its status as a grammatical sentence by being examined: testing it renders it an empirical sentence. 
amputation of the hands. If I phone that someone and he assures me of still having both hands, I won't doubt him, since I assume that he has first-hand proof (i.e. that he has removed the bandages to take a look) (cf. OC, 23).

We may thus sum up the distinction between empirical and grammatical propositions as follows: with empirical sentences we can claim knowledge, we can give grounds for this knowledge (in the sense that the arguments for our knowledge make it more certain), and error is an option. Concerning grammatical sentences we cannot talk of knowledge, our position is one of doubtlessness, for we exclude error and we cannot think of any grounds that would further our certainty: the proposition itself "is as sure [...] for me as any grounds I could give for it" (OC, I I I).

Furthermore, the status of a proposition as empirical or grammatical is not fixed once and for all, neither are there just these two extremes of grammatical and empirical proposition - the transitions between them are fluid (cf. OC, 96). This dynamics is expressed especially clearly by the picture of the river bank, in which Wittgenstein begins to compare the foundations of a world-picture with mythology, from where he goes on to say:

The mythology may change back into a state of flux, the river-bed of thoughts may shift. But I distinguish between the movement of the waters on the river-bed and the shift of the bed itself; though there is not a sharp division of the one from the other. (OC, 97)

And the bank of that river consists partly of hard rock, subject to no alteration or only to an imperceptible one, partly of sand, which now in one place now in another gets washed away, or deposited. (OC, 99)

Of course, within this way of looking at things, what we consider to be true is equally affected by our world-picture: "But I did not get my picture of the world by satisfying myself of its correctness; nor do I have it because I am satisfied of its correctness. No: it is the inherited background against which I distinguish between true and false." (OC, 94) According to Wittgenstein one has to come to the conclusion that 
the word truth may be used in a number of ways and therefore restrict oneself to the description of those various uses.

Asked about diverse theories of truth (the pragmatic theory, the theory of coherence, and that of correspondence) Wittgenstein gives as early as $193 \mathrm{I} / 32$ the following response:

Philosophy is not a choice between different "theories". It is wrong to say that there is any one theory of truth, for truth is not a concept. We can say that the word has at least three meanings; but it is mistaken to assume that any one of these theories can give the whole grammar of how we use the word; or to endeavour to fit into a single theory cases which do not seem to agree with it. (L, 75$)$

If Wittgenstein denies at that time that truth is a term, his viewpoint has changed - in my opinion-by the time of his writing the Philosophical Investigations. Only insofar, however, as now his ideas concerning terms undergo a change within his conception of languagegames, a change apparent in this remark (intended to express a dissociation from Frege):

One might say that the concept "game" is a concept with blurred edges. "But is a blurred concept a concept at all?"-Is an indistinct photograph a picture of a person at all? Is it even always an advantage to replace an indistinct picture by a sharp one? Isn't the indistinct one often exactly what we need? (PI $\$ 7$ I )

In place of an exact definition with clear demarcations, one ought according to Wittgenstein - to be content with giving examples:

One gives examples and intends them to be taken in a particular way.-I do not, however, mean by this that he is supposed to see in those examples that common thing which I - for some reason - was unable to express; but that he is now to employ those examples in a particular way. Here giving examples is not an indirect means of explaining - in default of a better. For any general definition can be misunderstood too. [...] (PI \$7I)

The above remark already hints at it: to abandon the attempt of sharply defining the boundaries of a word, is not to be seen as a sacrifice forced on one by circumstances or the lack of a better explanation: "If someone were to draw a sharp boundary I could not acknowledge it as the 
one that I too always wanted to draw, or had drawn in my mind. For I did not want to draw one at all." (PI $\$ 76$ ) Here one is immediately reminded of certain remarks from the Philosophical Investigations where Wittgenstein clearly denounces the search for the essence of language (cf. PI \$65). In place of general explanations Wittgenstein proposes a deliberate reduction to descriptions, to giving examples and showing the (variety of) usage of words.

If we take truth to be a term without sharp boundaries, and assert that the word truth is used with various meanings, moreover, that what we consider to be true rests on unexamined, even undoubted, foundations of our world-picture, we will conclude that in respect to truth or falsity of propositions, Wittgenstein's position consists in neither more nor less than in pointing at our ability to decide for or against a proposition: "Really 'The proposition is either true or false' only means that it must be possible to decide for or against it. But this does not say what the ground for such a decision is like." (OC, 200) It is thus only possible to talk of truth within certain limits: "I want to say: it's not that on some points men know the truth with perfect certainty. No: perfect certainty is only a matter of their attitude." (OC, 404) In the end, the decisive moment is action itself: "Giving grounds, however, justifying the evidence, comes to an end;-but the end is not certain propositions' striking us immediately as true, i.e. it is not a kind of seeing on our part; it is our acting, which lies at the bottom of the language-game." (OC, 204)

In On Certainty, Wittgenstein invents a number of situations showing us people who don't share our certainties. Among others, there is the example of a meeting between George Edward Moore and a king who has been raised in the belief that the world originated at the very moment of his birth (cf. OC, 92). An example, which demonstrates that there are not just those who share our picture of the world, people we would consider - hopefully just for a brief period - mad, if they started to doubt the longterm existence of our earth. There are the others, too, those who live in another world-picture with another, differing education. People who are not mad in the least, yet do not share all of our certainties. (One need not necessarily ponder the belief 
in a longterm existence of our earth, it may be a less "grave" manner; see for example OC, I 32: "Men have judged that a king can make rain; we say this contradicts all experience. Today they judge that aeroplanes and the radio etc. are means for the closer contact of peoples and the spread of culture.")

The hope for the existence of objective characteristics to establish truth ought to be abandoned: "Very intelligent and well-educated people believe in the story of creation in the Bible, while others hold it as proven false, and the grounds of the latter are well known to the former." (OC, 336) Here we have the encounter of two people with differing world-pictures.

Arguments for convincing the other of the truth of one's own view of the world will, as a rule, peter out somewhere - at that moment, where one reaches the foundations of the respective world-picture: "Where two principles really do meet which cannot be reconciled with one another, then each man declares the other a fool and heretic." (OC, 6I I) In this connection, Richard Raatzsch explains the relationship between heretics and self-appointed orthodox persons in the following manner:

As Wittgenstein tells us, each man declares the other a heretic. Here »each" and »other « are variables for which the respective sets are those of followers of certain principles. In his own eyes each is orthodox, and every one who follows another principle is a heretic. It goes without saying that the latter considers himself orthodox once again. The term 'orthodox' cannot stand on its own in the world: One can, even in one's own eyes, only ever be orthodox in relation to non-orthodox persons, be they either relevant nonorthodox, like heretics, or irrelevant non-orthodox, such as fools. If there is only one system of belief and each and everyone believes in it, it is rather trivial to say that there won't be any heretics, but it is less obvious that there won't be any orthodox persons either. (Raatzsch 1999,98 )

The interesting thing in this context is the fact mentioned by Raatzsch that any self-appointed orthodox person requires a fool or heretic in order to define himself as having the right belief. This means that certainty regarding my view of the world requires, first, the existence of human beings who don't share this view, and second, that I consider 
at least some of these people to be in error, that I define them as "heretics" rather than simply leaving it at condescendingly referring to them as "fools". For I do not grant a fool the right to another opinion; a fool's statements are considered too "unreasonable", if not simply "mad". The heretic's views are much nearer to my frame of reference and thus it is easier for me to dissociate myself from them.

The curious situation arises that a strong conviction regarding the rightness of my own view finally depends on the existence of a plurality of differing views (the supporters of which will be equally convinced of their rightness). Naturally, one may also be convinced of one's view of the world in the absence of differing views, but it is easy to see that this conviction will be different from one that arises out of a dissociation from other views.

II.

Wittgenstein's thoughts, as described above, reject the dogmatic primacy of one's own view of the world, in favour of a construction of a world of plurality. Moreover, attaining the "one and only" truth appears to be impossible. One may assume that this would lead Wittgenstein to consider all values in relative terms, to hold up a certain arbitrariness. None of that, however: Wittgenstein takes in a particular position, which itself becomes possible due to the importance he ascribes to style.

I want to show this in three steps: I. By explaining the importance of the style of thought for Wittgenstein's philosophy, 2. by referring to Hans Julius Schneider's approach of emphasizing openness and movement among language-games, and 3. by presenting Wittgenstein's thoughts on one's personal style and the call for truthfulness connected to it.

Conviction of one's own opinions is not impossible in Wittgenstein's view of things. Its primacy in convincing others is, however, not due to "better" grounds, but rather to "a kind of persuasion" (OC, 262), a "conversion", by which one's opponent "would be brought to look at the world in a different way" (OC, 92). 
There is the option of "propaganda"; the option, to propagate one's own way of thought, to talk others into adopting one's style of thinking: "I am in a sense making propaganda for one style of thinking as opposed to another. I'm honestly disgusted with the other." (LC, 28). Its aim is to get one's interlocutor to change his view of things.

A usually negatively connotated term, "propaganda" deserves a short comment at this point: in my opinion, Wittgenstein does not use propaganda in its political sense, nor as a description of "convincing others by dishonest means" (i.e. by withholding information or by presenting matters in a tendentious manner), nor even by putting pressure on one's interlocutor. Rather, the term "propaganda" is used precisely because one deals with certainties, not knowledge; the point here is to change a certain way of looking at things, not to correct a way of looking at things. Propaganda for or against a style of thinking aims at our view of the world (which is never simply held by individuals, but rather, by members of a community). In his Philosophical Investigations Wittgenstein describes propaganda for a style of thinking by example of his own procedure:

Well I should like you to say: "Yes, it's true, you can imagine that too, that might happen too!"-But was I trying to draw someone's attention to the fact that he is capable of imagining that?-I wanted to put that picture before him and his acceptance of the picture consists in his now being inclined to regard a given case differently: that is, to compare it with this rather than that set of pictures. I have changed his way of looking at things. (PI \I44)

The style of thought lies at the bottom of grave decisions, like, for example, seeing the world as God's creation or as having originated from a "nebula"-or, even the view that neither of both explanations may claim to be more rational, as Wittgenstein says in his Lectures 1930-32:

Causality stands with the physicist for a style of thinking. Compare in religion the postulate of a creator. In a sense it seems to be an explanation, yet in another it does not explain at all. Compare a workman who finishes something off with a spiral. He can do it so that it ends in a knob or tapers off to a point. So with creation. God is one style; the nebula another. A style 
gives us satisfaction; but one style is not more rational than another. (LWL, I04)

At this point, two matters become apparent: first, the grave consequences following from a particular style of thought, since one's style of thought shapes one's whole attitude and not only influences answers one may arrive at, but, prior to that, the questions one may ask oneself. Second, once more, the fact that explanations are in the end without foundation - a view that will hardly inspire most physicists and a great number of religious people, since, as a rule, both groups tend to consider their beliefs to be well-founded and rational. ${ }^{2}$ In this connection, Joachim Schulte points out that Wittgenstein's thoughts lead to the conclusion "that while there is no reason to believe that we may attain absolute knowledge, all kinds of certainty we can really reach will suffice for our human ends." (Schulte i 990, i i6)

Consequently one has to give up hope of ever knowing "the truth" and of convincing all others by means of better arguments and grounds, but the option of convincing others of one's own view of reality still remains (incidentally, a pre-requisite for any change of world-picture). This option only differs insofar, as it is less assuming, lacking dogmatism and avoiding the claim for absolute truth.

Hans Julius Schneider has made an interesting point in this context. Against the background of investigating the education of teachers for a potential subject concerned with "a non-solely Christian approach to "ethics, lifestyle and religious theory"” (Schneider I999, I38) he dealt with the question, whether philosophical reflections might be of aid in convincing another person of a change in his habitual way of thinking. This change ought to be of a kind "that would render the new step not simply an additional viewpoint, an 'enrichment', but a modification of one's whole way of thinking" (Schneider I999, I42). Based on the assumption that there is no "holistic meta-language-game", "by aid of which one can describe and judge all others", Schneider in a first step

2 Even if "well-founded" and "rational" are often defined in different ways. 
refers to the vertical relations of language-games. ${ }^{3}$ Here Schneider follows Ter Hark in giving as examples the language-games 'to feel pain', 'to feign pain' and 'to feign joy'. While the language-games 'to feign pain' and 'to feign joy' lie in horizontal relations to each other, one may discern a vertical relation between 'to feel pain' and 'to feign pain' inasmuch, as the latter "can for logical reasons only be played out, once one has mastered the sensuous language-game [of feeling pain]" (Schneider I999, I48). In connection to conflicts between forms of life Schneider considers the above reflection as relevant,

because language-games which serve the expression of forms of life, typically need to be understood by comprehending vertical steps. To overlook steps of that kind or to ignore them leads to the so-called 'ground floor fallacy' (a term coined by Hark), i.e. illusions based on the false assumption that all language-games take place on one and the same logical level, thus on the one and only ground floor. (Schneider 1999, I48)

Based on this subdivision of language-games, Schneider reaches the conclusion that conflicts among forms of life are those, where people who co-inhabit the same linguistic ground-floor ${ }^{4}$ undertake various differing vertical steps, which are in turn either rejected by, or, incomeprehensible for their respective interlocutors. At this point, Schneider sees a central argument in Wittgenstein's remarks concerning the frayed borders and openness of language-games (cf. PI \$68fff.). Schneider argues that these qualities show that movement between languagegames is not an exception, a peculiarity, but rather an everyday phenomenon, something we are all used to:

We have thus at the centre a bigger or smaller area of succeeding common actions, which includes opportunities for an extension beyond its habitual limits, limits which most of the time are not made explicit. It seems important to me that Wittgenstein views this openness not as a fault, as an

3 Schneider refers at this point to Michel Ter Harks distinction between "horizontal" and "vertical" lanugage-games; cf. Ter Hark 1990, quoted after Schneider 1999 .

4 It has to be pointed out that Schneider's assumption of a common linguistic ground-floor is not explicitly stated in Wittgenstein's writings. 
obstacle in the learning of language-games which ought to be explained away by psychological theories about ('the incompleteness of') speaking versus its more exact foundation in 'meaning'. The ability to actively take this openness and to make use of it time and again, to expand the possibilities for action is - on the contrary - from the very beginning a main ingredient of any linguistic competence. (Schneider 1999, I46)

Going back to our initial question, we now see that according to this interpretation various forms of life need not be fundamentally incompatible, conflicts between forms of life do not seem unsolveable in general.

It is with a certain amount of prudence that Schneider draws his conclusions, pointing out that it may be at times very difficult to convince another person to change his style of thought, however, that it is vital for the general procedure of solving conflicts between forms of life "whether we consider a task familiar to us from everyday little steps, or whether we view it as a problem for which we may never find a solution due to philosophical reasons." (Schneider 1999, I 2 2) By aid of this starting point one may, on the one hand, avoid a dogmatic position, while on the other hand avoiding to see matters solely in relative terms. The only relativistic concession one would have to make, albeit a "rather harmless" one, would be the concession that one could not take a totally neutral position - inasmuch, as

each of us can only ever articulate matters within the medium of that linguistic form in which he has learnt to move as his 'element of life' in the life he has lead so far. [...] But this kind of movement, we need to make in order to understand forms of life foreign to ours, is, however, deeply familiar to us in its simplest expression: it is the ordinary movement among language-games, for which we need not revert to a meta-language-game. The nonexistence of the latter does in no way cause any special problems. Not having an 'objective' rule does not invalidate the viewpoint we have reached according to our abilities, a viewpoint always valid for the respective moment only. (Schneider 1999, I 53)

In the end, it is about a reduction of the absolute claim regarding one's own view of the world, connected with, on the other hand, more openness towards things that had been foreign up to now. 
This brings me to the third part, dealing with Wittgenstein's remarks on the personal style of a person. In this context, I would like to point out that these remarks are not treated in writings Wittgenstein intended to publish, but are found mainly in Culture and Value and in his Diaries (MT). Accordingly, one needs to be wary of connecting Wittgenstein's thoughts on personal style to his philosophy.

In these remarks, Wittgenstein combines his thoughts on truth, knowledge and reality with a personal demand for truthfulness; a claim for authenticity which, in essence, makes up his usage of the word truth: "No one can speak the truth, if he has still not mastered himself. He cannot speak it;-but not, because he is not clever enough yet." (CV I939-1940, 78) What is asked for is to stop lying to oneself, to give up any self-deception - a way of action that demands courage. "Without a little courage one can't even write a sensible remark about oneself." (MT 26.4.30) Courage is not supposed to mean a special readiness to take risks, rather, it is - according to Wittgenstein - a sign of originality (cf. CV 1939-1940, 79) and "the beginnings of good originality are already there if [one does] not want to be something [one] is not [...]" (CV 1947, I I 8).

This demand Wittgenstein makes on himself is one of authenticity in life and thought. Language and action are here, as elsewhere, closely knit. To realize this demand, is a difficult and time-consuming process, in the course of which one encounters many a trap, as Wittgenstein expresses by complaining about his own vanity:

When I say I would like to discard vanity, it is questionable whether my wanting this isn't yet again only a sort of vanity. I am vain \& and insofar as I am vain, my wishes for improvement are vain, too. I would then like to be like such \& such person who was not vain \& whom I like, \& in my mind I already estimate the benefit which I would have from "discarding" vanity. As long as one is on stage, one is an actor after all, regardless of what one does. (MT i 5 .[I I or I2.3 I])

Wittgenstein illustrates these thoughts on one's personal style not least by using a picture in which he attempts to describe himself:

I could almost see myself as an amoral nucleus to which the moral concepts of other people stick easily. 
So that, what I am saying is eo ipso never my own, since this nucleus (I picture it as a white dead bundle) cannot talk. Instead, printed sheets stick to it. These then talk; of course, not in their original state but mixed up with other sheets \& influenced by the position into which they are brought by the nucleus. (MT 3 I.IO.[3 I])

For other people, however, the state of a person may not be discerned as easy as by that person himself (provided he thinks about it). Once again, Wittgenstein makes use of a picture to describe these difficulties: he compares people with "balls", some of which consist of "genuine gold", some of which are on the outside covered by some "worthless material”, and finally some, which apart from their deceptive gilding contain but "a kernel of genuine gold" or else only "dirt".

But how difficult it is to judge such a person. One finds him out, discovering that the first layer is false \& says: "so he is worthless" for no one believes that there can be falsely gilded genuine gild. Or one finds the trash under the false gilding \& says: "Of course! That was to be expected." But that there should then still be genuine gold hidden in this trash, that is difficult to suppose. (MT 3I.IO.[3 I])

This shows clearly that to recognize such distinctions in the supposedly alike or, to see similarities in the supposedly different is not easy at all and requires a lot of time.

Furthermore, one can easily have a mistaken self-image, which would become apparent in one's style: "If I perform to myself [...] then it's this that the style expresses. And the style cannot be my own. If you are unwilling to know what you are, your writing is a form of deceit." (MS I 20, quoted after Rhees, I93) If one does not stop performing, one will - according to Wittgenstein - never arrive at truth in the sense of truthfulness. The search for truth is thus defined by ethical criteria; it is not alone knowledge but most of all dealing with that knowledge which leads to truth: "That something occurs to you is a gift from heaven, but it depends on what you make of it." (MT I3.[IO.3 I]) By this, language and action are inextricably linked. Life is to Wittgenstein indispensable prerequisite to any philosophy: "For first one must live, - then one can also philosophize." (MT I.3.[37]) The way of life one leads influences thought as well as one's language: 
"But if one lives differently, one speaks differently. With a new life one learns new language-games." (MT 4.2.[37]) The language-games are not the only ones to change, once one leads a different life, the style, too, is a different one - and it is exactly by looking at the style of a person that one may recognise how seriously a person takes the demand for truthfulness. Style is where one can see whether a person's objective in life is defined, for example, by comfort or amusement; or whether the person tends to take life "seriously" and accordingly comes to certain considerations or at least aims at them. Equally one may discover how far a gap there is between life and writing. Style is thus not just a rhetorical accessory, but closely linked to life and thought of a person: “'Le style c'est l'homme.' 'Le style c'est l'homme même.' The first expression has cheap epigrammatic brevity. The second, correct version opens up quite a different perspective. It says that a man's style is a picture of him." (CV I949, I 49f.)

This last remark about style as a picture of man becomes clearer once one looks at the passage from Georges L. L. Buffon's Discours à l'Académie Française (also known as Discours sur le style) from 1753, which Wittgenstein knew, cherished and referred to (cf. CV, i8). To write a good style, one ought to consider the following, according to Buffon:

Enfin, si l'on écrit comme l'on pense, si l'on est convaincu de ce que l'on veut persuader, cette bonne foi avec soi-même, qui fait la bienséance pour les autres et la vérité du style, lui fera produire tout son effet, pourvu que cette persuasion intérieure ne se marque pas par un enthousiasme trop fort, et qu'il y ait partout plus de candeur que de confiance, plus de raison que de chaleur. (Buffon, I939, S.72) ${ }^{5}$

Here already it becomes apparent that there is a close connection between Buffon's view and Wittgenstein's remarks on truth and authen-

5 “And finally, if one writes as one thinks, if one is convinced of that one wants to convince others of, this good conscience regarding oneself, which constitutes the reputability to others and the truth of style, will have its effect, provided, that this inner conviction does not show itself by too much enthusiasm, and that he at all times has more objectiveness than confidence, more reason than heat.” 
ticity, on the relations between writing and life, which become visible in style. The fundamental motif in both is the demand for authenticity. Buffon places the style of a work above the "uniqueness of facts" and the "novelty of discoveries" (Buffon I939, 73), which make up the subject matter of a work, since the latter is accessible to all:

Ces choses sont hors de l'homme, le style est l'homme même: Le style ne peut donc ni s'enlever, ni se transporter, ni s'altérer: s'il est élevé, noble, sublime, l'auteur sera également admiré dans tous les temps[...] (Buffon I939, $73) \cdot{ }^{6}$

Just as with Wittgenstein, style is closely linked to the person. In Wittgenstein, this distinctive meaning of style shows itself among others in a remark on genius in which we encounter once more the ethical demand for life and writing of man: "Genius is talent in which character makes itself heard. [...] This is no mere intellectual skeleton, but a complete human being. That too is why the greatness of what a man writes depends on everything else he writes and does.” (CV I948, 65)

III.

Wittgenstein's demand for a constant examination of one's own thoughts and way of life seems to me to be an interesting starting point for a reflection on philosophy and its philosophers. If one takes Wittgenstein's remark on the inseparableness of philosophy and life seriously, each entirely "theoretical" or purely academic philosophy (provided such a thing is possible at all, if not, at least each philosophy considered, or else, aimed at by its proponents as purely "theoretical" or academic) would be a kind of deceit or delusion. A philosophy of that kind is lacking life. If life or philosophy is lacking truthfulness, each remains plain artifice, as Wittgenstein explains regarding ethics: "An artful ethical trick is something that I perform for others, or also

6 "These matters are outside of man, the style is man himself. The style can thus neither disengage, move to another place nor alter; provided it is elevated, noble, sublime, the writer will be honoured at all times." 
only for me (myself), in order to show what I can do.” (MT 7.[I I or I 2.3 I]) Philosophy and life alike are connected to an ethical criterion. The connection called for between language and action is therefore not characterised by thematic requirements, requirements of subject matter, but by an attitude towards and a way of dealing with them. Not which topic one treats is of primary importance, but how one deals with it.

It may well take some time and effort, but a reader can discern, based on a philosopher's writing, on his style, how close the link between thinking and living actually is, and how often the philosopher tackles the question of authenticity of his thinking and life respectively draws conclusions from this question. In short: the style of a philosophy shows how much of it is "authentic" and how much remains skillfulness, or an "artful trick".

To philosophize on the basis of Wittgenstein's thoughts is, as shown above, certainly not reduced to a relativism which is neither capable of any standpoint nor a basis for consistent steps or actions. Wittgenstein nowhere mentions an equality of world-pictures. The point he does criticize, however, in connection with dealings with proponents of differing world-pictures, is the tendency to judge other world-pictures using the standards (norms) of one's own world-picture (see in this context also Wittgenstein's remarks on Frazer).

Two central themes may be made out: on the one hand, Wittgenstein's abandoning the search for an essence (of language), abandoning the search for "ultimate" truth, in favour of a conscious reduction to descriptions rather than general explanations; on the other hand, a rigorous claim for authenticity in the life and thought of the individual. These two themes combine to the following view of a possible way to philosophize: the objection consists in - as much as possible - making transparent what is given, looking at things from a different point of view, and continually adding other aspects and perspectives. It is exactly this conscious reduction to close examination and description of the given, like the pointing toward and showing of alternative perspectives, which contains an ethical component: this way of action is a way to distance oneself from jumping to conclusions and theoretical constructions, a way to avoid rash and dogmatic judgements. Com- 
bining philosophy and life, together with the demand for authenticity of both, would involve, if taken seriously, that one's capacity for thought remains open, since no rigid and equally constricting theory functions as one's objective. Instead, the plurality of thoughts and experiences offered by life would influence not only life itself and one's view of life, but also thought, which in turn would result in a constant questioning, confirming, negating, adding to, or, modifying one's way of thinking.

A constant openness for hitherto unknown matters would be called for - an openness even for the unpleasant and frightening. Even if in the end one sticks to one's disapproval (which will quite often be the case), at least one knows what one's talking about (which is, sadly, not too often the case), because one would have made the attempt of an unbiased approach to another view of the world. It is unquestionably true that this procedure will time and again run into obstacles, be it that the other refuses a dialogue, be it because one's findings are so repulsive that one does not want to, or, cannot continue to deal with the matter, be it that there are differences too big to one's own views. Still, it seems to me that one ought to agree with Schneider's statement that an important element of solving practical conflicts consists in our view of a task as being of a kind that is "familiar to us from everyday little steps", rather than seeing us opposite of "a problem for which we may never find a solution due to philosophical reasons." (Schneider I999, I 52)

Moreover, we should be aware right there that the existence of other world-pictures does not only have the function of altering one's convictions, but equally, that of strengthening them. One the one hand, we have no right to dogmatically claim the truth of our own view of the world, in order to supposedly gain the right of imposing our view on others ("supposedly", because from the assumption that one holds the only correct view of the world, it does not simply follow that others ought to share this view). The idea of a generally binding set of rules which has to be followed always and everywhere, containing precise orders concerning what ought to be right or wrong, good or evil, is an idea clearly refuted by Wittgenstein. 
On the other hand, one is not reduced to relativism, leaving all views equally valid - it is precisely by pointing toward alternatives, by demonstrating the fact that other perspectives exist, that one gains the opportunity of changing the views of people, their styles of thought.

However, this requires far more of me, I have no automatic right to lean back (convinced of being in the possession of truth) and certainly no automatic right to suppress persons of a different opinion. Rather, I am expected to continually challenge my thoughts and actions by questioning them. In this context one ought to point out that authenticity is not a status one attains to keep. Truthfulness has to be gained anew each day, it is a neverending process.

In conclusion, one may emphasize the following: within the framework of sharing collective world-pictures, or, living in them (and the clearly emerging importance of acknowledgement, acceptance, as a basis for our insight, our knowledge), our personal contribution may be seen in two respects: first, in acknowledging plurality in a way that does not exclude other world-pictures and their proponents from the outset, that does not from the very start judge them as good or evil, pleasant or unpleasant, but rather maintains a maximum of openness for other views and pays them respect also insofar, as one pays attention to the various styles of thinking and living, attempts to uncover the foundations of each form of speaking and acting, the context in which they occur. The style of thought and life is not a rhetorical addendum, a nice, but unnecessary accessory, but something which penetrates and shapes a person collectively as well as individually. The second contribution consists in constantly questioning one's own point of view. On the one hand, this enables me, regarding myself, to realize other perspectives and possibly change my point of view. On the other hand-quite pragmatically-I may thus, regarding other persons, manage to present my point of view with greater conviction-in Buffon's sense-and maximize my chances of talking them into changing their style of thought. 
Bibliography

Buffon, Georges L.L. (1939): Discours à l'Académie Francaise, in: Georges L.L. Buffon: Pages choisies avec une Notice biographique, une Notice historique et littéraire, des Notes explicatives, des Jugements, un Questionnaire et des Sujets de devoirs, par Adrien Cart, publié sous la direction de Félix Guirand, 66-74. Paris 1939. RaAtzsch, Richard (1999): Ketzer und Rechtgläubige, Narren und Weise, in: Wilhelm LüTteRfelds / Andreas Roser (eds.): Der Konflikt der Lebensformen in Wittgensteins Philosophie der Sprache, 94-I 19. Frankfurt/Main 1999.

Rhees, Rush (ed.) (198r): Ludwig Wittgenstein. Personal Recollections. Oxford I98 I.

SCHNeIDER, Hans Julius (I999): Offene Grenzen, zerfaserte Ränder: Über Arten von Beziehungen zwischen Sprachspielen, in: Wilhelm LÜTTERFELdS / Andreas Roser (eds.): Der Konflikt der Lebensformen in Wittgensteins Philosophie der Sprache, I38-I55. Frankfurt/Main I 999 .

Schulte, Joachim (1990): Chor und Gesetz. Wittgenstein im Kontext. Frankfurt / Main I990.

Ter Hark, Michel (1990): Beyond the Inner and the Outer. Wittgenstein's Philosophy of Psychology. Dordrecht 1990. 


\title{
Sense of Ethics and Ethical Sense ${ }^{1}$
}

Jens Kertscher

\author{
Ma tâche ne consiste pas à construire l'éthique; \\ J'essaie seulement d'en chercher le sens. \\ Emmanuel Levinas \\ Man has to awaken to wonder [...]. \\ Science is a way of sending him to sleep again. \\ Ludwig Wittgenstein
}

To approach Wittgenstein's remarks on ethics from an academic standpoint is likely to frustrate the reader, whose learned expectation still makes it difficult to appreciate the sense of those remarks. ${ }^{2} \mathrm{We}$ have grown accustomed to associate ethics with a fixed canon of questions, emerging from problems and methods within the history of philosophy, which defines what ethics involves and promises suitable modes of discourse. Along these lines, ethics is typically understood, especially in the modern context, where the discipline implies the reflection and justification of existing norms, with specific reference to their legitimacy and general validity. To accept actions as morally valid, in so far as they depend on others' demands, it is not enough to invoke an arbitrary existing norm. Rather, it is necessary to supply reasoning

1 My thanks are due to Ulrich Arnswald for numerous intensive discussions that shed light on the way to approach Wittgenstein's ethics. The present study would not have emerged without these discussions.

2 Alongside several cryptic propositions in Tractatus, Wittgenstein's remarks are largely contained in the diary entries parallel to the development of Tractatus, in the Lecture on Ethics (1929), as well as minutes of conversations with Wittgenstein reproduced by Rush Rhees (I970). 
that matches expectations, such as they shape the task of ethics, to justify a moral principle, not merely in relation to the actions and moral code of a community, but to mankind as a whole. In the recent history of ethics, for example, these moral principles were represented by freedom (Kant), the principle of utility (utilitarianism), or justice (Rawls). These principles were to yield the concrete and morally valid rules for action and their suitability for consensus-building was to be made transparent.

Wittgenstein declared such a theoretical programme in ethics as lacking all prospects. In a conversation with Moritz Schlick he remarked, apodictically:

It is a priori certain that whatever definition of the good may be given - it will always be merely a misunderstanding to say that the essential thing, that what is really meant, corresponds to what is really expressed (Moore). (WVC, 69)

Not only did Wittgenstein reject the academic stance on ethics, along with its methods and discourses, but he evidently also despised them:

I regard it as very important to put an end to all the chatter about ethics whether there is knowledge in ethics, whether there are values, whether the good can be defined, etc. (LE, I3)

Wittgenstein could clearly do no other than treat objectivity in ethics as a philosophical discipline as a failed attempt to discuss questions and problems that are at one step removed from the formation of objective concepts. His asceticism with regard to moral philosophy, which was rather paradoxically based on an ethical motivation, could be contested by the fact that there is a legitimate interest to remain accountable for those moral convictions that are relevant to everyday living, as well as to those value judgements, which we make almost by force of habit. If we take it for granted that philosophy is to account for our common use of certain concepts and ideas in plenty, the outcome of Wittgenstein's categorical rejection of these entities is bound to strike us as unsatisfactory.

Primarily, however, it is not only his distaste for ethics as an academic discipline that makes it difficult to appreciate Wittgenstein's ethics, 
but rather his unorthodox conception of the sense of ethics. According to Wittgenstein, ethical questions belong to metaphysics. Ethics is "[...] the enquiry into the meaning of life, or into what makes life worth living, or into the right way of living." (LE, 5 ) Every attempt to answer this question in generally valid terms implies, in Wittgenstein's view, an abuse of language, especially the value-ridden expressions that occur in ethical discourses. Wittgenstein argued that, on that basis, an ethical theory is impossible in the sense of a science of the right action. Supposing that Wittgenstein's dismissal of the scientific foundation of ethics were to be accepted, what role remains for ethics? The following analysis defends the thesis that, above all, Wittgenstein opposed a particular approach to moral philosophical speculation: namely, those models that rely on examples of scientifically fashioned solutions in the paradigm of rationally justified norms. The sense of ethics, that is, its proper place in human life, cannot be captured by traditional methods of a normative and rational science. Logically to follow this aspect of Wittgenstein's thought is perhaps to suggest reasons why he associates, as a matter of course, ethics alongside mystics. Thus, as will be demonstrated, ethics is ineffable. While Wittgenstein may well locate ethics beyond the reach of science, his programme is neither positivistic nor leaning towards reductionism. Rather, his aim is fundamentally to change the picture that philosophers make of ethics.

The purpose of this study is neither to claim Wittgenstein as a supporter of a particular ethical theory, nor to develop an independent approach to ethics by an analysis of his writings. At the same time, the following reflections are based on my conviction that Wittgenstein's work includes insights that help overcome a series of what I see as weak alternatives, which currently dominate some areas of debate in ethics. Above all, I refer to the choice between universalism and particularism, or the distinction between a rigorous approach, as governed by rational thought in the manner of Kant, and a type of pluralism with relativistic implications. Wittgenstein's approach to ethics - as to be shown - cuts across these alternatives. In that case, the relevance of his views is due to the fact that he ushered in an innovative discourse on ethical matters that implies a reassessment of the existing paradigm 
of modern universal and rational tenets. The focus of the present discussion is not on a new system, not on an innovative and watertight reasoning that is, in any case, hardly likely to be in short supply in future. Rather, the emphasis is on a different route to what is generally regarded as an ethical problem.

Briefly to characterize at this point this alternative route in key phrases would be to accept Wittgenstein's turn to the individual case, the necessity of accepting plurality and contradiction as irreducible, as well as to highlight his emphasis on speech in the first person singular. Furthermore, Wittgenstein's later insights into forms of life and his views on certainty permit a critique of the view that a system of norms can only be regarded as rationally valid and therefore adequate for the claims of free individuals, whenever that system is based on a reasonable, that is to say, a compelling approach to all those whose behaviour may be deemed as rational action.

II.

Firstly, the task is to determine which prevailing view of ethics Wittgenstein rejects. To this end, it is valuable to place Wittgenstein's views in the context of several approaches that govern contemporary debate. Not only can Wittgenstein's ideas be highlighted in sharper relief against the prevailing paradigm, but above all, this route to his thought shows how some philosophers rely on Wittgenstein as a basis for their work, without really departing from the model that Wittgenstein himself contested. In that case, Wittgenstein is clearer than those who follow in his footsteps, whereas he himself drew conclusions from the irreducible plurality of life forms and language games.

Amongst the most frequently discussed examples of a universalistic approach is the discourse ethics of Jürgen Habermas. In dialogue with Hilary Putnam, Habermas recently gave a brief summary of his aims:

Those moral judgements are 'right', in so far as they earn universal respect, meaning that, in a rational discourse with virtually ideal conditions, they could meet with the approval of all those concerned. (Habermas 2000, 560) 
In this way, Habermas's reflections resemble the tradition of ethics as a universalistic proposition that dates from Kant. For Kant, the issue of individual good was, ultimately, an empirical question, so that no generally valid rules of behaviour could be established, such as for instance, for the individual's path to the happy or good life. By contrast, the moral conduct that we demand of our partners is to be grounded by gaining a firm grip on rationality and pure reason. In the same vein, Kant explained the absolute meaning of ethical duties, by interpreting the so-called propositions of moral duty (Sollenssätze), or rather, in Kant's terminology, the categorical imperative, as rational rules that the individual actor accepts, by the strength of his own decision-making. According to this view, it is irrational to act contrary to a categorical imperative. The refashioning of this programme in discourse ethics runs as follows:

The program of justification pursued by discourse ethics sets itself the task of deriving from suppositions of rationality [...] a rule of argumentation for discourses in which moral norms can be justified. It attempts to show that moral questions can be decided rationally as a general rule. (Habermas I993, 3If.)

Furthermore, such an approach is incontestable, for otherwise, it is not clear what distinguishes "[...] the argumentative practices of justification from other practices that are regulated merely by social convention.” (Habermas 1996, I5) Following Wittgenstein's thoughts, at least three assumptions underpinning the universalistic view are to be called into doubt.

In the Lecture on Ethics, it is clear that Wittgenstein vehemently opposes a distinction of ethics and individual morality that is implicit to the universalistic viewpoint. On that score, Wittgenstein approaches the basic question of ethics in an essentially more general and valueneutral context than Kant, such as putting “[...]before [...] a number of more or less synonymous expressions each of which could be substituted for [Moore's, J.K.] definition[...]" (LE, 4) The concept of the meaning of life that Wittgenstein then resorts to is in fact intrinsically more neutrally framed, in so far as he does not diminish the question of life conduct or the enquiry "into what is really important" (LE, 5), as a 
matter of the individual well being, as for instance, in the one-sided sense of Kant. Rather, by allowing for ways of life that are not necessarily compatible with the individual well being, Wittgenstein appears both to call to mind the sense question as a basic facet of ethical enquiry and, furthermore, to make no distinction between that enquiry and the moral philosophical approach to good and morally compelling actions. Ethics, that is, also as moral philosophy, refers to the sense question and, therefore, meaning or sense plays a leading role in the discourse of ethics. To be sure, a distinction between the sense matterin Wittgenstein's perception, the basic question of ethics - and the moral quality of action is possible, but there is no distinction on principle. Even assuming that such a distinction were made, in Wittgenstein's view, it would not suffice for the foundations of a universalistic theory, replete with its general criteria for evaluating actions and describing situations in which morally compelling decisions emerge. Such a general theory without preconceived ideas of the good life is in any case impossible because a formal moral principle implies a material understanding of the Good, or human happiness, not compatible with any arbitrary individual idea of the right way of living. ${ }^{3}$

Furthermore, Wittgenstein argued against universalisms that the study of ethical questions is not possible without considering the individual personality and the concrete situation in which an ethical crisis confronts the individual in a specific way. ${ }^{4}$ The conflicts that emerge in this context, such as for instance, amongst various directions and projections of the good life, or between an individual striving for happiness and moral needs, can therefore not be solved in a way that is universally binding. The remarks on ethics in the Tractatus and the

3 Even within a universalist and formal moral philosophy, the question must always be asked what idea of the right way of living is appropriate. That was recently demonstrated by Ursula Wolf (cf. Wolf i 999, i 5).

4 If Wittgenstein's conversations with various people about ethical themes, as documented by Rush Rhees, are also taken into account, there can be no doubt that he would have dismissed the idea that a moral problem consists in discovering what the Good actually is in each respective case (cf. Rhees I970, 98f.). 
associated diary entries already allude to this viewpoint. In these sources, we find: "What is good and evil is essentially the I, not the world." (NB, 5.8.I6). Not the action as a describable, worldly fact is to be qualified as ethical, but the individual intentions of the subject, in whose actions that ethical dimension is expressed. For that reason, Wittgenstein can also state in Tractatus that the will cannot be called the vehicle of the ethical (cf. TLP 6.423). In this context, the connection between the ethical dimension and the action would be associated with "the meaningfulness of action in the world, or the experience of a loss of meaning in this action" (Kroß 1993, I 33). ${ }^{5}$ This association is, however, entirely contingent. Only insofar as the subject evaluates his actions according to ethical categories, thus lending meaning to the world, does a connection emerge between the world of the subject and the world that is given as a finite entity. ${ }^{6}$ Wittgenstein also remained consistent to this view in his later works, although here, the metaphysical subject of Tractatus has "adopted the figure of 'I-saying' as grammatically special, as expressing certainty” (Kroß I993, I 42).

Wittgenstein's reconnection of language with life forms in their relation to language games, as significant in his late philosophy, was more compelling as a critique of universalism than his emphasis on the relationship between individuals and their ethical judgement and action. Those authors who followed Wittgenstein's lead found a basis to oppose the efforts of universalist theorists, seeking to underpin a generally valid canon, free of historical or cultural contexts and, instead of that, gain an anchor in value judgements and decisions in real world scenarios. In that case, the starting point is the indefatigable plurality of life forms, language games and the cultural and moral traditions that flow into them. Advocates of these possibilities such as Richard Rorty and Michael Walzer insist at the same time that this view implies no

5 The connection between the metaphysical subject and the ethical quality of action is extensively examined by Kroß (I993, I 27-I36). Cf. also Arnswald I998, 54f.

6 Cf. NB, 8.7.16: “The world is given me, i.e. my will enters into the world completely from outside as into something that is already there." Cf. also NB, I 5.I0.16: "Things acquire 'significance' only through their relation to my will." 
relativism, in so far as that represents a theory, by which all ethical value systems can be either proved true or false. ${ }^{7}$ That position can only be contradictory and easily refuted in a theoretical sense (cf. Putnam I992, I78). Whoever accepts or passes judgement on a specific ethics as true implies something about his life conduct. A theoretical statement on the superiority of his ethics is not yet achieved. To give reasons and to make moral judgements are activities documenting an individual's life conduct or actions, or those of a community, ${ }^{8}$ or else, life styles rooted in them that give meaning to possible or real actions. Every philosophical interpretation of action already rests on the assumption of such individual opinions, so that acting represents an incontestable precondition for any philosophical or ethical interprettation of reality (Kroß I993, I4I). Not relativism, but pluralism, in the sense of accepting diverse answers to value judgements in ethics is therefore a measured response to the requirements of universalism.

In this regard, Michael Walzer spoke of a 'moral minimalism' (cf. Walzer 1994). By that, he means a central residue of moral principles "in terms of a (thin) set of universal principles adapted (thickly) to these or those historical circumstances" (Walzer 1994, 4). In unison with the late Wittgenstein, Walzer's assumption is that moral systems are culturally integrated, only adopting a universal character in quite specific situations, "when moral language is turned to specific purposes" (Walzer 1994, 4), as for instance, in crisis situations - Walzer had the 1989 Prague demonstrations in mind. These situations produce partial common interests and solidarities. In other words, minimal morality implies a basic store of principles and norms that recur at particular times and in special situations and may be recognized by

7 Richard Rorty expressed this as follows: "This view is often referred to dismissively as 'cultural relativism.' But it is not relativistic, if that means saying that every moral view is as good as every other. [...] It is one thing to say, falsely, that there is nothing to choose between us and the Nazis. It is another thing to say, correctly, that there is no neutral, common ground to which a philosophical Nazi and I can repair to argue out our differences.” (Rorty I993, 44).

8 For that reason, the documentary value of Wittgenstein's ethics has been referred to, cf. Bouveresse 1994, I03. 
actors of various cultural, historical and linguistic backgrounds (cf. Walzer I994, I7). In Walzer's view, however, it would be a mistake to isolate this minimal morality from its cultural context, in the hope of one day achieving an objective, trans-cultural code. On the contrary, the code is irreducibly bound with particular meaning and semantically loaded and is always linked to specific morals, as they were developed in specific historical and cultural contexts. For that reason, a minimal morality cannot be the theoretical basis, to be deduced and anchored to specific and materially substantive morals, but merely seen as a slice of those circumstances (cf. Walzer I994, I8). Like the late Wittgenstein, Walzer's focus is not on the search for justifications, but on divided viewpoints and lifestyles that first facilitate a language game, that is, even make a particular form of practical reflection possible (PI \$24 If.). The life forms in which actors circulate, who act morally and reflect on their actions, are fed by a dense network of equally pre-contractual agreements, common interests, rules for participation that, taken together, constitute a way of life that has grown historically:

Minimalism [...] is less the product of persuasion than of mutual recognition among the protagonists of different fully developed moral cultures. (Walzer 1994, I7)

Rorty's and Walzer's differently weighted appropriations of Wittgenstein's pluralistic views make it possible to criticize the universalistic ideal of justification, since they place at the forefront of debate an irreducible premise, lacking a common historical root, that engenders a multiplicity of different life forms and language games anchored in their midst. ${ }^{9}$ In that way, it is clear that authors who support the paradigm of justification base their assumptions in ethics on an inadequate view of the problem: what should direct the interest of the ethicists is not the question of justification, but growing aware of the

9 Against Rorty, it can also be mentioned in this connection that, quite unlike Wittgenstein, he never questions the life form of western, liberal democracies and he thinks about moral progress exclusively in the sense of the universalization of this life form. In this view, Rorty is at one with Habermas, who otherwise remains his adversary. Cf. Rorty I994, 983. 
peculiarities and differences of lifestyles that are to be accepted as such. The concern expressed by some universalists against this alternative of giving up any sort of moral judging, if no rational foundation can be found for that process, ${ }^{10}$ is just as much a sign of an incorrect approach to the problem as the opposite claim: namely, that in this case, any course of action would be morally feasible, or every value system of equal merit. By contrast, to follow Wittgenstein is to remember that a particular ethics can only be defended, in so far as it forms an integral part of a form of life. The arguments to be brought in their favour are as much our own as the language used in that process is also our own. Indeed, only in that way can it be made plain what the justification of a particular norm or moral judgement is to mean. To understand, for instance, what is intended by someone who gives such weight to a moral judgement that he claims its value exceeds every context, it is necessary to know the relevant context in which the claim was made, to whom the claim was addressed, how it was expressed and received, how reactions were etc. The entirety of these practices and reactions of the linguistic and non-linguistic kind belong to a particular language game that the actors actually control, yet without the game resting on a metaphysical guarantee, like reason. No rational structure is available that points beyond the contexts in which individual languages are used and that underpins the related purpose still further; and, moreover, according to Wittgenstein, such a structure is superfluous. Likewise, as our language game is neither rational nor irrational, but merely there, like life itself, 11 so too, is the language we use in our moral discourses, in Wittgenstein's view, lastly only governed by the fact that we rely upon something. ${ }^{12}$

10 Tugendhat (1995, 22) is exemplary: "And we could no longer judge morally, if we could not keep hold of the inherently objective, that is, personally irrelative standard in moral, as in all judgements."

11 Cf. OC, 559; cf. also the interpretation by Putnam (1992, I $76 \mathrm{ff}$.$) .$

12 OC, 509: "I really want to say that a language-game is only possible if one trusts something, (I did not say 'can trust something')." 
III.

The ongoing chain of thoughts, in the present study, on the relationship between certainty and life form enables a deeper investigation of the question how Wittgenstein's views assist with an illustration of the boundaries of ethics, as measured by a modern conception of that discipline. Wittgenstein's commentaries on the concept of rules are especially relevant in this regard. The relevance of rules in ethics results from the fact that moral norms in ethical discourse are to be represented as a particular class of practical rules, according to which, specific ways of acting can be described as obligatory. ${ }^{13}$

If the description in Philosophical Investigations is followed, two decisive lines of argument can be highlighted as relevant to this case. Firstly, Wittgenstein insisted that following a rule is not an interprettation in the sense of theoretical activity, in which a general rule of thumb can be applied to individual cases. The perception of rule-following as interpretation leads to a regression of rules for rules. ${ }^{14}$ This perception of rule-following must therefore be given up in language games. Wittgenstein is very direct about this matter: "That is not what we ought to say, but rather: every interpretation, together with what is being interpreted, hangs in the air; the former cannot give the latter any support. Interpretations by themselves do not determine meaning." (PI \$I98) Interpretation alone cannot determine sense, as is the salient point of this argument; and, hence, it follows that not every course of action can be equated with a rule. The linguistic remark "rule" is rather to be brought into line with a way of reacting that has been learned; and, in turn, that acquired knowledge is embedded in a suitable mode of action. In this case, Wittgenstein used the example of route marks, allied to the course of action, in order to follow the direction that they

$13 \mathrm{Cf}$. for a basic survey Tugendhat 1995, $42 \mathrm{ff}$.

${ }^{14}$ Cf. PI $\$ 86$; cf. also $\mathrm{Z}$ 229: "But an interpretation is something that is given in signs. It is this interpretation as opposed to a different one (running differently). - So when we wanted to say "Any sentence still stands in need of an interpretation', that meant: no sentence can be understood without a rider." 
show: "I have been trained to react to this sign in a particular way, and now I do so react to it.” (PI $\$ 198)$

Wittgenstein's response to the possible objection that recourse to an embedded way of acting only provides a causal and no normative explanation for rule-following, is the reference to existing habits. The resulting characterization of rule-following as a practice neatly summarizes the embedding of using rule-expression with ways of action that they determine (cf. PI \I98f., \$202). That is Wittgenstein's second decisive view on the question of following rules. The manner of using a linguistic expression has no immediate equivalent in grammatical form. That tells us as little as interpretation about the right way to use an expression without any doubt. In that sense, following rules is a practice and to understand rules means to know how to practice a technique: "To understand a sentence means to understand a language. To understand a language means to be master of a technique.” (PI \$I99) The link between rule expression and use in a particular context, which is fixed by routine practice, is itself a normative process, yet without necessarily relying upon an interpretation because of that routine. On the contrary, in the language game of practicing, it is not yet a use to follow a rule. The only course of action is therefore to oppose the practiced link of expression and use. In that case, however, another game is already being played:

You cook badly if you are guided in your cooking by rules other than the right ones; but if you follow other rules than those of chess you are playing another game; and if you follow grammatical rules other than such-and-such ones, that does not mean you say something wrong, no, you are speaking of something else. ( $\left.Z_{320}\right)$

The use of linguistic expressions must therefore be understood as an inter-subjective practice, as a custom, or even an institution. In that sense, the use hardly differs from games like chess.

Rule application always takes place on the basis of practice of usage and, in that way, the process is continued. Usage alone is a criterion to test if someone actually follows the rule. For that reason, rulefollowing not only implies an understanding of rule expression, but also of uses that are appropriate for the rules, or as Wittgenstein writes: 
"If language is to be a means of communication there must be agreement not only in definitions but also (queer as this may sound) in judgments.” (PI \$242) The connection of definitions and judgements that is alluded to here depends on the internal link between rule and application. Therefore, the agreement of individuals in language, that is, in their active use of linguistic mechanisms in language games is no agreement "in opinions but in form of life" (PI \$24I). By that, Wittgenstein means the respective association of activities and actions in language games, amongst those language games, and in human life as a whole.

If Wittgenstein's perception is correct, that a consensus of opinion is based on a consensus in language, and in turn, a consensus of life form, then this assumption also has consequences for understanding the anchorage of ethical norms. The argument implies, namely, that consensus must already exist in the judgements themselves, before the rules that hold sway in discourse ethics can even be effective in society. Wittgenstein's explanation of rule following suggests that it is inadequate to achieve consensus in the definition of a terminology. Rather, what is necessary is a further consensus of the manner of its application. Yet that way is only made manifest in the practice of rule-following, which in turn, constitutes a way of life. Even rules of discourse, therefore, only consist of a complexity of practices that are relative to the life form. For that reason alone, they are recognized as such and followed as rules. With Wittgenstein's description, rules of discourse cannot be viewed as procedural, first giving rise to rules of a specific moral code, and to a degree, applied as special cases. Rules devised from such theories for ethical-practical discourses are

[...] simply abstracted from, and not very far from, contemporary democratic culture. If no such culture existed, this particular version of a minimal morality would not even be plausible to us. (Walzer 1994, I3)

Even discourse ethicists, such as Habermas, work with rules that imply material and ethical preconceptions. Various social practices lead to particular moral ideas, for instance, the practice of government carries "ideas about the responsibility of governors toward the governed" 
(Walzer I994, I5). However, these ideas only function with specific cultural systems that, in turn, yield independent and varying forms. The kind of consensus on these practices that exists in such a system is not the result of a rational consensus building, but is rather created by a common way of life. Only this common aspect facilitates the identification of valid norms; and it can be described as a complex process of participation in socially diverse practices, language games and discourses that provide the context for what may be called in this sense the basis of a line of argument:

All testing, all confirmation and disconfirmation of a hypothesis takes place already within a system. And this system is not a more or less arbitrary and doubtful point of departure for all arguments: no, it belongs to the essence of what we call an argument. The system is not so much the point of departure, as the element in which arguments have their life. (OC, I05)

Language and modes of argument are rooted in behavioural patterns that are neither rational nor irrational, but precede any kind of intellectual process: "Language did not emerge from some kind of ratiocination." (OC, 475) Here, too, the limits of a way of thinking that is based on the paradigm of justification are made plain, for the identification with specific practices is not vouchsafed by reasoning, but is rooted in the way of action that is inherent to the language game:

Giving grounds, however, justifying the evidence, comes to an end; - but the end is not certain propositions' striking us immediately as true, i.e. it is not a kind of seeing on our part; it is our acting, which lies at the bottom of the language-game. (OC, 204)

It is essential, to recognize this aspect, if the peculiarity of Wittgenstein's illustration is to be correctly assessed and its limits to be correctly described:"Where two principles really do meet which cannot be reconciled with one another, then each man declares the other a fool and heretic." (OC, 6II) And immediately following that remark: "I said I would 'combat' the other man, - but wouldn't I give him reasons? Certainly; but how far do they go? At the end of reasons comes persuasion." (OC, 61 2) Emphasis on the limits of justification not only magnifies the limits of a rationalistic ideal of communication, as based 
on consensus, but it also prevents false notions of homogeneity in life forms that are distinct and separate. At this point, another aspect comes into play that is preferably neglected in discussions about life forms and rules. ${ }^{15}$ The agreement about which Wittgenstein speaks in his elucidation of the rule concept is not to be treated as though the rules of everyday action bring to light an implicit contextual knowledge and common procedures that are shared by all members of the society in question. Rather than searching for such common elements, Wittgenstein invites a perception of language as "a complicated network of similiarities overlapping and criss-crossing [...]”. (PI \$66), for which he uses the expression "family resemblances" (PI \$67). This method of comparing and contrasting phenomena in their vital functions is meant to liberate from static and hypostatic considerations. ${ }^{16}$ By pitting the family resemblance against the ideal of identity, Wittgenstein holds up a different method to the quest for unity that is meant to culminate in respect for the irreducible plurality and diversity of life forms and, so too, for the ways in which ethical discourses can be conducted. In Wittgenstein's view, there is no single, possibly more rational approach than other ways of following a rule:

Following a rule is analogous to obeying an order. We are trained to do so; we react to an order in a particular way. But what if one person reacts in one way and another in another to the order and the training? Which one is right? (PI $\$ 206)^{17}$

15 On this point, authors like Michael Walzer differ from Wittgenstein, as Walzer typically emphasizes identities and common interests (cf. Walzer 1994, 7-8, I6). The unquestionable condition of homogeneity also describes approaches that, acknowledging Aristotle, intend to establish ethics on the reflection of tested ethical practices. Cf. also the basic work of Schnädelbach (I986). Kambartel's critique of ethical pluralism also relies on this condition of a homogeneous, common life form (cf. Kambartel 1986, 98).

16 Cf. AWL, 34: „One of the ways of looking at questions in ethics about good is to think that all things said to be good have something in common, just as there is a tendency to think that all things we call games have something in common."

${ }^{17} \mathrm{Cf}$. also $\mathrm{Z}$ 430: "Our language game only works, of course, when a certain agreement prevails, but the concept of agreement does not enter into the language- 
This question emerges in every deep-seated moral conflict and, so Wittgenstein, it cannot be answered by reference to the so-called right interpretation of the rule that is meant to comprise the conclusion of a rational discourse. On the whole, rules function so well in social practice because they are not static and do not leave an open field for interpretation. Hence, in Philosophical Investigations, Wittgenstein already warns in his first discussion of the rule concept to overlook the diverse functions of rules within language games: "it can be said that what we call a rule of a language-game may have very different roles in the game." (PI \$53)

\section{IV.}

The illustrations of the connection of rule-following, language game and life form have shown how several of Wittgenstein's views permit a correction of existing perceptions, questions and methods in practical philosophy and suggest alternative approaches. Wittgenstein's way of discussing philosophical problems has proved fruitful for ethics, since it is possible to call into question these hastily ordered theoretical approaches that falsely promote unity in the diversity of ethical discourse. In conclusion, Wittgenstein's method and its relevance for ethics is to be more closely considered. An aspect of his thought that was briefly mentioned in the introduction is to be highlighted: namely, the exclusion of ethics from empirical life in favour of a mystical interpretation. In that way, greater attention is to be paid to the thesis, as mentioned in the introduction, that Wittgenstein rejected as a matter of principle the over-theoretical and scientific appropriation of ethical questions.

The distinctions between Wittgenstein's early position on ethics, in Tractatus, in the Lecture on Ethics and in his late works have so far not been mentioned here. ${ }^{18}$ Rather, the working premise was a basic

game. If agreement were universal, we should be quite unacquainted with the concept of it"

18 On the fate of ethics in Wittgenstein's late philosophy, cf. the detailed discussion in Barrett I99I, $227 \mathrm{ff}$. 
approach to ethical questions that runs through Wittgenstein's collected works (although in his later writings he no longer explicitely considered ethical questions at all). That approach was Wittgenstein's mistrust of scientific attitudes and theoretical models in ethics. ${ }^{19}$ His Lecture on Etbics is a work of transition. To be sure, this text still visibly depends on the world-view of Tractatus; and yet, it also points forward to the method of grammatical analysis of contexts of words and their uses, as is characteristic of his later philosophy (Weiberg 1998, 57f). Had Wittgenstein been consistent about applying the method of Philosophical Investigations to his Lecture on Ethics, then he would have concentrated on describing the role that value expressions and ethical judgements play in actions in individuals' lives. In that case, he would presumably have omitted to depict these ways of speech as inauthentic (uneigentlich) expressions for a thing, namely, for a unified conception of ethics as metaphysics, religion and aesthetics. ${ }^{20}$ In view of this shift of method, his Lecture on Ethics itself could fall under suspicion as metaphysics, since the focus is on the distinction of an absolute, inexpressible ethical sphere and a limited sphere in which language refers to facts alone. However, closer scrutiny of Wittgenstein's analysis of ethical language use in his Lecture on Ethics, yields another perspective that gives precedence to the thought of the ineffability of ethics and in that case, the actor is at once, as it were, pre-empted in his most original responsibility.

Wittgenstein anchors moral language usage to a pre-eminent way of applying the basic vocabulary of ethics. A myriad of applications is plausible for these words, yet for Wittgenstein, they have an elevated

19 Weiberg arrives at this result $(1998,58 f$.) The orientation by scientific methods and problem solving was, according to Wittgenstein, a main source of conceptual confusion: "Philosophers constantly see the method of science before their eyes, and are irresistibly tempted to ask and answer questions in the way science does. This tendency is the real source of metaphysics, and leads the philosopher into complete darkness." (BB, I 8).

20 See Bouveresse (1994, I03): "It is [in the late philosophy, J.K.] no longer a question of the inauthentic (uneigentlich) language of ethics missing something like the essence of its object." 
meaning, if they are used in an absolute grammatical sense, that is, without recourse to prescribed goals of action or measures of evaluation. This manner of application qualifies them as ethical terms and Wittgenstein seems to imply that they are then always used as equivalent according to the form, if they emerge in sentences that contain such absolute ways of application. Wittgenstein is therefore able to identify the moral judgements with the absolute application of these words, to dissociate them from judgements about facts (cf. LE, fff.). His analysis yields the result that expressions such as "good" or "duty" have no clear sense, since they are non-relative predicates. Nor can it be seen how an action is absolute, that is, without justification, if relative to something else. It is also unclear, how something to be preferred is to be justified by any other means than relative to a wish, that is, relative to something that is, in turn, an act of preference (cf. Tugendhat I995, 5 I). To adopt Wittgenstein's example, you can talk of "a right" road in a relative sense, namely, relative to a particular goal, "and it is quite clear to us all that there is no sense in talking about the right road apart from such a predetermined goal." (LE, 7) The idea of an absolutely right road "which everybody on seeing it would, with logical necessity, have to go" (LE, 7) is, however, as nonsensical as talking about an "absolute good" or "the good in itself". Each notion is based on a false idea of a state of affairs, in so far as it forces a particular way of action as a logical necessity that has itself "the coercive power of an absolute judge" (LE, 7). Wittgenstein drew the consequence that the absolute claim raised in ethical judgements - whether as propositions of duty or of the absolute good - place them on a higher plane than mundane statements of fact. As a result, ethics cannot be put into words and is transcendental (cf. TLP 6.42 I). The linguistic nonsensical "duty in itself" is, as with all talk of "absolute values" or an "absolute good", an expression of a vain attempt to transcend what can be expressed in a language that makes sense (LE, I If.).

Wittgenstein intensifies this view of ethical language still further, by locating ethics in the vicinity of mystical and religious experiences, as in Tractatus. To be sure, the link between the investigations of ethical language use, as in propositions of duty, and linguistic expression that 
he called mystical experiences, is not immediately transparent. You could talk of absolute experiences of value that rise above every conceptual determination. Wittgenstein counts a feeling for the facticity of the world amongst them, a feeling of absolute security and of being guilty (cf. LE, 8ff.). The flow of the argument further implies that by excluding ethics from empirical facts, Wittgenstein intends to point to its theoretical ineffability. Thus, justice cannot be done to Wittgenstein's unearthing of an ineffable realm of ethics, if one refers to logical analysis, neither one that reduces ethics to a series of factual statements, nor one recreating a special empirical function, such as expressing feelings, or persuading the adoption of practical actions. ${ }^{21}$ What is literally essential is the element of nonsense:

$[\ldots]$ not only that no description that I can think of would do to describe what I mean by absolute value, but that I would reject every significant description that anybody could possibly suggest, ab initio, on the ground of its significance. (LE, I I)

The sense of ethics and its higher meaning for humanity is manifest, as Wittgenstein asserts, in the fact that it cannot be designated an object of scientific research, since no principles, no theoretical tasks, no process of universality or analysis is adequate. Nonetheless, Wittgenstein's thesis of the ineffability of the ethical realm is no example of a positivistic attitude of superiority, intent on contesting the meaning of ethical questions with linguistically logical arguments. The need to confront ethical questions, above all, on the basic level of the right conduct of life, is rather a testament to human conduct as such. An individual way of life can neither be legitimized by scientific ethics nor merely dismissed by a logical and empirically motivated philosophy of language.

To take into account Wittgenstein's remarks, as already stated, on the relationship between subject, ethical will and world, as in Tractatus, it is possible to treat the absolute experiences of value described in the Lecture on Ethics as an attempt, albeit indirectly, to point to the irre-

21 The interpretation of ethical statements as expression of feelings or as orders dates back to Alfred Jules Ayer (cf. Ayer 1936, I I I). 
ducible character of ethics as it is relative to each individual. The reference is indirect, since even the experiences Wittgenstein describes are based on a characteristic misuse of language. The misuse lies in employing expressions in an absolute sense, when only a relative usage makes sense. Towards the close of his Lecture on Ethics, Wittgenstein therefore shifts into the use of the first person and invites the reader to recall similar experiences of this kind.

The emphasis on the function of the basic ethical vocabulary, in the light of this interpretation, would be less of an approach to a possible theory of moral language still to be achieved, than an indication of the inherently indeterminate nature of ethical speech. All talk of a unified interpretation, conforming to rules, is pointless. There can be no such interpretation with the aid of ethical values for actions that are unconnected to the particular situation and the identity of the actors involved. What someone says whilst describing individual actions is related to his attitude to his obligations, intentions or even relationships to others (cf. Cavell I999, 325). In that case, diverse and contradictory motives collide and lead to conflicts that give rise not so much to the question of which action is now objectively appropriate, but rather the more urgent question of our self-perception and knowledge of another, that is, also the question of our responsibility: "[T]he trunk and branch of responsibility are what you are answerable for. And where your conduct raises a question, your answers will again be elaboratives." (Cavell I999, 3 I2) This perspective on the behaviour of actors who evaluate their own and others' actions in a moral light, first studied by Wittgenstein, was described by Stanley Cavell by the concepts of justification and responsibility. To treat another individual in the right way, to pay him his due, implies an appeal to his own selfconsciousness, particular status, evaluation of his situation and demands upon him: "The problems of morality then become which values we are to honor and create, and which responsibilities we must accept, and which we have, in our conduct, and by our position incurred." (Cavell 1999, 325) Not the search for a justification of one's actions, which might well be accepted by any rational being, but rather growing aware of responsibility, in the sense of an assurance of per- 
sonal and another's standpoint in their respective contexts, such elements characterize Wittgenstein's confrontation with ethical questions, according to this view (cf. Cavell I999, 3 I 2).

The "re-personalization" 22 of morality that occurred with the rehabilitation of individual responsibility also includes the recognition of the restricted relative nature of the individual standpoint and an insight into the risks associated with every decision and evaluation. Even the reference to a general rule is no escape route. A positive weighting of material values, or even formal rules of behaviour, would suggest a certainty that would turn the moral content on its head, by depriving the actor of his sense of responsibility. To forego a positive moral discourse is one way to deal with this situation. To make decisions, to fulfil moral judgements and to defend standpoints are all actions performed by individuals who cannot rely upon metaphysical guarantees. Every application of a rule - as illustrated by our previous emphasis on rule-following - involves a step into open territory that is only possible because the actor always relies upon something:

I really want to say that a language-game is only possible if one trusts something, (I did not say 'can trust something'). (OC, 509)

The addition in parenthesis denotes a decisive difference from a way of thinking that seeks certainty in the form of rational justifications; and by drawing attention to the particular uncertainty that lies in every act of trust and precedes every rational justification within the language game.

The element of uncertainty in every act is, nonetheless, necessary, in order for the actor to trust in his own sense of responsibility. Uncertainty, 'the undecidable'23, and responsibility therefore shift into a line of association that is obscured by any ethics that set store by the possibility of a rational consensus. Paradoxically enough, such irrational aspects are part of the rationality of the moral sphere. They depend, as Gerhard Gamm put it, on the fact "that in the destruction of

22 The expression is attributable to Bauman (1993, 34).

23 Cf. further Derrida I992, 24-26. 
reasons, we become free to take over responsibility for others" (Gamm 2000, 246). The transcendental dimension of ethics, as postulated by Wittgenstein, would then not only be intended (in the sense of beyond the natural order (transcendent) but also in the Kantian sense of transcendental, as a condition for the possibility of responsible action. ${ }^{24}$

V.

The leading thesis of these discussions was that Wittgenstein's thoughts on ethics offer a possible alternative to the predominance of the traditional paradigm of practical philosophy. Wittgenstein's approach to ethical questions leads not only to a critique of the ideal of rational justification of norms. Instead, his approach promotes a critical assessment of traditional ethical theories. These theories not only oversimplify because they conceal the variety of moral discourses, but also because they are based on the idea of the homogeneity of ethical life forms. On this count, incidentally, Aristotleans join forces with their Kantian counterparts. No matter whether they pay service to Ethos, or to communities of discourse, either way, notions of identity and homogeneity about Wittgenstein's emphasis on difference are what prevail. The task of considering moral expressions and actions, as schooled by Wittgenstein's thought, would be to bring this aspect of difference decisively into the forefront of debate. The quest for a unified theory to assist the process of differentiation, - a process that every morally competent actor must know -, would be substituted by a grammatical investigation and description of language games in which ethical expressions emerge. That change of approach is to recognize the

${ }^{24}$ Similar ideas are referred to by Derrida: "The undecidable remains caught, lodged, at least as a ghost - but an essential ghost in every decision, in every event of decision. Its ghostliness deconstructs from within any assurance of presence, any certitude or any supposed criteriology that would assure us of the justice of a decision." (Derrida I992, 24f.) Derrida incidentally associated his studies on the "mystical ground of authority" with Wittgenstein's mystics (cf. Derrida I992, I4). 
contexts in which expressions are employed and to become aware of actual events, regardless of arbitrary theoretical demands, when a moral debate is ongoing, or in cases of moral judgements and action. Furthermore, the shift would lead to a reorientation from the mode of justification and determination to the mode of description and continual interpretation. It is not a vain hope for this approach to achieve greater sensitivity towards the variety of voices from which an ethical sense is borne; and, equally, towards the inherently indeterminate and ambivalent character of moral discourses in modern societies that are irreversibly pluralistic. In this regard, a reminder is not only apt, since every material or formal general moral code, as well as every run of the mill consensus of a moral majority, unavoidably threatens to suffocate those voices that are not willing or able to be convinced and to appropriate a moral code.

Even if this rudimentary programme were to be held appropriate and, considering that the philosophical self-enlightenment of the individual's relation to the world no longer offers metaphysical guarantees, the person who confronts ethical questions is, nonetheless, not relieved of the need to answer them in a decisive way in his unique and concrete situation, and without laying claim to a comprehensive philosophical explanation. All that such a person can be advised in view of his individual life, after all, leads to the trivial endeavour of solving practical problems that arise on a pragmatic, case by case basis.

\section{Translated by Suzanne Kirkbright}

\section{Bibliography}

Arnswald, Ulrich (1998): "The Tension at the Core of the Tractatus", in: Acta Analytica, Vol. 2 I, 49-56.

Ayer, Alfred Jules (1936): Language, Truth and Logic, London 1936.

Barrett, Cyril (r99i): Wittgenstein on Ethics and Religious Belief, Oxford I99I.

Bauman, Zygmunt (1993): Postmodern Ethics, Oxford 1993. 
Bouveresse, Jacques (1994): Poesie und Prosa. Wittgenstein über Wissenschaft, Ethik und Ästhetik, Düsseldorf 1994 .

Cavell, Stanley (1999): The Claim of Reason. Wittgenstein, Skepticism, Morality, and Tragedy, Oxford 1999.

Derrida, Jacques (1992): Force of Law: The Mystical Foundation of Authority, in: Drucilla Cornell / Michel Rosenfeld / David Gray Carlson (eds.), Deconstruction and the Possibility of Justice, London I992, 3-67.

Gamm, Gerhard (2000): Nicht nichts. Studien zu einer Semantik des Unbestimmten, Frankfurt/Main 2000.

Habermas, Jürgen (1993): Justification and Application. Remarks on Discourse Ethics, translated by Ciaran Cronin, Cambridge / MA I993.

- (1996): Between Facts and Norms. Contributions to a Discourse Theory of Law and Democracy, translated by William Rehg, Cambridge 1996.

- (2000): „Werte und Normen. Ein Kommentar zu Hilary Putnams kantischem Pragmatismus“, in: Deutsche Zeitschrift für Philosophie, Vol. 48, 547-564.

Kambartel, Friedrich (1986): Begründungen und Lebensformen. Zur Kritik des ethischen Pluralismus, in: Wolfgang Kuhlmann (ed.), Moralität und Sittlichkeit. Das Problem Hegels und die Diskursethik, Frankfurt/Main I 986, 85-100.

Kross, Matthias (1993): Klarheit als Selbstzweck. Wittgenstein über Philosophie, Religion, Ethik und Gewißheit, Berlin I993.

Putnam, Hilary (1992): Renewing Philosophy, Cambridge / MA I 992.

Rhees, Rush (1970): Some Developments in Wittgenstein's View of Ethics, in: Rush RheEs, Discussions of Wittgenstein, London I970, 94-IO3.

RORTY Richard (1993): Trotsky and the Wild Orchids, in: Mark Edmundson (ed.), Wild Orchids and Trotsky. Messages from American Universities, Harmondsworth: Penguin Books, 29-50.

SchnädelbaCH, Herbert (1986): Was ist Neoaristotelismus? in: Wolfgang Kuhlmann (ed.), Moralität und Sittlichkeit. Das Problem Hegels und die Diskursethik, Frankfurt/Main: Suhrkamp i 986, 38-63. 
Tugendhat, Ernst (1995): Vorlesungen über Ethik, Frankfurt/Main I995.

Walzer, Michael (1994): Thick and Thin. Moral Argument at Home and Abroad, Notre Dame 1994.

Weiberg, Anja (1998): Und die Begründung hat ein Ende. Die Bedeutung von Religion und Ethik für den Philosophen Ludwig Wittgenstein und das Verständnis seiner Werke, Wien 1998.

Wolf, Ursula (1999): Die Philosophie und die Frage nach dem guten Leben, Hamburg 1999. 



\section{The Convergence of God, the Self, and the World in Wittgenstein's Tractatus}

\section{John Churchill}

\section{Clearly Wrong}

In this paper I aim to explain a peculiar aspect of the picture of logic, language, and the world in Wittgenstein's Tractatus. In that picture, logic and language limn the domain of sense, which corresponds to the world of facts, and exclude the domain of nonsense, occupied by philosophical explanations of logic, by aesthetics, by ethics, and by all talk about God, meaning, and value - a domain properly consigned to silence. What Wittgenstein says about this latter domain is a particularly elegant amalgam of insights and themes from an astonishing variety of sources. And yet - this is the peculiar aspect - it clearly cannot be correct. Seeing that it cannot be correct, and understanding why it cannot be correct are the two aims of my explanation.

In a nutshell, the explanation is this: Wittgenstein's picture demands a convergence of three concepts: God, the self, and the world. Attractive as this convergence may be, to certain sorts of pure mystics, it cannot be correct. If God, the self, and the world were all the identical selfsame thing, all our beginning intuitions - the otherness of the world and of God, and our own individuation, would be inexplicable. But in a matter of this sort, as Wittgenstein himself says in Zettel, "slow cure is all important" (382). One reason the slow cure is important is that it will assist our seeing that this convergence is also implicit elsewhere in the Western philosophical tradition. That, in turn, will lead to a deeper appreciation of the way in which Wittgenstein's rejection of this element of the world-view of the Tractatus is also a rejection of a central feature of much of the philosophical tradition. 
I aim to show that the Tractatus stands, perhaps alone with Spinoza's Ethics, as the purest and most unrelenting effort to articulate a world-picture in which logic entails a mystical union of the self with the world and with God. As such, the Tractatus, along with the Ethics, stands as monumental evidence that this perspective, worked out systematically and thoroughly, cannot produce a consistent or a liveable conception of the place of human being in the world. The perspective presupposed and worked out in each work is not that of a human being, merely, but of a human being who approaches union with God, a God who is at the same time identical with the world itself. And this is not a perspective a human being can indwell. But showing this will require some discussion. Let us enter the slow cure.

At a philosophical conference in Louisville, Kentucky, several years ago, a listener to a paper on the Tractatus asked, in a grumpy tone, "Why study something that is clearly wrong?" The answer, surely, is that we can learn from important mistakes. But the notion that some philosophical position could be "clearly wrong" has interestingly multiple senses. A claim could be clearly wrong in being obviously mistaken. We might hold a position to be clearly wrong in this sense without suggesting that we can state how it is wrong. Wittgenstein holds that there is no self, and yet that "I am my world." Even if we don't know how to refute him, and can't say just where his argument went astray, we may say, with justification, “That can't be right!” Let us call this status "obviously wrong." Second, a claim could be clearly wrong in the sense that it is perspicuously clear how it's wrong. When we see that Wittgenstein's commitment to atomism is premised on the idea that every proposition must have an absolutely determinate sense, and that he adopted this stricture from Frege, we may rightly feel that we have seen just how the position has gone wrong. Let us call this status "perspicuously wrong." Third, there is a sense in which some claims are clearly wrong in that they transparently and cogently open to our view the way in which other claims - perhaps whole domains of inquiry and explanation - are wrong as well. If we become convinced that the problems of perspective exhibited in Wittgenstein's Tractatus show - in their clarity - what is wrong with any such attempt, this 
realization can offer a panoramic view of a whole sea of error. We could call this status "importantly wrong."

My claim is that Wittgenstein's view of God, the self, and the world in the Tractatus is clearly wrong in the first and second senses, and that a due consideration of the character of his great mistake can let us see it as wrong in the third sense as well. Wittgenstein's mistake is a "great" one in two senses: it is a big, grave mistake, but it is also an important one. There is no put-down in this diagnosis. Some philosophical mistakes are tremendously important, as he acknowledged in Zettel: "In a certain sense one cannot take too much care in handling philosophical mistakes, they contain so much truth" (460). If Wittgenstein is obviously, perspicuously, and importantly wrong, the Tractatus may constitute a reductio argument, the reductio ad absurdum of rationalism. It will, though, show us less how to avoid and disdain an error, than how to recognize and cope with one of the enduring tendencies and most alluring temptations of philosophical reflection. Wittgenstein lived to diagnose his own tendency and to struggle, in his later work, against the temptation. Clarity about the fundamental problem with the Tractatus - its ultimate conflation of God, the self, and the world - is a necessary prodadeutic to understanding Wittgenstein's later work.

In his Preface he acknowledges that on the logical side his precursors are Russell and Frege. But beyond that, he gives stark discouragement: "[...] [T] he reason why I give no sources is that it is a matter of indifference to me whether the thoughts that I have had have been anticipated by someone else." We cannot share his indifference, because the implications of understanding even his mistakes depend on our seeing their relation to the often momentous projects that other philosophers have undertaken. And so the multiple roots of Wittgenstein's thought in the Tractatus have been amply documented. As is shown in Janik and Toulmin's Wittgenstein's Vienna, he drew, for example, from the cultural milieu of late Habsburg Vienna. In the English-speaking world he drew from Bertrand Russell, George Edward Moore, and others. Continental philosophers who influenced him include Tolstoy and Dostoyevsky. He certainly drew freely from Schopenhauer. 
A closer look at these influences will assist us in grasping Wittgenstein's conception of his problems. Paul Engelmann writes of Wittgenstein's "unreserved admiration and respect” for Tolstoy (1967, 79), an admiration manifest in Wittgenstein's predilection for spiritual simplicity, his tendency to seek out common and lowly positions cottager in Norway and Ireland, gardener, village school teacher, hospital porter - and his distaste for the trappings of donnish prestige at Cambridge. Georg Henrik von Wright writes of Tolstoy's "strong influence on Wittgenstein's view of life" (1972, 10), and Wittgenstein himself wrote to Ludwig von Ficker that Tolstoy's The Gospel in Brief virtually kept him alive at points during the war (Monk I990, I 32).

What does this Tolstoyan influence amount to? Brian McGuinness has noted that the passage 6.43II-6.43I 2 in the Tractatus closely parallels Tolstoy's contention that true life is non-temporal and is lived in a continuous present. From Tolstoy he drew the idea that spiritual truth must be simple, that it must be accessible without learning, and that it is most likely to be embodied in the humblest among humanity. This set of ideas strikes, of course, a familiar chord in traditional Christian thought, and with it comes an imperative to regard complexities of thought as obstacles to be overcome. This is one of the roots of the doctrine of ineffability: if the most adequate doctrines are the simplest, ultimately they cannot even be spoken, and thus are not doctrines at all. The best spiritual testimony is to be found, silently, in the good lives of plain people. This lesson must have gained strong reinforcement in Wittgenstein's affirmation of Dostoyevsky's Alyosha Karamazov, whose quiet virtue distinguishes him from his brothers, one lost in dissipated living, the other in philosophical quandaries.

Russell's influence was not limited to logic. In I9I3, Russell published in The Hibbert Journal, a now-famous article called "Mysticism and Logic." In this essay, well-analyzed by Brian McGuinness in his article "The Mysticism of the Tractatus," Russell outlines a particular strand of mystical thought with a long philosophical pedigree. Its distinctiveness is two-fold. First, it is rooted in doctrines of logic, and second, whatever its particular occasion of expression, it has four consistent tenets: (I) the underlying unity of everything; (2) the unrea- 
lity of time; (3) an overarching absolute value that subsumes all other; and (4) the availability of an experience of insight in which the first three tenets are disclosed. Russell finds this pattern in a variety of religious and philosophical traditions; he published this article shortly after Wittgenstein's association with him. Perhaps then it is not surprising to find all these tenets in the Tractatus. Russell's "logical mysticism" is the pattern to which the mysticism of the Tractatus is cut.

It is also highly likely that Wittgenstein was influenced in the development of ethical themes in the Tractatus by direct or indirect contact with George Edward Moore, the Cambridge philosopher whose Principia Ethica (1903) set the tone of discussion about value for a generation of English intellectuals including most famously the Bloomsbury group - Leonard and Virgina Woolf, Lytton Strachey, John Maynard Keynes, and others, tightly connected with intellectual currents at the Cambridge college, Trinity, where Russell and Wittgenstein collaborated. Michael Hodges has developed this likelihood, pointing out that Moore's intuitionism called for a wordless, definitionless, immediate recognition of value.

But of all the influences on the suppressed metaphysics of the Tractatus (as distinct from the logic), the most obvious and direct is that of Schopenhauer. The themes Wittgenstein sets out to develop in the Notebooks are drawn with, initially, little modification from The World As Will and Representation. Wittgenstein undertakes in those Notebooks to explore the problem of the individuation of the self to whom the world is presented, the relation between the will as subjectively experienced in one's own body and the metaphysical will as the inner nature of all reality, and the sense in which there is truth in solipsism. All of these are characteristically Schopenhauerian versions of common philosophical problems. Even the convergence of God, the self, and the world is already evident in these early thoughts. Taking a page from Schopenhauer, Wittgenstein already articulates the idea that oneself is the microcosm, and "I am my world" (NB, I 2.I0.16). While at the same time, "my will is the world-will" (NB, I7.I0.I6). The affinity for solipsism is traceable to Schopenhauer's influence (cf. NB, 23.5.15), and the dismissal of scepticism about the existence of an 
external world as a non-question (TLP 6.5 I) is a virtual echo of Schopenhauer: "After an examination of the [...] real character of sense perception, the question itself was bound to disappear, because there was no longer any meaning in it" (I969, I, I6).

Despite this clear and immediate derivation of problems and development of strategies from Schopenhauer, it is still the case that the sort of solution the Tractatus embodies takes Wittgenstein into the mainstream tradition of philosophical mysticism, where his great likeness is with Spinoza. That comparison awaits us in a later section of this paper.

\section{I Am My World}

Wittgenstein's solution to the problems of philosophy - all of them was to show them to be non-problems. A clear view of the logic of language and of its relation to the world would show that the questions of philosophy are pseudo-questions, nonsensical expressions which have no answers because they ask nothing. The vanishing of these pseudo-problems takes away the possibility of saying anything meaningful about philosophy, ethics and aesthetics, value, God, the self, or the meaning of life or of the world. He accomplishes this result between two remarkable bookend propositions: "The world is all that is the case." (TLP I), which opens the Tractatus, and "What we cannot speak about, we must pass over in silence." (TLP 7), which closes the book.

In our admiration of the logical elegance of his maneuvers, we cannot forget that the project grew from a sensibility anchored by staunch adherence to the principle that sense must be determinate that is, that at bottom the world and language must have absolutely sharp edges. It is easy to see the appeal of this commitment: it is the Law of the Excluded Middle, the world of "Yes or No," "On or Off." Terry Eagleton's script of the Derek Jarman film Wittgenstein places the following words in the mouth of a character based on the economist John Maynard Keynes, who says of Wittgenstein, 
There was once a young man who dreamed of reducing the world to pure logic. Because he was a very clever young man, he actually managed to do it. And when he'd finished his work, he stood back and admired it. It was beautiful. A world purged of imperfection and indeterminacy. Countless acres of gleaming ice stretching to the horizon. So the clever young man looked around the world he had created, and decided to explore it. He took one step forward and fell flat on his back. You see, he had forgotten about friction. The ice was smooth and level and stainless, but you couldn't walk there. So the clever young man sat down and wept bitter tears. But as he grew into a wise old man, he came to understand that roughness and ambiguity aren't imperfections. They're what make the world turn. $\mathrm{He}$ wanted to run and dance. And the words and things scattered upon this ground were all battered and tarnished and ambiguous, and the wise old man saw that that was the way things were. But something in him was still homesick for the ice, where everything was radiant and absolute and relentless. Though he had come to like the idea of the rough ground, he couldn't bring himself to live there. So now he was marooned between earth and ice, at home in neither. And this was the cause of all his grief. (Eagleton 1993, I42)

But let us explore that world of ice. The world is all that is the case. What can be the case are facts, and facts have a definable nature: they are composed of objects. Objects correlate with names; names combine into propositions; propositions depict possible facts, and the totality of possible propositions - the exhaustive extent of what can be said composes the whole of language. Language and the world, then, are two great, articulated systems, each mirroring the other, coextensive in their bounds. Outside those bounds there is nothing, and there nothing can be said.

Both the propositions of language and the facts of the world are structured according to logical form. To speak of logical form is to speak of the possible propositional combinations of the representatives of objects, and hence, about the possible combinations of objects themselves in states of affairs. This correlation of language with the world must be based at an atomic level, where absolutely simple signs are arrayed relative to each other in elementary propositions in ways that mirror the logical form of elementary facts - the arrangement of 
their unanalyzably simple constituents, or objects. It is essential to a proposition that it have a determinate sense, capable of being true or false. And if sense is to be determinate, analysis must come to an end: therefore there must be simple constituents of propositions and of the facts they depict.

A proposition shows its sense; that is, in its form it depicts the fact that is the case if it is true. And it says that "This is how things stand." Wittgenstein distinguishes clearly between what language says, which is, again, "This is how things stand." (cf. TLP 4.5), and what a proposition shows, which is how they do stand. This distinction is important because "What can be shown cannot be said." (cf. TLP 4.I2 I2) And while language is restricted to saying, in effect, "It's like this," the "this" being a reference to what the proposition shows, propositional language cannot say how things stand; nor can it say how it shows it. So there is no science of logic, no discourse of philosophy. But the Tractatus itself of course is exactly that.

So the Tractatus is composed of propositions which are, by its own standards nonsense. But instead of an embarrassment, the self-destructtive bent of Wittgenstein's doctrines is a touch of consummating elegance. In reaction to the threat of infinite regress of metalogical explanations posed by Russell's theories of logic, Wittgenstein proposed that logic must take care of itself. And that doctrine itself disappears so that logic may, in fact, do so.

Like logic itself, all the problems of philosophy vanish into the realm of the ineffable. For example, scepticism disappears: "Scepticism is not irrefutable, but obviously nonsensical, when it tries to raise doubts where no questions can be asked." (TLP 6.5I) And solipsism, with which Wittgenstein toyed for largely Schopenhauerian reasons, is strangely affirmed. But it amounts to nothing other than realism. Since the world is all that is the case, there can be no subject beholding it, so he affirms realism; i.e., the disappearance of the subject. On this reading there is no subject, and solipsism offers no substantive alternative to realism. But Wittgenstein says that what the solipsist wants to say is correct. What does he mean? 
The self, as he describes it, is not essentially correlated with any human body: "[...] [M]y body [...] [he writes] is a part of the world among others[...]" (NB, 2.9.16), and "[w]hoever realizes this will not want to procure a pre-eminent place for his own body[...]" The self of this solipsism is a transcendent metaphysical subject-albeit a vanishing one - with which the totality of facts - reality, the world is coordinated.

Along with this vanishing of the self, Wittgenstein insists that within the limits of language and the world, everything is valueless. On the linguistic side this assertion means that "It is impossible for there to be propositions of ethics" (TLP 6.42), while in the world "everything happens as it does happen: in it no value exists, and if it did exist, it would have no value." (TLP 6.4I) A purported ethical proposition since it would have to mention a value and since that value could not obtain as an object in a fact - would contain a nonsensical sign. Such a purported proposition could not have a proper logical form, and would be itself nonsensical.

Having disavowed any special standing or preferential consideration for the human body coordinated with the solipsistic subject, and having banished value from the world, Wittgenstein produces a curious set of remarks about happiness. It consists in a certain attitude toward the facts, namely, the attitude of wonder at the existence of the world. "It is not how things stand in the world that is mystical," he writes, "but that the world exists" (TLP 6.44). The factuality of the world, then, is the beginning point of the mystical. But for the "fact" that the world exists to have a mystical significance, there must be a substantive solipsistic self outside the world for whom it has that significance, and in whose will - of attunement or agreement with the facts - that significance inheres. There must be a self for whom "the world of the happy man is a different one from that of the unhappy man" (TLP 6.43). This view of the world sub specie aeterni depends on the status of the metaphysical subject at the limits of the world-the self of transcendental idealism. In this way the whole realm of the mystical depends, for its integration into the mainstream of the Tractatus, on the correctness of this substantive solipsism. This must be what Wittgen- 
stein means in writing: "[...] [W] hat the solipsist means is quite correct, only it cannot be said, but makes itself manifest" (TLP 5.62).

It seems as if Wittgenstein's discussion of happiness pertains to the psychological states of an embodied subject, a human being in the world. But this picture, to which we seem repeatedly driven, is ruled out by his assimilation of the phenomenal self into the world of facts. We then gravitate toward another picture - a transcendent metaphysical self to whom the world appears, capable of an attitudinal will that may affirm or struggle with it. But this picture is also ruled out, because it posits something beyond the facts, and violates the basic dictum that "The world is all that is the case." Neither picture is consistent with Wittgenstein's fundamental system, and yet both are apparently required to make sense of what Wittgenstein says about value, the will, and happiness. The combination cannot be reconciled. But Wittgenstein's vision would be true only for a subject that was the sole observer of the world, and a pure intellect, a subject who was, while retaining an individuated perspective, also, in a sense, the world's consciousness of itself. If we begin with the individuated subject, everything about it - body and perspective - must get pushed out into the world of facts until we are left with a point of view held by no one - the vanishing solipsistic subject of the Tractatus. And what we are left with is the world-everything. Only the God of pantheism could be construed as the self of Wittgenstein's mysticism.

The idea of God is the idea of a standpoint that brings everything into a single field and thus renders an intelligible totality - a whole. This standpoint corrects all partial perspectives by completing them, and in a determinate way fixes every individual thing and the totality as what it is. God is, then, that perspective from which things appear as they are. But a substantive God, regarding the world from the outside, would raise new problems. First of all, an extramundane God, like an extramundane self, would be something being the case beyond the world. Second, we should ask whether such a God has a representation of the world. If so, where is it? If it is in the world, then the world contains a perfect replica of itself - an impossibility. Or if that representation is not in the world, then we have another violation of the 
basic itself that the world contains all that there is. And if the world is not represented to God, then in what sense does God apprehend the world? God's representation of the world, and thus God's own being as an omniscient subject, can only be the very being of the world itself. Just as the self of solipsism collapses without remainder into the world, so the God of the omniscient perspective collapses in - as it were from the other side - without remainder. "The world is all that is the case." (TLP I)

This analysis clarifies the manifold problem of understanding how there is a subject, while at the same time there is no subject, and yet somehow also the subject is identical with the totality of the facts as a whole - the world, while, further, the facts themselves in that same totality are God. The world in its logical order as a whole simply is God and the self is the same. That is why the self - divorced from the body and from an individuated perspective - vanishes, and yet persists as a sole, limiting perspective, and in that role tends toward absorption into both the world itself and into a God's perspective on the world. Similarly, logical clarity about the order of the world, seeing it sub specie aeterni, as a whole limited by logic, simply is seeing its sense; i.e., seeing what the world shows, which is just that it is there. This awareness solves the problems of the will and of happiness, since there is, from this vantage point, nothing to say about value. There is just the world of facts, laid out in their inevitability.

It is important to see that this solution is a version of the classical mystical perspective. It entails that the self is one with the world and with God. Accordingly, there is in this perspective the problem how to assert this unity in a way that evades both unintelligibility and falsehood. Beyond that, the mystical solution provides a vantage point from which it is hard to see or explain how we could have been deluded in the first place: who is it who is unclear about logic, in the Tractatus? Finally, the solution, however appealing intellectually and spiritually, leaves the embodied human subject in a position that is very hard to account for conceptually, and impossible to live out. It will be instructtive to compare this philosophical predicament with the view of God, self, and the world in Spinoza's Ethics. 
III. The Very Love With Which God Loves Himself

The likeness of the Tractatus to Spinoza's Ethics was first noted by George Edward Moore. In the discussions surrounding the publication of the book in England and its translation into English by C.K. Ogden, Wittgenstein's advocates in that country discussed various titles. After consideration of simply Philosophy, and Philosophical Logic, the Latin title was suggested by Moore. Superficially, the Tractatus has an organization that is reminiscent of the Ethics. Short, numbered entries arranged in a tightly constructed logical order, using extreme condensation of expression in a style intended, in its rigor, to echo the precision of mathematical reasoning. Each deals with absolutely elemental concepts: substance, attribute, being, and logic, world, object. And each moves from a logical consideration of what - in the most elemental sense - there is, to a set of dicta regarding the relation of the individual to God and the world as a whole, linking logic with mysticism. Both Spinoza and Wittgenstein produce systems in which clarity of logical insight yields an apprehension of ultimate meaning, the sense of things of which mystics have spoken.

Spinoza's core thought is that there can be only one substance, an infinitude we call God, or Nature. Mind and body are not substantial categories, but attributes which the mind perceives as constituting the essence of substance. But they are not different orders of being. Spinoza must be taken at his word in remarks like this: "The idea of the body and the body itself, that is, the mind and body, are one and the same individual, which is now conceived under the attribute of thought, and now under the attribute of extension." (Ethics, Pt. II, Prop. XXI, Note.) This remark is typical of a dominant thread in Spinoza, emphasizing the substantial identity of things perceived under the attribute of thought (as mind) and under the attribute of extension (as body); that is, emphasizing that they are the same thing, perceived under different essences. It is in this spirit that Spinoza can assert the identity of God and Nature. This is the burden of Prop. VII in Pt. II: "The order and connection of ideas is the same as the order and connection of things." He means not just that there are two isomorphic 
orders, but that there is only one ordering of things, perceived in one way as bodies and in another as ideas. It is with this in mind that we must approach his account of the formation of adequate and inadequate ideas, the activity and passivity of the mind, and their relation to the emotions and to happiness.

The aim is to understand Spinoza's idea of the intellectual love of God which makes it conceptually impossible to hope that God should love in return (Ethics, Pt. V, Prop. XIX), because it is, in fact, the very love with which God loves himself (Ethics, Pt. V, Prop. XXXVI). The route to this comprehension is through the doctrine of knowledge.

Spinoza holds that there is no contingency in the nature of things, but that all things are determined and necessitated in their being (Ethics, Pt. I, Props. XXIX, XXXIII). Consequently, an adequate knowledge of things must consist in knowing them in their determination and necessity; that is, in relation to their causes. And as this sort of knowledge is an activity of reason (Ethics, Pt. II, Prop. XLIV, corollary), with regard to such knowledge the mind is active. The mind, then, is active in entertaining ideas of things in their necessary causal order (i.e., as eternal); that is, the mind is active in having adequate ideas. Inadequate ideas, on the other hand, are suffered by the mind. So the growth of knowledge in the acquisition of adequate ideas correlates with the growth of the mind's rational activity. This correlation is important, among other reasons, in its relation to the origins of the emotions.

An emotion, Spinoza says, is a modification of the body. If we are the cause, it is an action, and a source of joy. If another is the cause, it is a passion, and a source of suffering (Ethics, Pt. III, Prop. I). He passes immediately from this stipulation to this corollary: "Hence it follows that the mind is more or less subject to passions according as it has more or less inadequate ideas, and, on the other hand, to more action the more adequate ideas it has." The route, then, from the unhappiness of suffering to the happiness of action is the progress from undergoing the passion of inadequate ideas to undertaking the activity of entertaining adequate ones, and since the having of adequate ideas is seeing them according to reason, that is to say, in their necessary and eternal 
causal order, it follows that the life of knowledge in reason is the happy life. Or to put it another way, happiness is seeing the world sub specie aeternitatis.

The implication of this scheme emerges early in the Ethics. Already in Pt. II Spinoza writes:

"The human mind is a part of the infinite intellect of God, and thus when we say that the human mind perceives this or that, we say nothing else than that God, not in so far as he is infinite, but in so far as he is explained through the nature of the human mind, or in so far as he constitutes the essence of the human mind, has this or that idea." The thought emerges again explicitly late in the text: "Our mind, in so far as it understands, is an eternal mode of thinking, which is determined by another eternal mode of thinking, and this one again by another, and so on to infinity: so that they all constitute at the same time the eternal and infinite intellect of God.” (Ethics Pt. V, Prop. XL, Note)

To sum this up, Spinoza's system, then, is one in which the individuated mind and the individuated body are substantially identicalthe same thing - considered once under the aspect of ideas and once as among extended things. The whole order of things is substantially one, as God or as Nature. And the individual mind, growing in its understanding of the rational order of things, participates in the mind of God. If it could grow infinitely in knowledge, it would be that mind. Thus its love for God cannot be returned, for the love of God is not a different love: "The mental intellectual love towards God is the very love of God with which God loves himself [...] in so far as he can be expressed through the essence of the human mind considered under the species of eternity" (Ethics, Pt. V, Prop. XXXVI).

The individuated human mind must come to a realization - with the growth of its action and happiness, its entertainment of adequate ideas and its apprehension of the world under the aspect of the eternal - of its identity with the mind of God. What's the problem here? 


\section{Importantly Wrong}

The likeness of this outcome to Wittgenstein's is too striking to be coincidental. The explanation for the likeness is that both Wittgenstein and Spinoza attempt with exemplary rigor to work out a fully analyzed account of the relation of reason - the mind's possession of adequate ideas, for Spinoza, and for Wittgenstein, the structure of propositions and their semantic relation - to the world. Both, in so doing, arrive at conclusions which identify the world, in the eternity and necessity of the logical relations of its constituents, with God, and the knowing self, in so far as it achieves adequate understanding, enters into this complex, making it a unified triad of world, self, and God. And for both Wittgenstein and Spinoza the unity of the triad is the fulfilment that resolves life's problems.

Spinoza, of course, evoked outrage from the orthodox of all stripes, being expelled from the Amsterdam synagogue with elaborate curses, despised by Catholic and Protestant alike, and suffering the most ironic of indignities-being excoriated as an atheist by David Hume. Wittgenstein evoked only puzzlement, perhaps most of all from the brisk, science-minded philosophers who had expected him to share their atheism and their general disdain for religious thought. But both drew the reactions they did because they articulated the traditional essence of mysticism: the ideas that all - call it world or God - is ultimately one, and that one's self is somehow identical with that great unity.

There is, of course, another problem with this mysticism. How can we understand the assertion of the identity of the individual with the world and with God. If the self is unified with God and the world, how is it that we begin with a perspective that is individuated and partial? Why is there unclarity about logical form? How is it possible that there are inadequate ideas? There must be some truth in individuation in order for error to be possible, in order for there to be such a thing as striving toward a realization of the truth. And once truth is articulated and gained, how it is that our perspective remains individuated and partial? How can the world, having waxed with meaning, 
wane again? How, having seen the world sub specie aeternitatis, can I remain plagued with partial knowledge? I believe that much of the tortuous detail work in Spinoza's Ethics and in Wittgenstein's Tractatus is the attempt to weave continually back into the individuated perspective from a progression of thought that is headed out toward unity with God.

That detail work is tortuous because the perspectives cannot be made to coincide. For the perspectives to coincide the individuated perspective would have to remain its individuation (and thus be one perspective among many, a part of the whole) while at the same time being the universal perspective itself. Leaving aside the problem of imagining what "the universal perspective" could possibly be, we can see that for the two to coincide would be this: that the big picture contains itself, in itself, as one part among many. In Philosophical Investigations Wittgenstein entertains the idea of a city that contains in a central square a map of itself. Suppose that this map contains a depiction of the square, and of the map itself, within which would have to be a depiction of the square and the map again, within which [...], and so on infinitely. What this shows is that under the rigor of fully explicit analysis, the idea of a whole containing itself as one of its parts yields a vicious infinite regress. That is to say, it is logically impossible. And that means that it is incoherent to suppose that a perspective can assume the viewpoint of God while retaining any semblance of individuation as an item within the world that is depicted. The standpoint cannot be attained because it is logically impossible.

Furthermore, unavoidable facts of everyday life offer constant reminders that the philosopher views the world from a partial, individuated perspective. This problem is insuperable for anyone who attempts to live out the world-picture of either book, as Wittgenstein attempted with the Tractatus. Perhaps the most revealing comment on the unliveability of the Tractatus is Wittgenstein's confession in a letter to Paul Engelmann: "I am in a state of mind that is terrible to me [...] it is the state of not being able to get over a particular fact" (Engelmann, 33). If the self has vanished, and all particular facts are valueless, how could this predicament occur? 
Let me now try to state the problem more generally, and in so doing show that Spinoza and Wittgenstein are importantly wrong in the same way. There is a fundamental conceptual problem: it consists in the attempt to articulate a system in which the perspective from which the system is developed is an item in the system itself. The perspective of the system will be prone to the absurdities of self-reference. It must depict itself as an item within its own act of depiction: it must contain itself. Both Wittgenstein and Spinoza attempt to finesse this contradiction by inconsistently moving from one standpoint to the other and back again - that is, from the standpoint of the individuated human subject, body and all, to the standpoint of the transcendent, nonindividuated subjectivity of God, while attempting - both of them to reconcile the inconsistency by bringing both subjects into identity with the world itself.

How does this show that they are importantly wrong? The inclination they manifest clearly - so clearly that it becomes actually possible to see how it is wrong - is the inclination to portray our apprehension of the world on the model of a subject who surveys it from no particular perspective - from everywhere and nowhere, a perspective which is not essentially related to a particular, embodied, culturally and historically conditioned human being. It is what Thomas Nagel has called "the view from nowhere". And its corrective is the perspective of the later Wittgenstein, locating our rationality in the context of "the natural history of humanity," not in the abstract thought of a lone subject yearning for union with the world and God.

\section{Bibliography}

Eagleton, Terry (1993): Wittgenstein. The Terry Eagleton Script. The Derek Jarman Film, London 1993.

Engelmann, Paul (1967): Letters from Ludwig Wittgenstein. New York 1967.

Hodges, Michael (1990): Transcendence and Wittgenstein's Tractatus, Philadelphia 1990. 
Janik, Allan / Toulmin, Stephen (I973): Wittgenstein's Vienna. New York 1973 .

McGuinness, Brian (1966): “The Mysticism of the Tractatus", in: Philosophical Review, Vol. LXXV, 305-328.

Monk, Ray (1990): Ludwig Wittgenstein: The Duty of Genius. New York I990.

Moore, George Edward (1903): Principia Ethica, Cambridge 1903.

Russell, Bertrand (I9I4): "Mysticism and Logic", in: The Hibbert Journal, Vol. I 2 (July I 9I4), 780-803.

Schopenhauer, Arthur (1969): The World as Will and Representation, 2 Volumes, translated by E.F.J. Payne, New York I969.

Wright, Georg Henrik von (1972): Biographical Sketch, in: Norman Malcolm: Ludwig Wittgenstein. A Memoir, New York 1972. 


\section{'Objectively there is no truth' - Wittgenstein and Kierkegaard on Religious Belief}

\section{Genia Schönbaumsfeld}

Kierkegaard's influence on Wittgenstein's conception of religious belief was profound, but this hasn't so far been given the attention it deserves. Although Wittgenstein wrote comparatively little on the subject, while the whole of Kierkegaard's oenvre has a religious theme, both philosophers have become notorious for refusing to construe religious belief in either of the two traditional ways: as a 'propositional attitude' on the one hand or as a mere 'emotional response' with no reference to the 'real world' on the other. This refusal to play by the orthodox dichotomies, as it were, has led to gross misrepresentation of their thought by numerous commentators. Neither Wittgenstein nor Kierkegaard has been immune to allegations of both 'relativism' and 'fideism', although neither charge could be wider of the mark. It is not that Wittgenstein and Kierkegaard reject the role that reason has to play in both religion and philosophy, but that they try to undermine from within certain common assumptions about the nature of both religious faith and the point of philosophical activity that make us believe that the traditional dichotomies exhaust all the available options.

What I hope to show in this paper is that more sense can be made of Wittgenstein's controversial remarks on religion, if we juxtapose them with Kierkegaard's religious thought, especially that of Kierkegaard's pseudonym, ${ }^{1}$ Johannes Climacus, in Concluding Unscientific Postscript. The focal point of this paper is going to be the attempt to read what little Wittgenstein has to say about this topic through the lens of

1 Given space constraints, I cannot address the problem of how to read Kierkegaard's pseudonyms here. 
Climacus' claim that 'objectively there is no truth; an objective knowledge about the truth or the truths of Christianity is precisely untruth.' I will begin by giving a brief exposition of Climacus' views, will then sketch out what Wittgenstein has to say on the matter and will then attempt to bring the two together. In the remainder of the paper I will assess the implications of Wittgenstein's and Kierkegaard's conception as well as address some of the problems that their account might be said to engender.

\section{Concluding Unscientific Postscript}

Climacus is well known for claiming in the Postscript that in religious matters 'truth is subjectivity'. What he means by this is that because for him, as for Wittgenstein, the question of faith is not an 'objective', 'empirical' issue which can be resolved by appeal to evidence, historical or otherwise, we have to concentrate instead on the 'existential' or 'personal' significance that this question has for us. This is what Climacus means by 'subjectivity'-i.e. pertaining to the 'subject' - and this has nothing to do with relativism or 'irrationalism', as commentators often suppose. Climacus says:

The way of objective reflection turns the subjective individual into something accidental and thereby turns existence into an indifferent, vanishing something. The way to objective truth goes away from the subject, and while the subject and subjectivity become indifferent, the truth becomes indifferent, and that is precisely its objective validity, because the interest, just like the decision is subjectivity. (Kierkegaard I992, I93)

In other words, precisely because religious belief does not, on this view, consist of assenting to propositions, it follows that in order to resolve the question of faith I must be infinitely interested in it as an existing person, not as a lofty scholar. For religious belief, on this conception, is something much more fundamental than simply being of the opinion that God exists. Therefore, even if evidence could be had, then on Climacus' and Wittgenstein's view, it would no longer be religious belief, and the belief in the Last Judgement, for example, 
would not be fundamentally different from the secular belief that one will be put into prison for certain crimes. Of course the very concept of 'belief' would then become obsolete too, as, on this conception, it makes no sense to say that I believe in something that is, as it were, before my 'very eyes'. That is, in a world where 'God' could 'empirically manifest' himself, our concept of a 'God' to be believed in would lose its point. Climacus puts it like this:

Without risk, no faith. Faith is the contradiction between the infinite passion of inwardness and the objective uncertainty. If I am able to apprehend God objectively, I do not have faith; but because I cannot do this, I must have faith. If I want to keep myself in faith, I must continually see to it that I hold fast to the objective uncertainty, see to it that in the objective uncertainty I am out on 70,000 fathoms of water and still have faith. (Kierkegaard I992, 204)

What Climacus means by 'objective uncertainty' isn't, therefore, empirical uncertainty, but rather the kind of uncertainty that accrues to making certain 'existential' choices. The ' 70,000 fathoms of water' do not refer to the extreme degree of 'empirical uncertainty', then, but to the intellectual and existential risk you take when you stop pondering a question 'objectively' and rather want to resolve it by making a decision, i.e. by changing the way you live in the relevant way. What Climacus is consequently referring to is the risk of commitment - and that is always a risk, be it in the religious domain or in other walks of life where you cannot remain dispassionate and disinterested (what Climacus means by 'objectivity'). Where something can be resolved objectively, however, faith, on this view, becomes conceptually impossible and passion becomes madness. Hence, someone, says Climacus, who clings to something finite that could be settled objectively with the passion appropriate only to faith is on the brink of insanity (which is just what happens in the case of religious fanatics or religious fundamentalists).

According to Climacus, taking God to be amenable to some kind of empirical investigation or thinking that some sort of 'direct' relationship with Him is possible, is really nothing more than paganism. As he puts it: 
If God had taken the form, for example, of a rare, enormously large green bird with a red beak, that perched in a tree on the embankment and perhaps even whistled in an unprecedented manner-then our partygoing man would surely have had his eyes opened. [...] All paganism consists in this, that God is related directly to a human being, as the remarkably striking to the amazed. (Kierkegaard I992, 245)

Therefore, if it is the latter that people take Christianity to be, then, for Climacus, they are either pagans in disguise or hypocrites.

Consequently, on Climacus' conception, Christianity is not a philosophical theory and the apostles are not a little professional society of scholars. This means that the question of whether to have faith in Christ (the Incarnation, what Climacus calls the 'absolute paradox') only genuinely arises for someone who wants to be a Christian, not for someone who is merely pondering this issue from an 'objective' point of view:

Objectively there is no truth; an objective knowledge about the truth or the truths of Christianity is precisely untruth. To know a creed by rote is paganism, because Christianity is inwardness. (Kierkegaard 1992, 224)

Hence, the attempt to relate to Christianity 'objectively', as if to a metaphysical theory, is the worst possible misunderstanding. As Climacus says:

Suppose that Christianity does not at all want to be understood; suppose that, in order to express this and to prevent anyone, misguided, from taking the road of objectivity, it has proclaimed itself to be the paradox. Suppose that it wants to be only for existing persons and essentially for persons existing in inwardness, in the inwardness of faith, which cannot be expressed more definitely than this: it is the absurd, ${ }^{2}$ adhered to firmly with the passion of the infinite.' (Kierkegaard I992, 214)

The emphasis on 'existence' is crucial here, because Climacus believes that it is impossible for any finite, existing being to apprehend truth sub specie aeterni (which is just what the Hegelians against which Kierke-

2 By 'absurd' Climacus means something resistant to 'objectification' (and consequently 'mediation'). 
gaard was reacting denied). The reason why Climacus is emphasizing the finitude of human beings is, I think, because it is an awareness of finitude that tends to draw people out of and away from themselves, as it were, in the search of an objective point of view - of the God's eye view. Christians are just as finite as anybody else. Therefore Christians too exhibit this tendency, and this is why the figure of Christ represents a continuing challenge even from the perspective of the Christian way of living. The challenge, or the on-going struggle, is continually to reaffirm oneself, as a Christian, as someone with the relevant unconditional commitments, sustained in the face of the temptations to objectivity with which one's finitude presents one. Thus, getting away from seeing the Incarnation as an intellectual or philosophical problem is not something that one can do once and for all. Rather, it is something that one has to keep on doing, and it is in that process that the authentically Christian relation to the understanding (and indeed to the relation between faith and the understanding) can be recognized.

From the non-Christian perspective, then, the paradox cannot be understood. From the Christian perspective, the paradox is Christ, the God-Man, the 'sign of contradiction', who is a mere human being to non-believers but God to the faithful. But precisely because Christ is such a 'sign of contradiction', whether $\mathrm{He}$ is in deed God, is not something that can be settled by theoretical means and consequently faith does not consist of saying 'yes' or 'no' to the 'thesis' that 'Christ is the Son of God'. When Climacus therefore speaks of the paradox as 'absolute', what he means is that only an existential ('subjective') response to the question is possible in the sense that I either become a follower of Christ or I reject Him: offence or faith. No theoretical ground is available here to determine whether the 'thesis' or its converse is philosophically defensible or not. And as long as I am in the faith and have an existence-relation to Christ, the very idea that I should regard my religious commitment as commitment to a theoretical claim which may stand in the need of proof, will strike me as ludicrous and absurd. In moments of doubt, however, which are generally moments of detachment, I may indeed begin to see my faith 
in such terms, and from such a perspective it may seem to me that Christianity is a bizarre metaphysical doctrine about the 'two natures' of Christ ${ }^{3}$, say. But this is a temptation, a sign that I am beginning to lose my faith, not the 'correct', because 'objective', point of view. Thus, the difficulty of becoming a Christian consists, among other things, of the ever-present struggle against the temptation to view the claims of Christianity objectively - a struggle so intense that Climacus calls it a 'martyrdom'.

\section{Culture and Value and On Certainty}

In Culture and Value Wittgenstein makes the following remark:

Life can educate one to a belief in God. And experiences too are what bring this about; but I don't mean visions and other forms of sense experience which show us "the existence of this being", but, e.g., sufferings of various sorts. These neither show us God in the way a sense impression shows us an object, nor do they give rise to conjectures about him. Experiences, thoughts - life can force this concept on us. So perbaps it is similar to the concept of "object". (last italics mine) (CV 1950, 86)

What Wittgenstein is suggesting here by drawing an analogy between the concept 'God' and the concept 'object' is that the former functions more like the formal concept 'object' (Gegenstand) than like a word referring to a particular thing, such as a table, chair, white elephant or what have you. In other words, the two concepts are grammatically similar, according to Wittgenstein, in the sense that they would both make for nonsense when employed in the subject-place of ontological assertions: it would make as little sense, on Wittgenstein's view, to assert (or to deny) that objects exist as it does to assert (or to deny) that God exists. The reasons for this, initially perhaps rather baffling, claim are as follows: contrary to Moore, who insisted on the truth of this proposition against the sceptic, Wittgenstein thinks that the proposition 'there are physical objects' is a piece of philosophical nonsense,

3 Of course I can also have moments of being, as it were, 'existentially' offended at Christ à la Nietzsche. 
as, according to him, it is not an empirical proposition for which one could have evidence. Wittgenstein says:

But can't it be imagined that there should be no physical objects? I don't know. And yet "there are physical objects" is nonsense. Is it supposed to be an empirical proposition? - And is this an empirical proposition: "There seem to be physical objects"? (OC, 35$)$

In order for the proposition 'there are physical objects' to make sense, it would have to be possible to know or to explain what would have to be the case if there were no physical objects. Should the proposition make sense, then it would have to be a kind of bypothesis, for which one could have evidence. But what would such evidence look like? Moore held the view that it is possible to infer 'there are physical objects' from the proposition 'here is a hand', but this was an illusion. For the latter means no more than that a hand is a physical object, and far from being an ontological hypothesis, this, according to Wittgenstein, is no more than a grammatical proposition that tells us what kind of thing a hand is. If this were an ontological hypothesis, then we would have to be able to indicate what would count as evidence for it, what as evidence against it, how the question could be settled beyond any reasonable doubt. But it is just this that is impossible, for we cannot explain what would be different if there were no physical objects, and, consequently, we also cannot explain what is the case when physical objects do exist. Furthermore, it is even less possible to give criteria for what would have to be the case if physical objects only seemed to exist, but do not actually do so (the classical sceptical scenario). All of this indicates that the proposition 'there are physical objects' is not an empirical one. No sense-perception or impression of an object (such as a hand) can lead us to the conclusion that there are physical objects, for the concept of 'physical object' is not a theoretical one, nor is it employed in the same way as the concept of a particular object. Therefore it makes sense to say 'there are frogs' or 'there are no unicorns', as the opposite of these sentences also makes sense, but not to say 'there are physical objects'. 
In other words, it only makes sense to doubt whether there are physical objects, if it also makes sense to assert it. But it only makes sense to assert it, if, at least in principle, there exists a means of settling the question. In the case of physical objects in general, we have no such means. For we might, for example, have evidence for the existence of life on Mars, but we couldn't have evidence for the existence of physical objects in general, as neither 'sense-data' nor Quinean 'surface irradiations' constitute such evidence. Pace Moore, I don't infer the existence of an object from the sense-impression. Of course I know that someone or something is present inasmuch as I see them. But to see an object is not a 'surface irradiation' or 'sense-datum' and although it involves perceptual stimuli, I am ignorant of them and make no inferences from them. That is to say, perceiving an object is not evidence for its existence in the way that fingerprints, for example, are evidence for someone's having been at the scene of a crime. Consequently, there is no such thing as 'demonstrating' that my hand exists.

Of course, there are cases where it makes sense to speak of having evidence for the existence of something - life on Mars, distant planets, Great Pumpkins etc. - but where it is a matter of being directly confronted by something in ordinary circumstances, such as by a hand, say, it does not make sense, since in such cases doubt is logically excluded: talk of evidence is only meaningful if there is also logical space for being wrong and here there is none. As Wittgenstein says:

If Moore were to pronounce the opposite of those propositions which he declares certain, we should not just not share his opinion: we should regard him as demented. (OC, I55)

Wittgenstein and Kierkegaard therefore agree that it is a mistake to want to demonstrate God's existence. In Climacus' words:

To demonstrate the existence of someone who exists is the most shameless assault, since it is an attempt to make him ludicrous, but the trouble is that one does not even suspect this, that in dead seriousness one regards it as a godly undertaking. [...] A king's existence or presence ordinarily has its own expression of subjection and submissiveness. What if one in his most majestic presence wanted to demonstrate that he exists? Does one demonstrate it, then? No, one makes a fool of him, because one demonstrates his presence 
by the expression of submissiveness. [...] And thus one also demonstrates the existence of God by worship - not by demonstrations. (Kierkegaard I992, 545 f.)

Two objections to this conception might suggest themselves at this point. First, we would not regard someone who was not religious as demented and second, if it makes sense to speak of having evidence for non-directly-perceivable things, then, given that on Climacus' view, God is not directly perceivable, why can we not talk of inferring the existence of God in the way we might infer the existence of black holes, say? I will take these objection in turn.

\section{(i) Objection One}

While someone who pronounced the opposite of those propositions that Moore declares certain would be regarded as demented, someone who declared the opposite of what the religious person affirms, would not. This is indeed so, but this isn't fatal to Wittgenstein's account. For of course Wittgenstein holds in On Certainty that declaring either Moore's propositions or their converse certain is misconceived. If it is the case that 'there are physical objects' is grammatical and not empirical, then neither the proposition nor its converse can be affirmed or denied. For grammatical remarks are neither true nor false, as they assert nothing (no state of affairs). Rather, they function as conditions of sense (rules) without which the form of life they are grammatical to would become unintelligible or lose its point. What Wittgenstein is therefore saying when he says we would regard someone as demented who affirmed the opposite of what Moore said is that if someone said this and actually meant it - i.e. wasn't just, say, engaging in a philosophical dispute about realism-then this person would become unintelligible to us and we could no longer understand him or make any sense of him.

Naturally, in the religious case, we are confronted with 'pluralism' in the sense that there is not just one way of looking at human life. That is to say, while losing one's religious faith would neither wholly under- 
mine one's ability to act in and think about the world, nor leave that ability entirely unaltered, denying that there are physical objects would (either undermine one's ability or leave it completely unaltered). In this respect there is indeed a significant disanalogy between the concept 'God' and the concept 'object'. But this is compatible with the view that Wittgenstein's analogy nevertheless shows something important, namely, that just as one can't make an inference from the existence of tables and chairs to the existence of physical objects, so one can't make an inference from the existence of the universe (or of religious experience etc.) to the existence of God. 'There is a God' is consequently just as little an ontological (hypo)thesis as 'there are physical objects'. So there are no a priori reasons why a community should possess the concept of 'God', any more than a society need have our abstract concept of 'physical object'. That is to say, a tribe could perfectly well have the concepts 'chair', 'turnip', 'pigeon' etc. and treat these things in the way that we do without thinking that they all have one property in common, namely, that they are all physical objects.

Does asserting any of this deny 'the reality of God'-something that 'orthodox' Christians are often worried about? Not at all. Wittgenstein and Kierkegaard are only saying that the 'reality of God' is not on a par with the 'reality of empirical objects' and that consequently, it makes no sense to approach God 'objectively'-as if relating to an empirical concept or to a metaphysical theory. Hence, it is only if we desire the 'reality of God' to be akin to that of (super-)empirical objects (something that both Wittgenstein and Kierkegaard would call conceptually confused) that their account could legitimately be accused of denying anything.

(ii) Objection Two

There are two possible responses to the second objection. First, 'evidence', in the religious case, does not play the role it usually does when we are dealing with evidence for the existence of empirical objects. Second, if it made sense to ask for evidence of God's existence, then the proposition 'God exists' would have to be a hypothesis for which we 
would have to be able to specify what would, at least in principle, count as confirmation or disconfirmation of it. But this is just as impossible as in the 'there are physical objects' case.

What Wittgenstein is trying to bring out by way of the analogy is that, just as we cannot infer the proposition 'there are objects' from the proposition 'here is a hand', in the case of religious belief it is also not a matter of making inferences from certain sense-perceptions. For religious experiences do not stand to the proposition 'there is a God' as, say, satellite pictures of the earth (or of Loch Ness monsters, black holes or what have you) stand to the proposition 'the earth is round' (as Wittgenstein says, we did not learn the concept 'God' by being shown pictures of him, nor 'could' we be shown pictures of him and the nature of this 'could' is logical). There simply is nothing that we would ordinarily call an 'evidential basis' here. Would seeing Christ rise from his grave constitute such evidence? But if we are not religious, would we be seeing Christ as opposed to, say, some bizarre and hitherto unexplained phenomenon?

The main reason why I think that Wittgenstein would want to insist that 'God exists' is grammatical is that, if we are not religious already, nothing would count as 'evidence for the existence of God' for us, even if we could, per impossibile, have any. For we could always explain even the most outlandish events simply as strange natural phenomena. This is also the reason why no one, even in principle, bothers to mount a search for God (which would really be the sensible thing to do, if one thinks that 'there is a God' is similar to 'there is a Loch Ness monster'). That this idea seems ludicrous, even funny, shows, I think, that language is idling when we try to construe religious belief analogously to empirical beliefs.

Furthermore, it is possible to describe what would be different, or what would have to be the case, if there were unicorns, or if there were a Loch Ness monster, but not how it would be if there were a God, or how it would be if God existed. For nothing would change in the world if God existed - at least nothing that would be cashable out in propositions. This is, I think, the significance of Wittgenstein's remark in the Tractatus that 'God does not manifest himself in the world' 
(TLP 6.432). Of course the world of the religious person is in some sense a different world to that of the atheist, just as Wittgenstein said in the Tractatus that the world of the happy person is a different world to that of the unhappy. But this 'difference' does not show up on a 'propositional' level - the empirical world remains the same and yet the atheist would say other things about it than the religious person. Wittgenstein says:

God's essence is supposed to guarantee his existence-what this really means is that what is at issue here is not the existence of something.

Couldn't one actually say equally well that the essence of colour guarantees its existence? As opposed, say, to white elephants. Because all that really means is: I cannot explain what 'colour' is, what the word 'colour' means, except with the help of a colour sample. So in this case there is no such thing as explaining 'what it would be like if colours were to exist'.

And now we might say: There can be a description of what it would be like if there were gods on Olympus - but not: 'what it would be like if there were such a thing as God.' And to say this is to determine the concept 'God' more precisely. (CV I949, 82)

The reason why it is possible to describe what it would be like if there were Gods on Mount Olympus is because in pagan religions the deities are on a par with other empirical objects, just vastly more powerful. There is therefore no grammatical difference between talk of, say, Poseidon and talk of an ordinary human being, except that Poseidon has super-human powers. But this is ultimately not qualitatively different from encountering, say, a new species from a distant planet who have powers surpassing our own. In Christianity (and other monotheistic religions) talk of God is not like that, however. The grammar of the word 'God' does not function analogously to talk of some empirical object, as any state of affairs in the world is taken by the religious person to be compatible with God's existence (and the converse is probably true of the atheist). One could perhaps therefore say that during the transition from paganism to Christianity the word 'God' underwent a grammatical shift and changed from being some kind of super-empirical concept to a grammatical one. When some- 
thing becomes a grammatical remark, of course, it is ex bypothesi impossible to describe what the world would have to be like, were the grammatical remark to be true, as grammatical remarks function as conditions of sense and cannot therefore themselves be either true or false.

\section{Implications of Wittgenstein's and Kierkegaard's Conception}

Wittgenstein and Kierkegaard agree that religious belief is non-rational: it is neither reasonable nor unreasonable, as faith is not the result of philosophical deliberation or the consequence of weighing up empirical evidence. But in this respect the religious form of life is not, in the end, so very different from other language-games or forms of life, for as Wittgenstein says in On Certainty, 'You must bear in mind that the language-game is so to say something unpredictable. I mean: it is not based on grounds. It is not reasonable (or unreasonable). It is there like our life.' (PI \$559) Faith cannot be objectively justified (for if it could, Wittgenstein and Kierkegaard would agree, it would eo ipso not be faith), but ultimately, what Wittgenstein is saying in On Certainty is that none of the concepts that lie at the heart of our forms of life can be so justified. In this respect use of the word 'object' can no more be justified than use of the word 'God', and yet the employment of these terms need not, for all that, be in the least arbitrary. As Wittgenstein keeps reiterating: life forces these concepts on $\mathrm{us}^{4}{ }^{4}$

4 Now in the case of physical objects one might think that one is more 'forced' than in the religious case, although I am not entirely sure what that is really supposed to mean. If this means only that physical objects can be perceived, but God cannot and direct perceivability is the criterion of 'forcedness', then Wittgenstein would agree (as would any religious person) that in the case of physical objects one is more 'forced'. If it means that one cannot in all seriousness doubt that there are physical objects, while one can doubt whether there is a God, then, naturally Wittgenstein, I take it, would also agree. If one, however, takes this to imply that therefore the former is more 'true' and more 'certain' than the latter, then I think that Wittgenstein would object. For as he has argued, neither belief is a hypothesis and even if it were one, there would not 
While it seems fairly clear, however, how life forces the concept of 'object' on us, it is far from clear how this happens in the case of God. Given that Wittgenstein and Kierkegaard have both repudiated all 'objective' approaches to religion, one might wonder how one can come to have faith at all. In Practice in Christianity Anti-Climacus perhaps gives a rather surprising answer to this question which Climacus had left hanging in the Postscript:

But if the essentially Christian is something so terrifying and appalling, how in the world can anyone think of accepting Christianity?" Very simply and, if you wish that also, very Lutheranly: only the consciousness of sin can force one, if I dare to put it that way [...], into this horror[...]. Considered in any other way Christianity is and must be a kind of madness or the greatest horror. (Kierkegaard I991, 67)

Now Wittgenstein doesn't speak of 'consciousness of sin', but in the foregoing quotation from Culture and Value he says that life can educate one to a belief in God and he cites, for example, 'sufferings of various sorts'.

What Wittgenstein and Kierkegaard seem to be saying here is that the shape of one's life and the experiences one has can teach one a use for certain religious concepts. This is why all of Kierkegaard's pseudonyms keep stressing the existential (i.e. 'subjective') dimension of faith. Being religious means living life according to the Christian teachings and examining one's life according to the Christian categories. One simply has to find these concepts appropriate in despite of any problems they may cause, as Anti-Climacus keeps emphasizing. It is only within the life of a religious person, then, that religious concepts become properly meaningful. Taken out of context, as it were, these concepts cannot but strike one as part and parcel of some obsolete metaphysical doctrine. How one therefore comes to have faith must, in the end, remain a 'subjective' matter. Just as there is no 'recipe' for how to live,

be any absolute justification for it. As he puts it: "Well, if everything speaks for an hypothesis and nothing against it - is it then certainly true? One may designate it as such. - But does it certainly agree with reality, with the facts? With this question you are already going round in a circle." (OC, I9I) 
there is no 'recipe' for how to have faith. This is ultimately the significance of Climacus' remark that as regards Christianity 'objectively there is no truth'.

\section{Conclusion}

By way of concluding, I will briefly address a criticism that is frequently made of both Wittgenstein's and Kierkegaard's conception of religious belief. Many commentators have taken the foregoing to imply that Wittgenstein and Kierkegaard are equally guilty of reducing religion to simply living life in a certain way, which, they think, can do no justice to what religious people actually believe. This, I think, is erroneous and in part a result of being mesmerized by two exhaustive seeming dichotomies: either religious beliefs can be cashed out propositionally (realism) or they reduce merely to taking up a certain kind of attitude (anti-realism). However, there are many domains of discourse, where this stark either/or is simply inappropriate, ethics and aesthetics also being cases in point.

I think that one of the main motivating factors behind Wittgenstein's later philosophy is to show that there is no such thing as 'simply living life in a certain kind of way' as opposed to 'believing certain things'. Genuine beliefs can never be divorced from the consequences they have in one's life. That is why Wittgenstein, for example, holds that idealism or global scepticism is really a non-starter, for all it reduces to, in the end, is talking in a certain way without this making any practical difference at all. As Wittgenstein says:

For there are people who say that it is merely extremely probable that water over a fire will boil and not freeze, and that therefore strictly speaking what we consider impossible is only improbable. What difference does this make in their lives? Isn't it just that they talk rather more about certain things than the rest of us do? (OC, 338$)$

Beliefs and the forms of life which are their home cannot be divorced from each other. There is no such thing as believing something in vacuo - without a context - unless one thinks that believing is tanta- 
mount to holding a certain mental image before one's mind. ${ }^{5}$ Consequently, it is not the case that Wittgenstein and Kierkegaard deny that religious people believe different things to non-religious people - far from it. What they are denying, however, is that any sense can be made of those beliefs completely independently of the form of life which gives them sense. That is to say, stating that Christians believe, for example, in the forgiveness of sins, is, as yet, not to have said anything apart from, as Climacus would undoubtedly say, reciting a formula by rote.

In this respect it is interesting to note that Wittgenstein, contrary to Kierkegaard, who, on all accounts of him, was obsessed by his 'sins', nevertheless could not become a genuinely religious person. So, it seems that Anti-Climacus' claim that only 'consciousness of sin' can force one into Christianity leaves something rather fundamental out. It is not only consciousness of sin that is necessary, but also the belief that one's sins will ultimately be forgiven by Jesus Christ, the Redeemer. ${ }^{6}$ It appears to be the latter that Wittgenstein could not bring himself to accept. As Wittgenstein puts it:

I read: "No man can say that Jesus is the Lord, but by the Holy Ghost." And it is true: I cannot call him Lord; because that says nothing to me. I could call him the 'paragon', 'God' even - or rather, I can understand it when he is called thus; but I cannot utter the word "Lord" with meaning. Because I do not believe that he will come to judge me; because that says nothing to me. And it could say something to me, only if I lived completely differently. (CV 1937, 33)

This quotation, I think, illustrates very well that Wittgenstein does not hold that religious people don't believe different things to non-religious people. Consequently, he is not advocating some form of 'antirealism' about religion. However, he does agree with Kierkegaard that the Christian teaching addresses primarily the individual's life and the

5 I cannot go into the reasons why Wittgenstein takes this to be a misguided conception of belief here. For a detailed exposition, see my A Confusion of the Spheres, chapter four.

6 This is an issue that Anti-Climacus discusses in The Sickness unto Death. 
way the individual thinks about and assesses his life, not the mind of the speculative philosopher, as 'formal' proofs or 'evidence' (if there could, per impossibile, be such things) would never exert motivation enough for a life-change as drastic as that required by Christianity. Therefore, both philosophers would agree that the way of 'objectivity' leads only into darkness, or, what for Climacus would amount to the same, reduces Christianity to paganism ${ }^{7}$.

\section{Bibliography}

Kierkegaard, Søren (i 980): The Sickness unto Death, edited and translated by Howard and Edna Hong, Princeton 1980.

- (I99I): Practice in Christianity, edited and translated by Howard and Edna Hong, Princeton I99I.

- (I992): Concluding Unscientific Postscript to Philosophical Fragments, edited and translated by Howard and Edna Hong, Princeton 1992.

Schönbaumsfeld, Genia (2007): A Confusion of the Spheres. Kierkegaard and Wittgenstein on Philosophy and Religion, Oxford 2007.

7 I would like to thank Peter Momtchiloff for permission to draw on material from A Confusion of the Spheres and Aaron Ridley for comments on previous drafts. 



\section{About the Contributors}

Ulrich ARnswald studied economics, political science and philosophy at Heidelberg, Kent at Canterbury and at the London School of Economics and Political Sciences. Since 2005 he is a lecturer in philosophy at the Universität Karlsruhe (TH). He is the editor or coeditor of a number of books including Gadamer's Century: Essays in Honor of Hans-Georg Gadamer (MIT Press, 2002), Wittgenstein und die Metapher (Parerga, 2004), Die Zukunft der Geisteswissenschaften (Manutius, 2005), Hermeneutik und die Grenzen der Sprache (Parerga, forthcoming). He has published widely in the field of philosophy of language, political philosophy as well as Wittgenstein's philosophy.

John Churchill studied philosophy at Rhodes College in Memphis, Tennessee and at Oxford University, and received the Ph.D. from Yale University. He taught for many years at Hendrix College in Arkansas. He has published on the philosophy of Wittgenstein in journals in the U.S., Britain, and Australia.

Liam Hughes studied humanities and social sciences at the Open University. He completed a post-graduate certificate in English and religious education at Westminster College and was awarded a Ph.D. from the University of Wales (Swansea) in I990. He published articles in the philosophy of religion, on the freedom of the will and Wittgenstein.

Jens Kertscher studied philosophy and romance studies at Cologne, Florence, Tübingen and Heidelberg, where he obtained his Ph.D. Since $200 \mathrm{I}$ he is a lecturer in Philosophy at the Technische Universität Darmstadt. He is the co-editor of Gadamer's Century: Essays in Honor of Hans-Georg Gadamer (MIT Press, 2002), Performativität und Praxis (Wilhelm Fink, 2003), Wittgenstein und die Metapher (Parerga, 2004) 
as well as the author of numerous articles on the philosophy of language and Wittgenstein's philosophy.

Dieter Mersch studied mathematics and philosophy in Cologne and Bochum. He obtained his Ph.D. as well as his Habilitation at Darmstadt. Since 2004 he is professor of media theory at the Universität Potsdam. He is the author of a number of books including Medientheorien zur Einfübrung (Junius, 2006), Was sich zeigt: Materialität, Präsenz, Ereignis (Wilhelm Fink, 2002) and Ereignis und Aura: Untersuchungen zu einer Ästhetik des Performativen (Suhrkamp, 2002), and the editor or co-editor of Performativität und Praxis (Wilhelm Fink, 2003), Die Medien der Künste: Beiträge zur Theorie des Darstellens (Wilhelm Fink, 2003) as well as Kunst und Wissenschaft (Wilhelm Fink, 2007).

Genia Schönbaumsfeld studied philosophy at Oxford, Cambridge and Vienna. She is a lecturer in philosophy at the University of Southampton. She is the author of A Confusion of the Spheres: Kierkegaard and Wittgenstein on Philosophy and Religion (Oxford University Press, 2007) as well as of numerous articles on Wittgenstein's and Kierkegaard's philosophy. In 2003 she was awarded a prestigious Hertha Firnberg research fellowship from the Austrian Science Fund.

Anja Weiberg studied German studies and philosophy at Vienna, where she also obtained her Ph.D. in philosophy. Since $200 \mathrm{I}$ she is a lecturer in philosophy at Vienna. She is the author of , Und die Begründung hat ein Ende': Die Bedeutung von Religion und Ethik für den Philosophen Ludwig Wittgenstein und das Verständnis seiner Werke (Wiener Universitätsverlag, I 998 (2002)) and co-author, with Esther Ramharter, of ,Die Härte des logischen Muß.' Wittgensteins Bemerkungen über die Grundlagen der Mathematik (Parerga, 2006) as well as of numerous articles on Wittgenstein's philosophy and on medical ethics. 


\section{Index}

Adorno, Theodor Wiesengrund

Anscombe, Gertrude Elizabeth Margaret

Aristotle

Arnswald, Ulrich

Augustine, Saint, Bishop of Hippo

Ayer, Alfred Jules

Barrett, Cyril

Bauman, Zygmunt

Beethoven, Ludwig van

Benjamin, Walter

Birnbacher, Dieter

Bouveresse, Jacques

Brecht, Bertolt

Buffon, Georges Louis Leclerc

Butler, Judith

Cavell, Stanley

Churchill, John

Danto, Arthur

Derrida, Jacques

Diamond, Cora

Dostoyevsky, Fyodor

Eagleton, Terry

Edwards, James C.

Emerson, Ralph Waldo

Engelmann, Paul

Ficker, Ludwig von

Frege, Gottlob

Gamm, Gerhard

Griffiths, A. Phillips

Habermas, Jürgen

Hegel, Georg Wilhelm Friedrich

Heidegger, Martin

Hodges, Michael

Hughes, Liam

Hume, David

Jarman, Derek

Janik, Allan

Kambartel, Friedrich

Kästner, Erich

Kant, Immanuel

Kertscher, Jens

Keynes, John Maynard

Kierkegaard, Søren

Kross, Matthias

Levinas, Emmanuel

Lichtenberg, Georg Christoph

Leibniz, Gottfried Wilhelm
36 Fn 20

8,23

35, 101 Fn 15, 108

87 Fn 1, 93 Fn 5, 109, 149

48

105 Fn 21, 109

102 Fn 18, 109

107 Fn 22, 109

53

35f., 36 Fn 19, 36 Fn 20, 37, 37 Fn 22, 49

14,23

94 Fn 8, 103 Fn 20, 110

37,49

81f., $85 f$.

30 Fn 3

106f., 110

147

33 Fn 9

30 Fn 3, 107 Fn 23, 108 Fn 24, 110

10,23

$48,63,115 f$.

118f., 129

7, 10, 23

48

$54,66,116,128 f$.

6, 26, 116

$71,114 \mathrm{f}$.

107f., 110

52, 66

90f., 95 Fn 9, 99, 110

40,134

30 Fn 4, 33, 33 Fn 11, 35, 35 Fn 16, 41 Fn 30,

45 Fn 35, 49

117,129

149

59, 127

118

48 Fn 37, 50, 54, 66, 115, 130

101 Fn 15, 110

25

35, 35 Fn 18, 50, 88f., 91f., 108

149

$117 f$.

35 Fn 15, 38, 47, 50, 131-134, 131 Fn 1, 138f., $140,143-147$

2f., 6, 13ff., 23, 93f., 93 Fn 5, 110

87

32 Fn 7

35 
Nagel, Thomas

Nietzsche, Friedrich

Machan, Tibor R.

Maslow, Alexander

McGuinness, Brian

Mersch, Dieter

Momtchiloff, Peter

Monk, Ray

Moore, George Edward

Mosès, Stéphane

Mounce, Howard Owen

Nieli, Russell

Ogden, Charles Kay

Plato

Putnam, Hilary

Quine, Willard van Orman

Raatzsch, Richard

Rawls, John

Rentsch, Thomas

Rhees, Rush

Ridley, Aaron

Rorty, Richard

Russell, Bertrand

Schelling, Friedrich Wilhelm Joseph

Schlick, Moritz

Schnädelbach, Herbert

Schneider, Hans Julius

Schönbaumsfeld, Genia

Schopenhauer, Arthur

Schulte, Joachim

Shakespeare, William

Silesius, Angelus

Spinoza, Baruch

Stern, David G.

Strachey, Lytton

Strawson, Peter Frederick

Ter Hark, Michel

Tolstoy, Leo or Count Lev Nikolayevich

Toulmin, Stephen

Tugendhat, Ernst

Valéry, Paul

Waismann, Friedrich

Walzer, Michael

Watzka, Heinrich

Weiberg, Anja

Winch, Peter

Wolf, Ursula

Woolf, Leonard

Woolf, Virginia

Wright, Georg Henrik von

Zemach, Eddy M.
129

44, 136 Fn 3

5,23

8f., 23

25, 25 Fn 1, 32 Fn 7, 34 Fn 14, 50, 116, 130

25 Fn 1, 28, 48 Fn 37, 50, 150

147 Fn 7

116,130

72, 88, 91, 115, 117, 124, 130, 136-139

37 Fn 22, 50

54,66

64, 66

124

35, 61, 66

90, 94, 96 Fn 11, 110

138

73, 86

88

14,23

59, 65f., 80, 86, 87 Fn 2, 92 Fn 4, 110

147 Fn 7

93, 94 Fn 7, 95, 95 Fn 9, 110

25, 115ff., 120, 130

31 Fn 6, 35, 35 Fn 17, 44, 50

51,88

101 Fn 15, 110

74, 76ff., 77 Fn 3, 77 Fn 4, 84, 86

147, 150

32 Fn 7, 35, 35 Fn 15, 44, 44 Fn 33, 47, 50, 60, 115, 117f., 120,130

76, 86

63

48

32, 32 Fn 8, 50, 114, 118, 123-129

7, 23

117

63, 66

77, 77 Fn 3, 86

32 Fn 7, 48, $115 f$.

48 Fn 37, 50, 54, 66, 115, 130

96 Fn 10, 97 Fn 13, 104, 111

36 Fn 19

2f., 32, 41

93ff., 99f., 101 Fn 15, 111

31 Fn 5, 36 Fn 21, 50

16, 18, 19, 24, 103, 103 Fn 19, 111, 150

55, 61, 66

92 Fn 3, 111

117

117

6, 24, 116, 130

56, 66 



\section{EUKLID - Studien 1}

The essays collected in this volume explore some of the themes that have been at the centre of recent debates within Wittgensteinian scholarship. This book is an attempt to express the difficult nature of ethics, mysticism and religion, their problematic status in the modern world, and the possible justifications for ethical and religious commitment. Naturally, it also discusses some of the main ideas of Ludwig Wittgenstein. His very personal and often aphoristic way of writing cannot simply be restated or interpreted. However, his philosophy is in need of interpretation, and interpretations are - as we all know - often rather controversial.

The collected contributions aim, therefore, at bringing new insight into the essence of Wittgenstein's ethical and religious beliefs by understanding his concepts of thought and language in a more detailed way. In opposition to what we are tentatively inclined to think, the articles of this volume invite us to understand that our need to grasp the essence of ethical and religious thought and language will not be achieved by metaphysical theories expounded from such a point of view, but by focusing on our everyday forms of expression. The articles have in common an understanding of Wittgenstein as not proposing metaphysical theories, but rather showing us the way to work ourselves out of the confusions we become entangled in when philosophizing. Thus, the authors show from a Wittgensteinian perspective that the standard modern approaches to ethics cannot justify traditional moral beliefs.

The volume includes contributions by Ulrich Arnswald, John Churchill, Liam Hughes, Jens Kertscher, Dieter Mersch, Genia Schönbaumsfeld and Anja Weiberg.

\section{About the editor}

Ulrich Arnswald studied economics, political science and philosophy at Heidelberg, Kent at Canterbury and at the London School of Economics and Political Sciences. Since 2005 he is a lecturer in philosophy at the Universität Karlsruhe (TH). He is the editor or co-editor of a number of books including Gadamer's Century: Essays in Honor of HansGeorg Gadamer (MIT Press, 2002), Wittgenstein und die Metapher (Parerga, 2004), Die Zukunft der Geisteswissenschaften (Manutius, 2005). He has published widely in the field of philosophy of language, political philosophy as well as Wittgenstein's philosophy.

ISSN: $1867-5018$

ISBN: $978-3-86644-218-4$ 